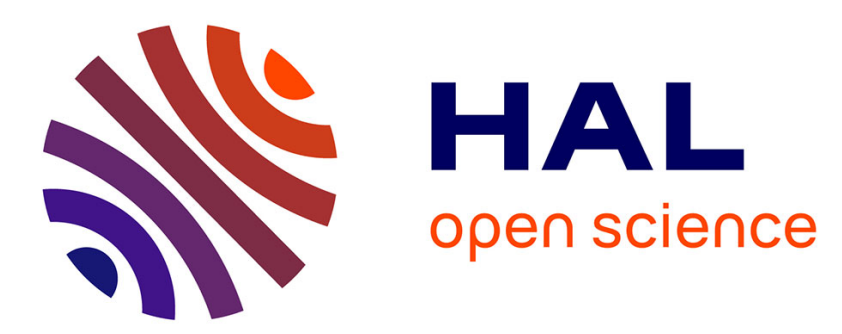

\title{
Experimental Studies of Gas-Phase Reactivity in Relation to Complex Organic Molecules in Star-Forming Regions
}

\author{
Ilsa R. Cooke, Ian R Sims
}

\section{> To cite this version:}

Ilsa R. Cooke, Ian R Sims. Experimental Studies of Gas-Phase Reactivity in Relation to Complex Organic Molecules in Star-Forming Regions. ACS Earth and Space Chemistry, 2019, 3 (7), pp.11091134. 10.1021/acsearthspacechem.9b00064 . hal-02278042

HAL Id: hal-02278042 https://hal-univ-rennes1.archives-ouvertes.fr/hal-02278042

Submitted on 19 Sep 2019

HAL is a multi-disciplinary open access archive for the deposit and dissemination of scientific research documents, whether they are published or not. The documents may come from teaching and research institutions in France or abroad, or from public or private research centers.
L'archive ouverte pluridisciplinaire HAL, est destinée au dépôt et à la diffusion de documents scientifiques de niveau recherche, publiés ou non, émanant des établissements d'enseignement et de recherche français ou étrangers, des laboratoires publics ou privés. 


\title{
Experimental studies of gas-phase reactivity in relation to complex organic molecules in
} star-forming regions

\author{
Ilsa R. Cooke and lan R. Sims* \\ Université de Rennes 1, CNRS, IPR (Institut de Physique de Rennes) - UMR 6251, \\ F-35000 Rennes, France \\ E-mail: ian.sims@univ-rennes1.fr
}

\begin{abstract}
The field of astrochemistry concerns the formation and abundance of molecules in the interstellar medium, star-forming regions, exoplanets and solar system bodies. These astrophysical objects contain the chemical material from which new planets and solar systems are formed. Around 200 molecules have thus far been observed in the interstellar medium; almost half containing six or more atoms and considered "complex" by astronomical standards. All of these complex molecules consist of at least one carbon atom and thus the term complex organic molecules (COMs) has been coined by the astrochemical community. In order to understand the formation and destruction of these COMs under the extreme conditions of star-forming regions, three kinds of activity are involved: (1) the astronomical identification of complex molecules present in the ISM; (2) the construction of astrochemical models that attempt to explain the formation routes of the observed molecules; and (3) laboratory measurements and theoretical calculations of critical kinetic parameters that are included in the models. In the following review, we present recent laboratory efforts to produce quantitative
\end{abstract}




\begin{abstract}
kinetic data for gas-phase reactions at low temperatures. We discuss the use of the CRESU technique, a French acronym standing for Cinétique de Réaction en Ecoulement Supersonique Uniforme, which means reaction kinetics in uniform supersonic flow, to measure reactions of astrochemical importance. In particular, we highlight recent and future advances in the measurement of product-specific reaction kinetics at low temperatures.
\end{abstract}

Keywords: astrochemistry, chemical kinetics, laboratory astrophysics, low temperatures, interstellar medium

\title{
Introduction
}

A little over 200 molecules have been observed in the interstellar and circumstellar medium, ${ }^{1}$ among which are a large number of complex organic molecules that have been found even in very cold $(\leq 10 \mathrm{~K})$ environments (e.g. Bacmann et al. ${ }^{2}$ ). The detection of complex molecules in cold astrophysical environments poses a challenge to experimentalists and modellers alike. Currently, two distinct mechanisms are used explain the formation of COMs: their production in icy mantles condensed onto dust grains or their formation by gas-phase reactions. While the formation of some COMs can be explained by their formation in ices, it is unknown how they are delivered to the gas-phase at dust temperatures below that required for their thermal desorption. Experiments are needed to provide quantitative parameters (i.e. rate coefficients, cross sections) for both ice and gas-phase processes to input into theoretical models in order to assess their importance at various stages of star-formation.

This review focuses on the role of laboratory experiments in understanding chemical pathways to complex organic molecules in star-forming regions; in particular, we concentrate on gas-phase reactions at low temperatures. It is organized as follows: in section 1 we present the astrophysical context for this review and classes of reactions expected to take place under astrophysical conditions. We then outline the role of laboratory measurements in elucidating 


\section{Reactions in star-forming regions}

The physical conditions under which chemical reactions take place vary dramatically during the sequence of star-formation. In the early stages, gas and dust from old stars collapses inward under the influence of gravity to form diffuse clouds that have temperatures of 50$100 \mathrm{~K}$ and gas densities of $10-10^{2} \mathrm{~cm}^{-3}$, dominated by atomic hydrogen and other atomic species at lower concentrations. ${ }^{3}$ Further gravitational collapse leads to the formation of dense clouds with higher gas densities of $10^{4}-10^{6} \mathrm{~cm}^{-3}$ and with temperatures typically 10$20 \mathrm{~K} .{ }^{4}$ Here, molecular hydrogen, $\mathrm{H}_{2}$, becomes the most abundant species in the cloud due to surface-catalyzed production of $\mathrm{H}_{2}$ from $\mathrm{H}$ atoms adsorbed on dust grains. The $\mathrm{H}_{2}$ can then undergo cosmic-ray ionization to produce $\mathrm{H}_{2}^{+}$, initiating a network of barrierless ion-neutral reactions that can, at least in part, explain the exotic chemistry that has been observed in dense clouds. ${ }^{5}$

Collapse of the dense cloud core leads to low-mass star formation. A central condensation builds up that is so dense that radiation cannot escape, causing the collapsed area to warm up, eventually reaching temperatures of 100-300 K where it is called a "hot core". The hot cores host dramatically different chemistry, in particular, high abundances of organic species are observed such as alcohols, aldehydes, esters, acids and ethers commonly found on Earth. ${ }^{6}$ To conserve angular momentum, a rotating disk is produced around the protostar forming a nascent protoplanetary disk. Within the disk, dust particles begin to coalesce and aggregate to form the beginnings of meteoritic material and eventually young planets. 
Due the wide variety of pressures, temperatures and atomic abundances, a large number of different chemical processes are expected to take place in astrophysical environments. In order to reproduce astronomical observations, networks of reactions must be built that incorporate the many individual reaction rates to solve for the time-dependent molecular abundances. The great majority of bimolecular gas-phase reactions expected to take place in these astrophysical environments can be placed in the following classes: (a) ion-neutral reactions, (b) neutral-neutral reactions (where neutral can also refer to radicals), (c) radiative association reactions, and (d) dissociative recombination reactions.

Ion-neutral reactions involve the reaction of either a positively charged cation with a neutral, $\mathrm{A}^{+}+\mathrm{B} \longrightarrow \mathrm{C}^{+}+\mathrm{D}$, or a negatively charged anion with a neutral, $\mathrm{A}^{-}+\mathrm{B} \longrightarrow$ $\mathrm{C}^{-}+$D. Perhaps the most famous astrochemical example is the reaction of $\mathrm{H}_{3}^{+}$with neutrals, initiating a network of ion chemistry in the ISM. ${ }^{5}$ Neutral-neutral reactions involve the reaction of two species that do not possess a charge, but at least one radical possessing unpaired electrons; they can be represented by the chemical equation $\mathrm{A}+\mathrm{B} \longrightarrow \mathrm{C}+\mathrm{D}$, or more accurately, $\mathrm{A}+\mathrm{B}^{\bullet} \longrightarrow \mathrm{C}^{\bullet}+\mathrm{D}$. For example, neutral-neutral reactions of $\mathrm{CN}$ with unsaturated hydrocarbons of the form $\mathrm{C}_{2 n} \mathrm{H}_{2}$ have been shown to provide competitive formation pathways for cyanopolyynes as compared to ion-neutral reaction routes. ${ }^{7}$ Radiative association involves an ion-neutral or neutral-neutral reaction in which the products are stabilized via the emission of a photon, that is, $\mathrm{A}+\mathrm{B} \longrightarrow \mathrm{AB}+h \nu$ or $\mathrm{A}^{+}+\mathrm{B} \longrightarrow \mathrm{AB}^{+}+h \nu$; for example, the reaction between $\mathrm{C}^{+}$and $\mathrm{H}_{2}$ to produce $\mathrm{CH}_{2}^{+}$, a possible first step in the formation of small hydrocarbons in the ISM. ${ }^{8}$ Dissociative recombination involves the attachment of an electron to a positive ion which causes the ion to dissociate into two or more neutral fragments, i.e. $\mathrm{AB}^{+}+\mathrm{e}^{-} \longrightarrow \mathrm{A}+\mathrm{B}$. It is considered a significant process in ISM chemistry as it terminates ion chemistry by leading to stable neutral species. An astrochemically relevant example is the dissociative recombination of $\mathrm{N}_{2} \mathrm{H}^{+}$to form $\mathrm{N}_{2}+\mathrm{H}$, which is considered the main destruction route for $\mathrm{N}_{2} \mathrm{H}^{+}$in $\mathrm{CO}$ poor environments and has 


\section{The role of laboratory measurements of gas-phase reactions}

Astrochemical observations of star-forming regions rely heavily upon laboratory data; not only for understanding the abundances of molecules that have been detected but also for predicting the detectability of other species in various astrophysical environments. Laboratory experiments on elementary reaction processes seek to provide two types of information: the first is a quantity that describes the intrinsic efficiency of reaction - the rate coefficient, symbolized by $k$ or by $k(T)$ in order to emphasize that rate coefficients generally depend on temperature. Many formation and destruction pathways involving COMs are bimolecular and can be represented by the chemical equation:

$$
\mathrm{A}+\mathrm{B} \longrightarrow \mathrm{C}+\mathrm{D}
$$

The rate of removal of reactant $\mathrm{A}$ is then given by:

$$
-\frac{d[\mathrm{~A}]}{d t}=k[\mathrm{~A}][\mathrm{B}]
$$


where $k$ is the bimolecular rate coefficient for the reaction with standard units of $\mathrm{cm}^{3}$ molecule $\mathrm{s}^{-1}$. In order to isolate the bimolecular reaction the laboratory measurement is often conducted in pseudo-first order conditions where the concentration of one reactant, say $B$, is kept in large excess of the other. Under these conditions the concentration of B remains essentially constant and equation (3) becomes:

$$
-\frac{d[\mathrm{~A}]}{d t}=k^{\prime}[\mathrm{A}]
$$

where $k^{\prime}=k[\mathrm{~B}]$ is the pseudo-first order rate coefficient.

Laboratory measurements of gas-phase processes generally focus on extracting this rate coefficient as a function of temperature $(k(T))$. These rate coefficients are often expressed by the Arrhenius equation:

$$
k(T)=A \exp \left(-E_{A} / T\right)
$$

Where $A$ is a pre-exponential factor, $E_{A}$ is the activation energy (in units of $\mathrm{K}$ ) and $\mathrm{T}$ is the gas kinetic temperature. In astrochemical databases, e.g. the KIDA Home Page: kida.obs.u-bordeaux1.fr/ (accessed March, 2019), a modified Arrhenius equation is used in order to express the temperature dependence of the pre-exponential term:

$$
k(T)=\alpha(T / 300 K)^{\beta} \exp (-\gamma / T)
$$

Here, three parameters $(\alpha, \beta$ and $\gamma)$ are used to extrapolate $k(T)$ over various temperatures. Theoretical calculations can also be used to calculate $k(T)$ in some cases; however, the rate coefficients are often sensitive to the presence of small energetic barriers, which can be difficult to determine computationally. In addition, reactions of astrochemical interest often involve ions or radical species with unpaired electrons which can form complexes and intermediates before dissociating to products. The calculation of their low temperature rate coefficients is challenging; in particular, quantum mechanical tunneling through the reac- 


\section{Laboratory methods for measuring low-temperature re- action kinetics}

A wide range of experimental methods exist for studying the reactivity of cold molecules relevant to astrochemistry; however, many techniques do not permit the measurement of absolute rate coefficients. The determination of absolute rate coefficients requires accurate knowledge of the concentration of the reactant species, or at least one reactant if the experiment is conducted under pseudo-first order conditions. Cold gas-phase reactants are typically produced either through collisions with cryogenically cooled walls of a reaction cell or by the expansion of gas from high to low pressure. Cryogenic cells can be used to measure reactions involving species with moderate vapour pressures; however, for species with low vapor pressures at temperatures below $\sim 200 \mathrm{~K}$, condensation on the cold cell walls makes 
the absolute reactant concentration difficult to determine. The use of cryogenic cells is therefore limited to the measurement of reaction kinetics at temperatures above a few hundred Kelvin - except for reactions involving light species e.g. $\mathrm{CN}+\mathrm{O}_{2}$ and $\mathrm{CO}+\mathrm{OH}$, which have been measured down to $99 \mathrm{~K}$ and $80 \mathrm{~K}$, respectively. ${ }^{11,12}$ This problem motivated the search for "wall-less" experimental techniques that could produce cold molecules at uniform temperatures without interaction with the reaction vessel walls.

Expansion of high-pressure gas through a small aperture to a low-pressure region can be used to produce cold gaseous molecules without the use of cryogens. Free jet expansions have been used extensively in spectroscopy to produce cold isolated molecules; however, they have limited application to reaction kinetics because their strong temperature and density gradients produce molecules that are not in local thermodynamic equilibrium. Such limitations motivated the development of the CRESU technique, a French acronym standing for Cinétique de Réaction en Ecoulement Supersonique Uniforme, which means reaction kinetics in uniform supersonic flow. Below we discuss the details of this technique and its application to the study of various reactions at low temperature.

\section{The CRESU technique}

The CRESU technique takes advantage of flow properties of gases after expansion through convergent-divergent Laval nozzles. Laval nozzles are a type of axisymmetric nozzle with a convergent section followed by a divergent section and were first described in 1888 by Gustaf de Laval for use in steam turbines. The gas is accelerated in the convergent section of the nozzle, reaching Mach 1 at the throat and higher Mach numbers as it is expanded in the divergent section. Following the isoentropic expansion through the nozzle, a flow of gas is produced that is uniform in velocity, temperature and density, and persists for tens of centimetres. The temperature of the flow $\left(T_{\text {flow }}\right)$ is related to the Mach number by:

$$
T_{\text {flow }}=T_{0}\left(1+\frac{\gamma-1}{2} M^{2}\right)^{-1}
$$




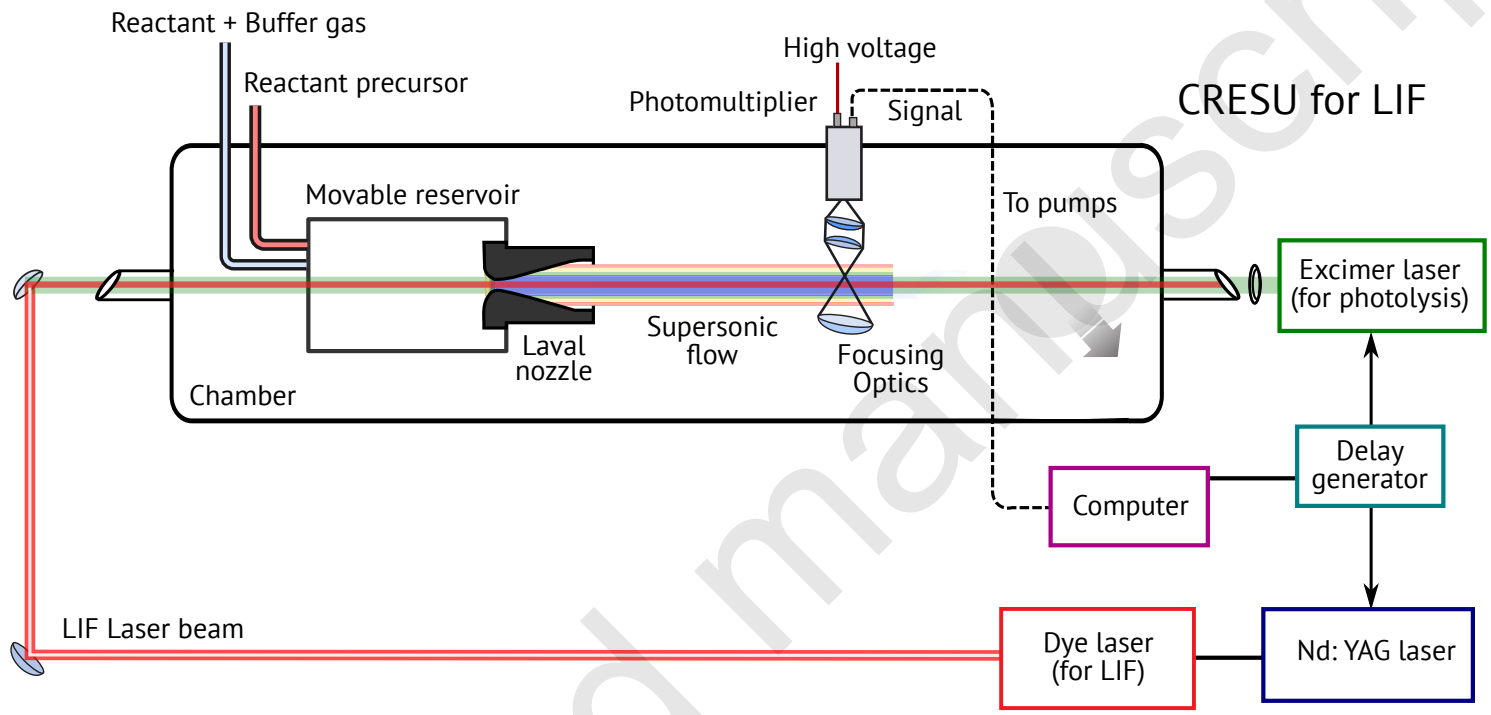

Figure 1: Schematic of a CRESU apparatus configured for the study of neutral-neutral reactions using laser-induced fluorescence, based on the setup at the Université de Rennes. The reactant, buffer gas and radical reactant precursor are delivered to the reservoir via a series of flow controllers. The gas mixture enters the chamber through the Laval nozzle, through which expansion produces a uniform supersonic flow. Radicals are produced in the supersonic beam by photolysis of a precursor using radiation from a fixed frequency pulsed excimer laser and are detected by LIF that is excited using tunable radiation from a dye laser. 
where $T_{0}$ is the temperature of the gas in the reservoir, $\gamma=\mathrm{C}_{p} / \mathrm{C}_{v}$ is the ratio of the specific heat capacities at constant pressure and volume, and $M$ is the Mach number. Following their passage through the Laval nozzle, the reactants and reactant precursors are delivered to a high-pressure reservoir diluted (typically $<1 \%$ ) in a buffer gas of helium, argon, nitrogen and occasionally hydrogen. The gas mixture passes through the nozzle and the reaction is initiated by crossing the gas flow with an electron beam (to produce ions) or with a UV laser (to produce radicals). Figure 1 shows a schematic of a CRESU experiment configured for laser-induced fluorescence detection. Here, the reaction is initiated when radicals are produced via the photolysis of a radical precursor within the supersonic flow. The reaction is monitored by following the time-dependent LIF of the radical reactant.

A separate Laval nozzle must be designed and constructed to produce each desired temperature and density. The nozzle geometry is calculated by numerically solving the inverse Navier-Stokes flow equations. Construction of the nozzle then requires precise machining, particularly of the inner throat geometry, where any imperfections can perturb the uniformity of the flow. Once constructed, the flow produced by each nozzle must be characterized in order to confirm its uniformity. The standard way this is done is by producing a flow under conditions matching the calculated reservoir and chamber pressures and sampling the flow with a Pitot probe. This Pitot measures the impact pressure behind the shock wave that is produced by the impact between the flow and the probe tip. The impact pressure is then used to deduce the Mach number and thus the temperature, density and flow velocity. If the pressure conditions are well met, i.e. the reservoir and chamber pressure are maintained at their calculated values, then the temperature and density conditions are highly reproducible.

The lowest temperatures obtainable in the CRESU environment are set first, by the necessity that the reactant concentration is accurately known and secondly, by practical limitations of machining of nozzles with narrow throats. At low temperatures, the clustering of reactants in the flow may become significant, such that their concentration becomes uncertain. Condensation on the walls of the reservoir or the nozzle also becomes significant for 


\section{Measurements of ion-neutral reactions}

Early laboratory measurements at low temperatures focused on reactions between neutral species and ions. This was motivated by the assumption at the time that the low temperatures of interstellar clouds would reduce the importance of reactions between neutral species and that ion-molecule reactions would dominate the cloud chemistry. In dense clouds, $\mathrm{H}_{2}$ 
becomes the most abundant species in the cloud due to surface-catalyzed production of $\mathrm{H}_{2}$ from atomic $\mathrm{H}$ on dust grains. The $\mathrm{H}_{2}$ can then undergo cosmic-ray ionization to produce $\mathrm{H}_{2}^{+}$, initiating a network of barrierless ion-neutral reactions (equation 7) with other species, $\mathrm{X}$, that can explain some of the exotic chemistry that has been observed in dense clouds. ${ }^{27}$

$$
\begin{gathered}
\mathrm{H}_{2}^{+}+\mathrm{H}_{2} \longrightarrow \mathrm{H}_{3}^{+}+\mathrm{H} \\
\mathrm{H}_{3}^{+}+\mathrm{X} \longrightarrow \mathrm{H}_{2}+\mathrm{HX}^{+}
\end{gathered}
$$

The $\mathrm{HX}^{+}$ion may then undergo a chain of ion-neutral reactions to produce larger ionic hydrocarbons, which are eventually terminated by dissociative recombination with electrons. Ion-neutral reactions have been invoked, for instance, to explain the high abundance of unsaturated carbon chains in the dense ISM e.g. via reactions between $\mathrm{C}^{+}$and neutral hydrocarbons. ${ }^{28-30}$

Laboratory methods used to study ion-neutral reactions can be placed into two categories: those that utilize ion-trapping and those that inject ions into a gas expansion or flow. Early methods were limited to measurements close to room temperature; though, for many ionneutral reactions, it is straightforward to predict how the rate coefficient changes as the temperature is decreased using capture theories. The simplest case is the reaction between ions and non-polar neutral species, which can be well predicted by the expression for the Langevin rate coefficient:

$$
k_{L}=2 \pi e \sqrt{\frac{\alpha}{\mu}}
$$

where $e$ is the charge on an electron, $\alpha$ is the polarizability of the neutral and $\mu$ is the reduced mass of ion-neutral pair. The capture models become more complex when the neutral species is polar and in cases where the reactions possess a barrier and more complete theoretical treatments must be used. The potential for polar neutrals is anisotropic and 


$$
x=\frac{\mu_{D}}{\left(2 \alpha k_{B} T\right)^{1 / 2}}
$$

where $\mu_{D}$ is the effective dipole moment of the neutral, $\alpha$ is its polarizability, $k_{B}$ is the Boltzmann constant and $T$ is the gas temperature.

This treatment is only reliable in the classical regime and temperatures above which rotational motion can be considered classical, typically above $10 \mathrm{~K}$.

Most measurements of ion-neutral reactions up until the 1980s were made using ion cyclotron resonance (ICR) or flowing afterglow (FA) experiments. In the former technique, ions are trapped by electric and magnetic fields and a neutral species is introduced. ${ }^{32}$ Other trapping methods have been applied at low temperatures, including the Penning trap of Barlow et. al., which has been used to measure the rate coefficient of several reactions with $\mathrm{H}_{2}$ down to $\sim 10 \mathrm{~K}^{33-35}$ and 22-pole traps, which have made possible the study of ion reactions with $\mathrm{H}$ atoms. ${ }^{8,36,37}$ These traps operate at low pressures, giving long trapping times (as long as 1 hour) and thus allowing very slow reaction rates (down to $\sim 10^{-15} \mathrm{~cm}^{3}$ molecule ${ }^{-1} \mathrm{~s}^{-1}$ ) to be measured.

The second category of experiments comprises those based on the use of gas expansion or flow techniques. The flowing afterglow method was first developed in the late 60 s and 
remains an important technique for the measurement of ion-neutral rate coefficients. ${ }^{38}$ The apparatus is comprised of a cylindrical flow reactor in which ions are produced and diluted in a buffer gas. Neutral co-reactants are introduced downstream and changes in the ion signal of the gas mixture are detected by a mass spectrometer. The use of cryogenically cooled jackets have allowed reactions to be measured down to around $80 \mathrm{~K} .{ }^{39}$ Several variations to this method have been made, including the addition of a quadrupole mass filter to permit mass selection of the reactant ion. ${ }^{40}$ This technique, known as selective ion flow tube (SIFT), has been used to study a number of ion reactions down to around $90 \mathrm{~K}$ as well as their reactions with radical atoms at room temperature. ${ }^{41}$

Flowing afterglow methods were also developed for the measurement of rate coefficients involving the recombination of ions with electrons to form neutral species. The flowing after glow Langmuir probe (FALP) technique incorporated a movable Langmuir probe (LP) to determine the electron density along the FA tube. The FALP method provides no information about the products and thus the branching ratios into the different channels are unknown. In addition, the excited internal states of the ions are neither relaxed nor well defined, and it is difficult to cool the apparatus, though there are some measurements down to $\sim 95 \mathrm{~K}$.

To determine the products of ion-electron recombination reactions, a method was developed in the 1970 s known as the merged beam technique. ${ }^{42,43}$ This technique involves two interacting beams of particles that are made to travel along a common axis for some finite distance. Heavy ion storage rings are particularly useful for the study of ion-electron reactions. They are comprised of a vacuum system, usually $>40 \mathrm{~m}$ in circumference, with magnetic focusing elements to keep the ions in a closed orbit — producing high intensity ion beams and giving enough time to radiatively cool any vibrationally excited molecules. The ion beam is merged with an electron beam and neutral products are produced. These neutral species are not confined by the magnetic fields and exit the ring to strike a mass-selective detector, giving a complete set of branching ratios. The collision energy can be varied by changing the ion and electron beam velocities, allowing the rate coefficients to be derived 
from the cross sections observed as a function of collision energy.

A major advancement in the measurement of ion-neutral reaction kinetics came with the development of the first CRESU apparatus by Bertrand Rowe and colleagues. ${ }^{44}$ In early experiments, ions were produced by irradiating the gas exiting the Laval nozzle by an electron beam. The rate coefficient for the ion-neutral reaction could then be determined by varying the distance of the sampling port. Later developments incorporated mass selection of the ions. $^{45}$

The first reactions studied with the CRESU technique were the reactions of $\mathrm{O}_{2}$ cations with $\mathrm{CH}_{4}$ and the association reactions of $\mathrm{O}_{2}$ and $\mathrm{N}_{2}$ with their cations. ${ }^{44,46}$ Following this, systematic studies of positive ion reactions with non-polar molecules, polar molecules and molecules with large quadrupoles have been undertaken. A number of ion-neutral bimolecular reactions involving $\mathrm{H}_{3}^{+},{ }^{47} \mathrm{He}^{+},{ }^{48-50} \mathrm{~N}^{+},{ }^{48} \mathrm{C}^{+49-51}$ or $\mathrm{Ar}^{+} / \mathrm{Ar}^{2+52,53}$ ions have been studied, as well as some case studies involving $\mathrm{N}_{2}^{+},{ }^{54} \mathrm{CH}^{+},{ }^{55} \mathrm{O}_{2}^{+46}$ and $\mathrm{O}^{+} .{ }^{56}$ Ionneutral association reactions have also been investigated in CRESU flows for $\mathrm{C}^{+},{ }^{45,57} \mathrm{~N}_{2}^{+}, 44$ $\mathrm{O}_{2}^{+},{ }^{44} \mathrm{CH}_{3}^{+},{ }^{45} \mathrm{Ar}^{+},{ }^{58} \mathrm{NH}_{4}^{+},{ }^{59}$ and $\mathrm{H}_{3} \mathrm{O}^{+} .{ }^{60}$ The ion-neutral reactions measured to date using CRESU apparatuses are listed in Table 1.

Figure 2 shows some example cases displaying the types of temperature dependences that have been observed: the $\mathrm{N}^{+}$ion reactions with a non-polar neutral $\left(\mathrm{O}_{2}\right),{ }^{48}$ polar neutrals $\left(\mathrm{H}_{2} \mathrm{O} \text { and } \mathrm{NH}_{3}\right)^{51}$ and a neutral with a large quadrupole moment $\left(\mathrm{C}_{6} \mathrm{~F}_{6}\right) .{ }^{49}$ In general, the rate coefficients for the reactions of ions with nonpolar molecules match the simple estimate based on the Langevin equation quite well even when the neutral species has a large quadrupole moment, like $\mathrm{C}_{6} \mathrm{~F}_{6}$. In reactions between ions and polar neutrals, there is an anisotropic attractive force between the charge on the ion and the permanent dipole of the neutral. In this case, the rate coefficients increase as the temperature is lowered, as observed in the reaction between $\mathrm{N}^{+}$and $\mathrm{H}_{2} \mathrm{O}$. In the case of $\mathrm{N}^{+}$reaction with $\mathrm{C}_{6} \mathrm{~F}_{6}$, the authors concluded that the existence of a large quadrupole moment did not significantly change in collision rate coefficient or reaction efficiency over a large temperature range. 


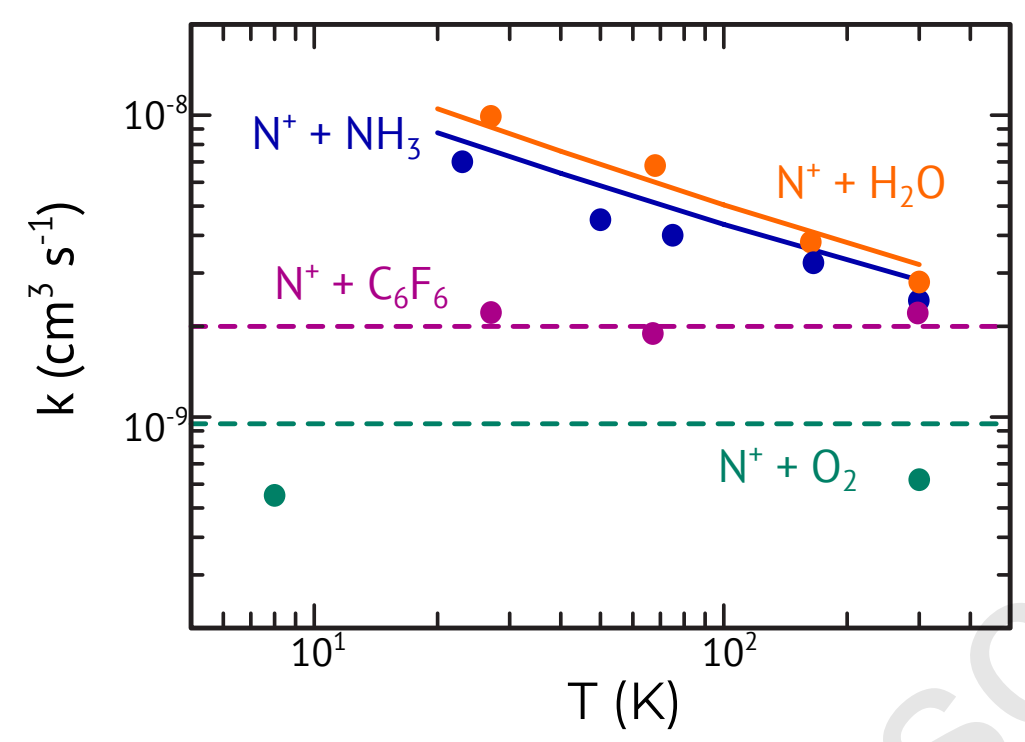

Figure 2: Examples of rate coefficients for some classes of ion-neutral reactions using $\mathrm{N}^{+}$ ions reactions as examples. The reaction of $\mathrm{N}^{+}$with: a non-polar neutral, $\mathrm{O}_{2}$ (cyan dots), ${ }^{48}$ polar neutrals $\mathrm{H}_{2} \mathrm{O}$ (blue dots) and $\mathrm{NH}_{3}$ (orange dots) ${ }^{51}$ and with a neutral with a large quadrupole, $\mathrm{C}_{6} \mathrm{~F}_{6}$ (purple dots). ${ }^{49}$ Predictions using the Langevin formula are shown in dashed lines (for $\mathrm{O}_{2}$ and $\mathrm{C}_{6} \mathrm{~F}_{6}$ ) and using the method of $\mathrm{Su}$ and Chesnavich in the bold lines (for $\mathrm{H}_{2} \mathrm{O}$ and $\mathrm{NH}_{3}$ ).

Most of the ion-neutral reactions that have been studied in the laboratory are between singly charged cations and neutral molecules that can be purchased commercially or, in a few cases, synthesized in-house. These molecules comprise only a fraction of the neutral species that could be involved in reactions in dense clouds. A key class of reactions significant in astrophysical environments are the reactions between radicals and ions, which are particularly challenging to study since it is difficult to quantify the concentration of either species. Reactions between several ions and some radical atoms such as $\mathrm{H}\left({ }^{2} \mathrm{~S}\right), \mathrm{N}\left({ }^{4} \mathrm{~S}\right)$, and $\mathrm{O}\left({ }^{3} \mathrm{P}\right)$ have been studied using the SIFT technique (see the review by Snow and Bierbaum ${ }^{41}$ ), though predominantly at room temperature.

\section{Anion reactions}

While a number of reactions between cations and neutral species have been studied down to low temperatures, very few reactions of anions have been measured below $100 \mathrm{~K}$. This is due to a combination of the practical difficulties of producing anions in the laboratory 
and assumptions that negative ions would not be present in appreciable quantities in the ISM. While positive ions have been known to exist in the ISM since the discovery of $\mathrm{CH}^{+}$in $1941,{ }^{61}$ it wasn't until 2006 that the first anion $\left(\mathrm{C}_{6} \mathrm{H}^{-}\right)$was detected. ${ }^{62}$ In the laboratory, the study of anion reactions is more challenging than the study of cation reactions due to the difficulty in producing a stable quantity of the anion reactant species.

The reaction of $\mathrm{Cl}^{-}$with $\mathrm{CH}_{3} \mathrm{Br}$ was studied by Le Garrec et al. ${ }^{63}$ in 1997, and marks the first study of an anion reaction using the CRESU technique. The reaction was measured between 23-300 K as a classic example of an organic chemistry substitution reaction, rather than in an astrophysical context. Chlorine anions were formed through the dissociative attachment of electrons to $\mathrm{CCl}_{4}$ by passing a high energy, low intensity electron beam perpendicular to the flow. A dramatic increase in the rate coefficient was found, with the experimental value at $23 \mathrm{~K}$ being over two orders of magnitude larger than that observed at $300 \mathrm{~K}$. Motivation to continue laboratory measurements of anion reactions was revived in the mid-2000s with the discovery of negatively charged linear polyynes $\mathrm{C}_{2 n} \mathrm{H}^{-62,64,65}$ and cyanopolyynes $\mathrm{C}_{2 n+1} \mathrm{~N}^{-66-68}$ in the ISM.

Reactions of $\mathrm{C}_{2 n+1} \mathrm{~N}^{-}$(with $\mathrm{n}=0,1$ and 2) cyanopolyynes have recently been studied by the group in Rennes for their application to reactions in Titan's ionosphere and in the ISM. ${ }^{69-71} \mathrm{CN}^{-}$and $\mathrm{C}_{3} \mathrm{~N}^{-}$and $\mathrm{C}_{5} \mathrm{~N}^{-}$anions were produced by the dissociative electron attachment to cyanogen bromide $(\mathrm{BrCN})$, bromocyanoacetylene $\left(\mathrm{BrC}_{3} \mathrm{~N}\right)$ and 5-bromopenta2,4-diynenitrile $\left(\mathrm{BrC}_{5} \mathrm{~N}\right)$, the latter two requiring in-house chemical synthesis. Reactions between these small anions and neutral species are predicted to be involved in the growth of anions by initiating a chain of anion reactions.

Biennier et al. ${ }^{69}$ studied the reaction of $\mathrm{CN}^{-}$with $\mathrm{HC}_{3} \mathrm{~N}$ down to $\sim 50 \mathrm{~K}$. They found fast rate coefficients for the reaction of $\mathrm{k} \geq 4 \times 10^{-9} \mathrm{~cm}^{3}$ molecule $\mathrm{e}^{-1} \mathrm{~s}^{-1}$ with a weak negative temperature dependence agreeing with a long-range capture theory. The formation of the $\mathrm{C}_{3} \mathrm{~N}^{-}$anion via the major exit channel $\mathrm{C}_{3} \mathrm{~N}^{-}+\mathrm{HCN}$ demonstrated that the reaction may be involved in the growth of negative ions in the atmosphere of Titan. In contrast, experiments 


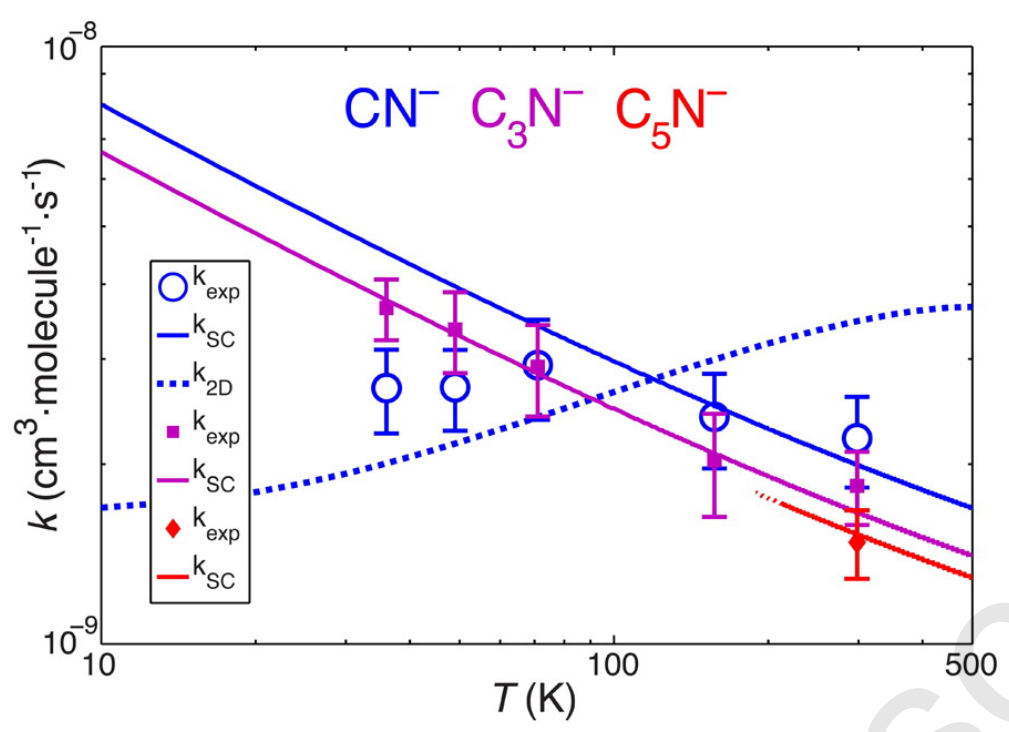

Figure 3: Rate coefficients for the $\mathrm{C}_{2 n+1} \mathrm{~N}+\mathrm{HCOOH}$ reactions measured between $36 \mathrm{~K}$ and room temperature $\left(\mathrm{k}_{\exp }\right)$ and those estimated from the $\mathrm{Su}$ and Chesnavich capture model ( $\mathrm{k}_{\mathrm{SC}}$, solid line). The result of the $2-\mathrm{D}$ quantum model for the $\mathrm{CN}^{-}+\mathrm{HCOOH}$ reaction is also shown $\left(\mathrm{k}_{2 \mathrm{D}}\right.$, dashed line). Reprinted from Joalland et al. ${ }^{71}$

of Bourgalais et al. ${ }^{70}$ showed that in Titan's low-temperature atmosphere the reaction of $\mathrm{C}_{3} \mathrm{~N}^{-}$with $\mathrm{HC}_{3} \mathrm{~N}$ will not produce anions but instead will lead to the loss of the negative charge.

The kinetics of proton-transfer reactions between these cyanopolyyne anions and formic acid $(\mathrm{HCOOH})$ has been studied at 36-300 K. ${ }^{71}$ Figure 3 shows the measured rate coefficients for the reactions of $\mathrm{CN}^{-}, \mathrm{C}_{3} \mathrm{~N}^{-}$and $\mathrm{C}_{5} \mathrm{~N}^{-}$with $\mathrm{HCOOH}$. They found a negative temperature dependence for the reaction of $\mathrm{C}_{3} \mathrm{~N}^{-}$with $\mathrm{HCOOH}$ that could be well reproduced by long-range capture theory using the classical trajectory model of $\mathrm{Su}$ and Chesnavich ${ }^{31}$. In contrast, the experiments showed a surprisingly weak temperature dependence for the $\mathrm{CN}^{-}$ $+\mathrm{HCOOH}$ reaction, disagreeing with the temperature dependence predicted by capture theories, but agreeing with the temperature dependence predicted by a 2-D time-independent quantum approach.

Comparing the $\mathrm{HCOOH}$ reactions to their previous results for $\mathrm{HC}_{3} \mathrm{~N}$ suggests that dipoledipole interactions must play an active role in overcoming this limiting effect at low temperatures. The low-temperature reactivity of $\mathrm{HCOOH}$ and $\mathrm{HC}_{3} \mathrm{~N}$ with $\mathrm{CN}^{-}$and $\mathrm{C}_{3} \mathrm{~N}^{-}$is 


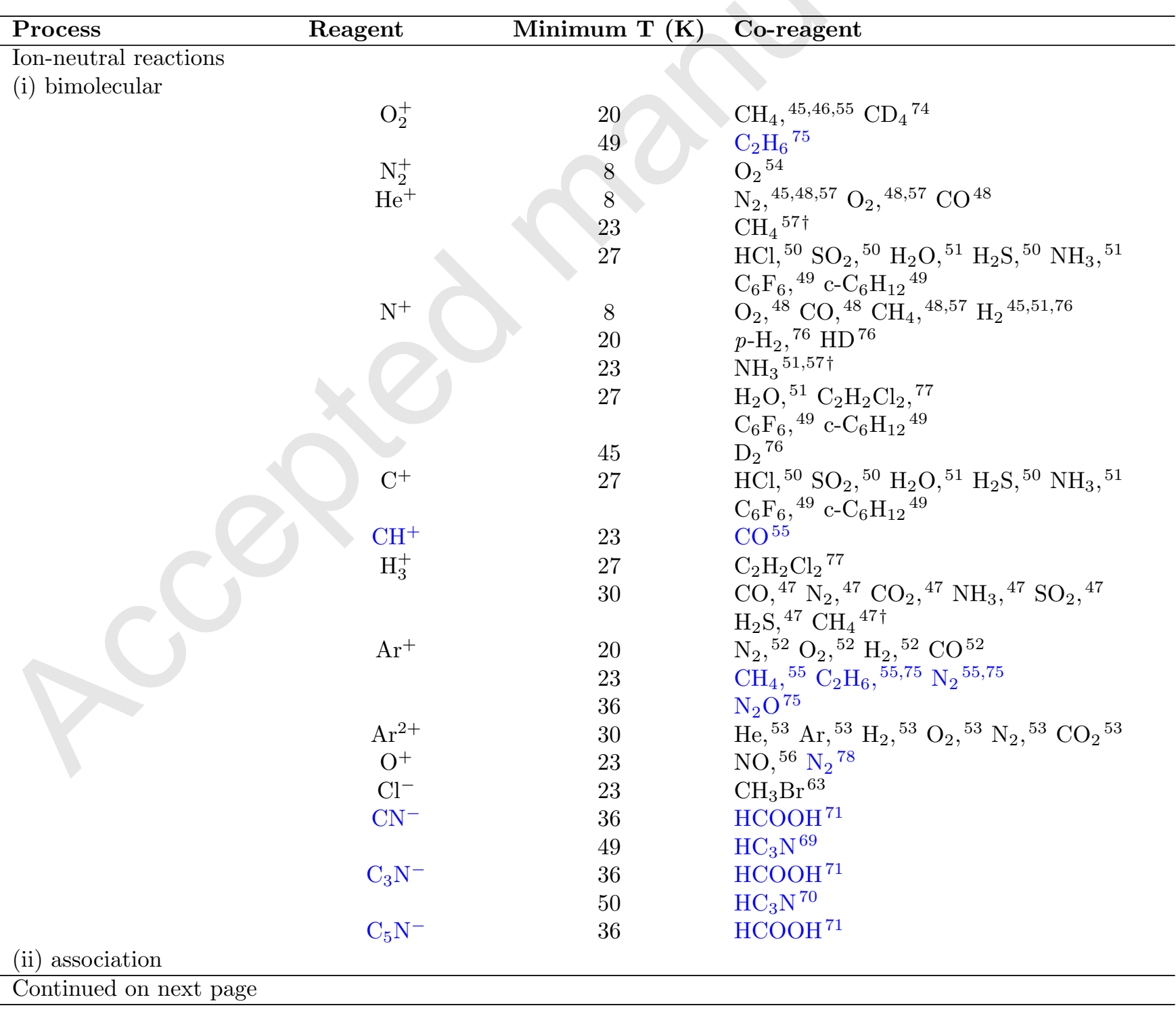

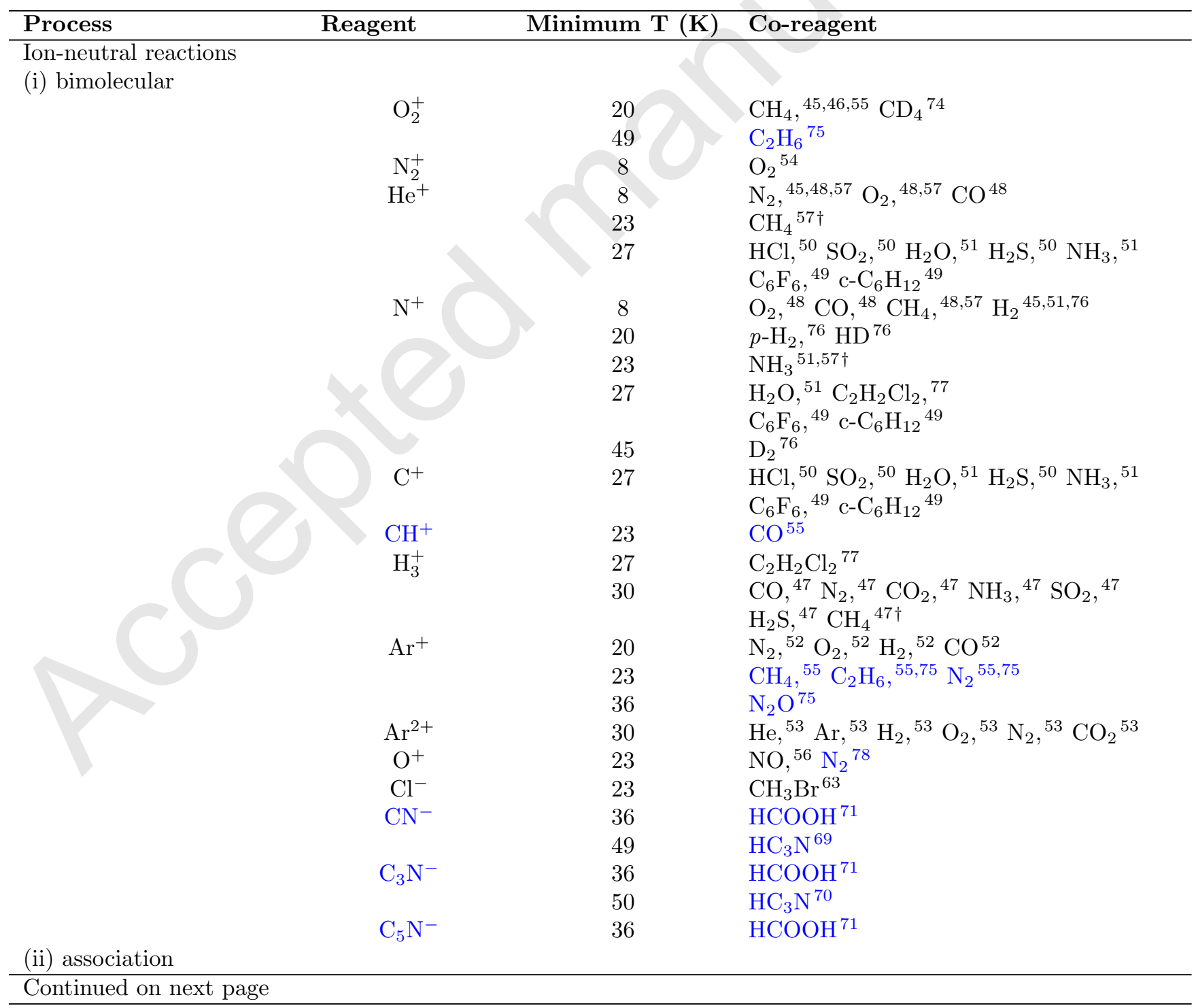

Table 1: Summary of processes studied in CRESU apparatuses, updated from Smith and
Rowe ${ }^{72}$. Reactions studied since the publication of Smith and Rowe ${ }^{72}$ in 2000 are shown in
blue.

Table 1: Summary of processes studied in CRESU apparatuses, updated from Smith and
Rowe ${ }^{72}$. Reactions studied since the publication of Smith and Rowe ${ }^{72}$ in 2000 are shown in
blue.

Table 1: Summary of processes studied in CRESU apparatuses, updated from Smith and
Rowe ${ }^{72}$. Reactions studied since the publication of Smith and Rowe ${ }^{72}$ in 2000 are shown in
blue.

There is still much to be understood regarding the reactivity of anions with neutral species and their importance in COM formation and destruction in the ISM is yet to be fully explored, both experimentally and computationally. 
Table 1 - continued from previous page

\begin{tabular}{|c|c|c|c|}
\hline Process & Reagent & Minimum T (K) & Co-reagent \\
\hline \multirow{43}{*}{$\begin{array}{l}\text { Neutral-n } \\
\text { (i) bimole }\end{array}$} & $\mathrm{C}^{+}$ & 13 & $\mathrm{H}_{2} 45,57$ \\
\hline & $\mathrm{N}_{2}^{+}$ & 20 & $\mathrm{~N}_{2}^{44}$ \\
\hline & $\mathrm{O}_{2}^{+}$ & 20 & $\mathrm{O}_{2}^{44}$ \\
\hline & $\mathrm{CH}_{3}^{+}$ & 20 & $\mathrm{H}_{2},{ }^{45,55} \mathrm{CO},{ }^{45} \mathrm{~N}_{2}{ }^{45}$ \\
\hline & $\mathrm{Ar}^{+}$ & 27 & $\mathrm{Ar}^{58}$ \\
\hline & $\mathrm{NH}_{4}^{+}$ & 15 & $\mathrm{NH}_{3} 59$ \\
\hline & $\mathrm{H}_{3} \mathrm{O}^{+}$ & 23 & $\mathrm{H}_{2} \mathrm{O}^{60}$ \\
\hline & $\mathrm{CN}$ & 13 & $\mathrm{O}_{2}{ }^{15,79}$ \\
\hline & & 15 & $\mathrm{CH}_{2} \mathrm{CCH}_{2},{ }^{80} \mathrm{CH}_{3} \mathrm{CCH}^{80,81}$ \\
\hline & & 23 & $\mathrm{C}_{3} \mathrm{H}_{6},{ }^{82} \mathrm{C}_{3} \mathrm{H}_{8},{ }^{82} \mathrm{CH}_{3} \mathrm{CH}_{2} \mathrm{CCH},{ }^{83}$ \\
\hline & & & $\begin{array}{l}\mathrm{C}_{4} \mathrm{H}_{6},{ }^{82} \mathrm{HC}_{3} \mathrm{~N},{ }^{23} \mathrm{CH}_{3} \mathrm{NH}_{2},{ }^{84} \\
\left(\mathrm{CH}_{3}\right)_{2} \mathrm{NH},{ }^{85}\left(\mathrm{CH}_{3}\right)_{3} \mathrm{NH}^{85}\end{array}$ \\
\hline & & 25 & $\mathrm{NH}_{3},{ }^{15} \mathrm{C}_{2} \mathrm{H}_{2},{ }^{86} \mathrm{C}_{2} \mathrm{H}_{4},{ }^{86} \mathrm{C}_{2} \mathrm{H}_{6}{ }^{86}$ \\
\hline & & 105 & $\mathrm{c}-\mathrm{C}_{6} \mathrm{H}_{6},{ }^{87} \mathrm{c}-\mathrm{C}_{7} \mathrm{H}_{8}{ }^{87}$ \\
\hline & & 123 & $\mathrm{C}_{6} \mathrm{H}_{5} \mathrm{CCH}^{88}$ \\
\hline & $\mathrm{OH}$ & 12 & $\mathrm{CH}_{3} \mathrm{OH},{ }^{14,89-91 *} \mathrm{CH}_{3} \mathrm{COCH}_{3}{ }^{92,93 * \S}$ \\
\hline & & 21 & $\mathrm{CH}_{3} \mathrm{CH}_{2} \mathrm{OH}^{94,95}$ \\
\hline & & 22 & $\mathrm{HC}(\mathrm{O}) \mathrm{OCH}_{3},{ }^{96} \mathrm{H}_{2} \mathrm{CO}^{97}$ \\
\hline & & 23 & $\mathrm{HBr},{ }^{98-100} \mathrm{C}_{4} \mathrm{H}_{8},{ }^{24,101-104}$ \\
\hline & & 39 & $\mathrm{O}\left({ }^{3} \mathrm{P}\right)^{105}$ \\
\hline & & & $\begin{array}{l}\mathrm{CH}_{3} \mathrm{CHO},{ }^{106} \\
\mathrm{CH}_{2} \mathrm{CH}\left(\mathrm{NH}_{2}\right) \mathrm{COOC}_{2} \mathrm{H}_{5} 107,108\end{array}$ \\
\hline & & & $\mathrm{C}_{2} \mathrm{H}_{5} \mathrm{CHO}^{109}$ \\
\hline & & 63 & $\mathrm{CH}_{3} \mathrm{OCH}_{3}{ }^{92,93^{*}}$ \\
\hline & & 86 & $\left(\mathrm{CH}_{3}\right)_{3} \mathrm{COOH}^{21}$ \\
\hline & & 88 & $\mathrm{CH}_{3} \mathrm{CH}(\mathrm{OH}) \mathrm{CH}_{3}{ }^{94}$ \\
\hline & & 93 & $\mathrm{CH}_{3} \mathrm{C}(\mathrm{O}) \mathrm{CH}_{2} \mathrm{CH}_{3}{ }^{92}$ \\
\hline & & 96 & $\mathrm{H}_{2} \mathrm{O}_{2} 110$ \\
\hline & $\mathrm{CH}$ & 13 & $\mathrm{NO},{ }^{111} \mathrm{O}_{2},{ }^{111} \mathrm{D}_{2}{ }^{112}$ \\
\hline & & 23 & $\begin{array}{l}\mathrm{NH}_{3},{ }^{111 \dagger} \mathrm{CH}_{4},{ }^{113} \mathrm{C}_{2} \mathrm{H}_{2},{ }^{113} \mathrm{C}_{2} \mathrm{H}_{4},{ }^{113} \\
\mathrm{C}_{2} \mathrm{H}_{6},{ }^{113} \text { butenes }\end{array}$ \\
\hline & & 50 & $\mathrm{H}_{2} \mathrm{O}^{114}$ \\
\hline & & 58 & $\mathrm{c}-\mathrm{C}_{14} \mathrm{H}_{10}{ }^{115}$ \\
\hline & & 77 & $\mathrm{CH}_{3} \mathrm{CCH},{ }^{17} \mathrm{CH}_{2} \mathrm{CCH}_{2},{ }^{17} \mathrm{C}_{3} \mathrm{H}_{6}{ }^{17}$ \\
\hline & $\mathrm{C}_{2} \mathrm{H}^{\dagger}$ & 15 & $\mathrm{O}_{2},{ }^{73,116,117} \mathrm{C}_{2} \mathrm{H}_{2},{ }^{73,117-119}$ \\
\hline & & & $\mathrm{C}_{2} \mathrm{H}_{4},{ }^{73,120} \mathrm{C}_{3} \mathrm{H}_{6}{ }^{73,120}$ \\
\hline & & 63 & $\mathrm{CH}_{3} \mathrm{CCH},{ }^{80,117} \mathrm{CH}_{2} \mathrm{CCH}_{2}{ }^{80,117}$ \\
\hline & & 74 & $\mathrm{CH}_{3} \mathrm{CH}_{2} \mathrm{CCH}^{121}$ \\
\hline & & 79 & butenes, ${ }^{122-124}$ \\
\hline & & 96 & $\mathrm{C}_{2} \mathrm{H}_{6},{ }^{125} \mathrm{C}_{3} \mathrm{H}_{8},{ }^{125} \mathrm{n}-\mathrm{C}_{4} \mathrm{H}_{10}{ }^{125}$ \\
\hline & & 104 & $\mathrm{C}_{4} \mathrm{H}_{6},{ }^{123} \mathrm{i}_{-} \mathrm{C}_{4} \mathrm{H}_{10},{ }^{123} \mathrm{NH}_{3},{ }^{126 \dagger}{ }^{\dagger} \mathrm{ND}_{3}{ }^{126}$ \\
\hline & & 105 & $\mathrm{c}-\mathrm{C}_{6} \mathrm{H}_{6}{ }^{127}$ \\
\hline & & 165 & $\mathrm{CH}_{3} \mathrm{CN}^{123}$ \\
\hline & $\mathrm{NH}$ & 53 & $\begin{array}{l}\mathrm{NO},{ }^{128} \mathrm{CH}_{4},{ }^{128} \mathrm{C}_{2} \mathrm{H}_{2},{ }^{128} \mathrm{C}_{2} \mathrm{H}_{4},{ }^{128} \\
\mathrm{C}_{2} \mathrm{H}_{6},{ }^{128} \mathrm{C}_{3} \mathrm{H}_{6} \mathrm{C}_{4} \mathrm{H}_{2}{ }^{128}\end{array}$ \\
\hline & ${ }^{1} \mathrm{C}_{2}$ & 24 & $\begin{array}{l}\mathrm{NO}, 129 \mathrm{CH}_{4},{ }^{130} \mathrm{C}_{2} \mathrm{H}_{2},{ }^{130,131} \mathrm{C}_{2} \mathrm{H}_{4}{ }^{130} \\
\mathrm{C}_{2} \mathrm{H}_{6},{ }^{130} \mathrm{C}_{3} \mathrm{H}_{8}{ }^{130}\end{array}$ \\
\hline & & 77 & $\mathrm{CH}_{3} \mathrm{CCH},{ }^{131} \mathrm{CH}_{2} \mathrm{CCH}_{2},{ }^{131} \mathrm{C}_{3} \mathrm{H}_{6}{ }^{131}$ \\
\hline
\end{tabular}


Table 1 - continued from previous page

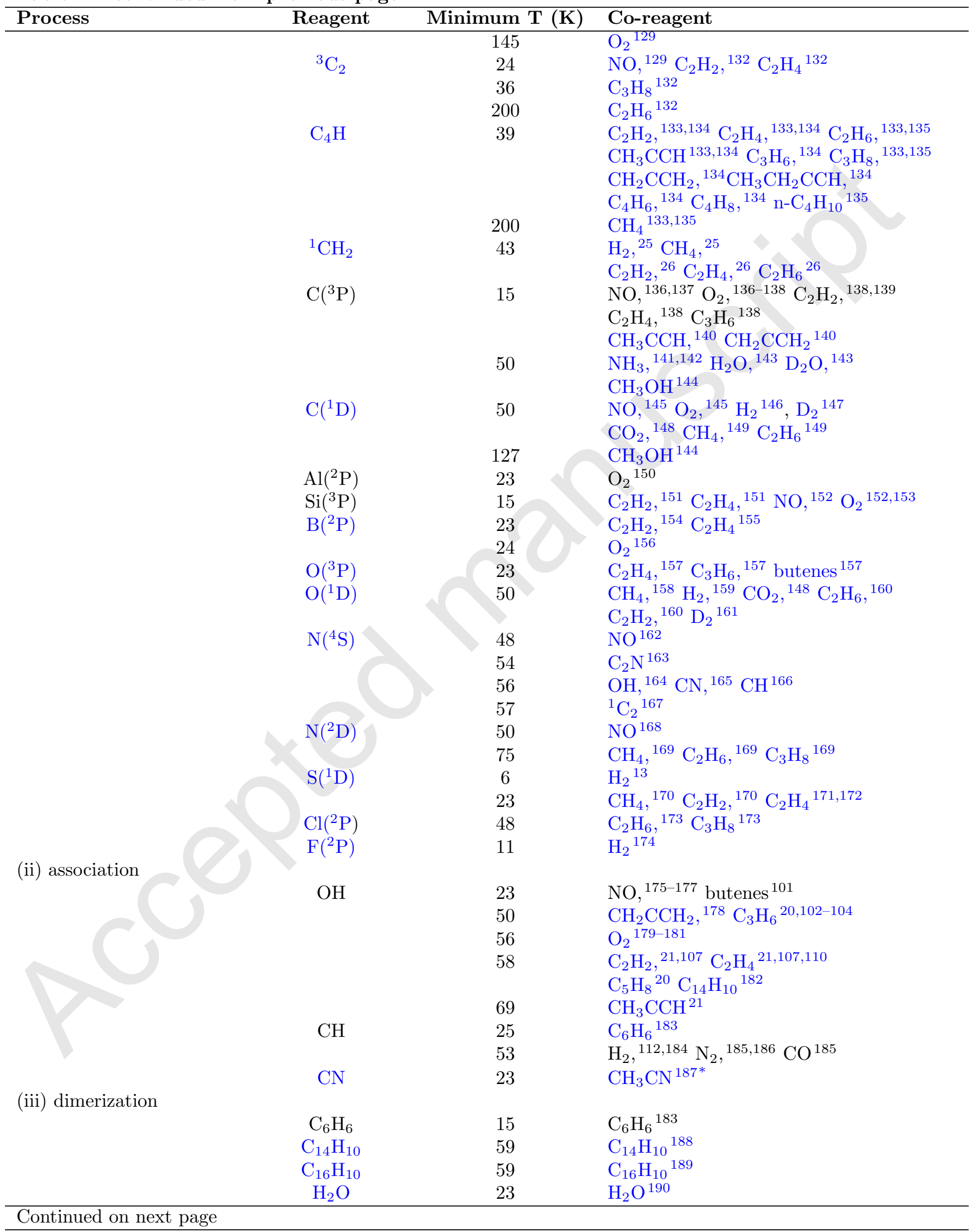


Table 1 - continued from previous page

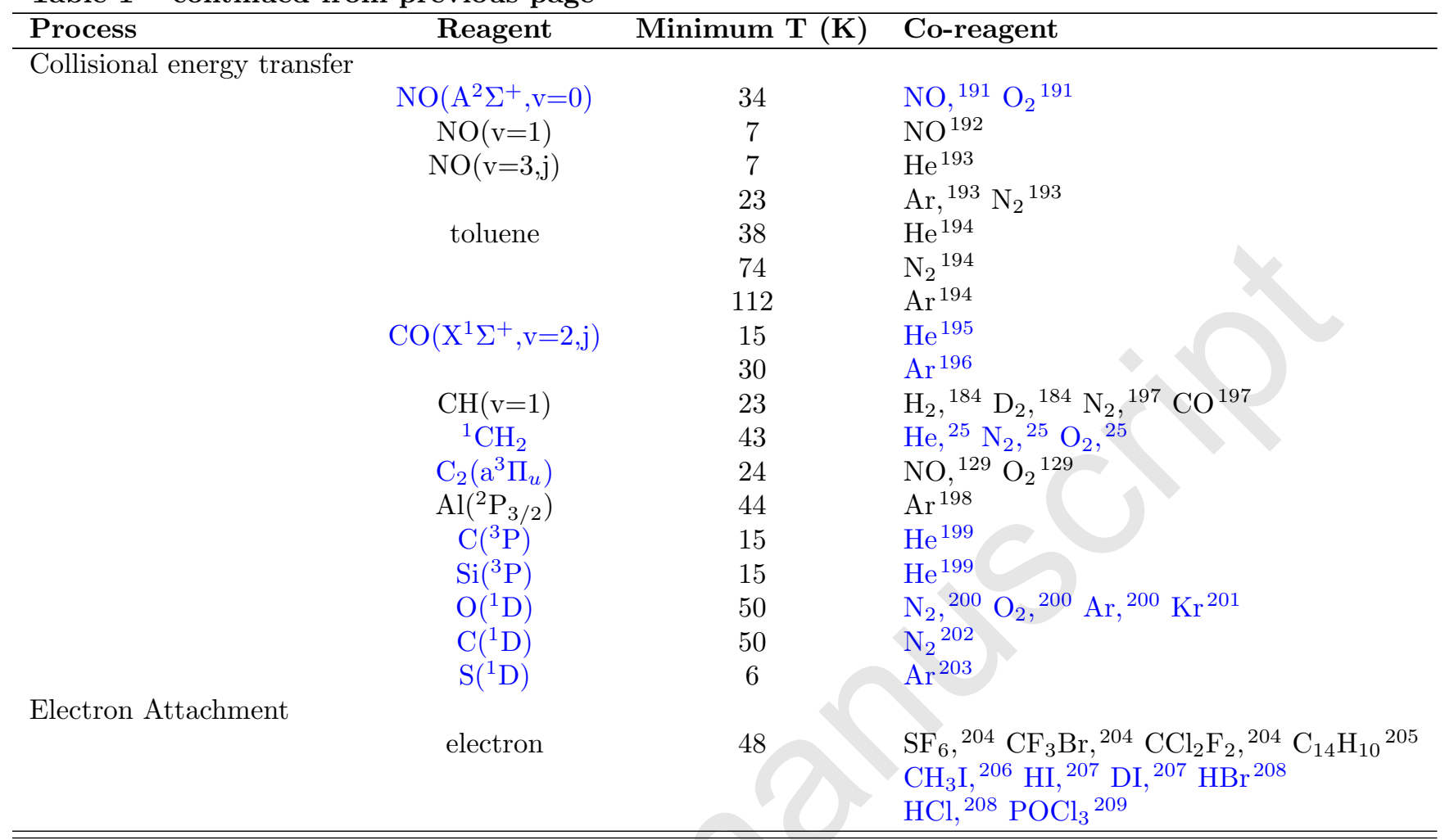

$\dagger$ Corrections to Smith and Rowe ${ }^{72}: \mathrm{He}^{+}+\mathrm{CH}_{4}$ was omitted, $\mathrm{N}^{+}+\mathrm{NH}_{3}$ was measured at $23 \mathrm{~K}_{3} \mathrm{H}_{3}^{+}+\mathrm{CH}_{4}$ was measured at $30 \mathrm{~K}$, reactions of $\mathrm{C}_{2} \mathrm{H}$ with $\mathrm{C}_{2} \mathrm{H}_{2}, \mathrm{C}_{2} \mathrm{H}_{4}$ and $\mathrm{C}_{3} \mathrm{H}_{6}$ by Chastaing et al. ${ }^{73}$ were measured at $15 \mathrm{~K}$, $\mathrm{C}_{2} \mathrm{H}+\mathrm{O}_{2}$ was omitted, the $\mathrm{NH}_{3}+\mathrm{C}_{2} \mathrm{H}$ was reportedly measured at $25 \mathrm{~K}$ but we were unable to source this publication. $\mathrm{NH}_{3}+\mathrm{CH}$ was measured at $23 \mathrm{~K}$

* These reactions may display mixed bimolecular and termolecular mechanisms.

$\S$ Blázquez et. al. to be published in this issue.

\section{Measurements of neutral-neutral reactions}

Most chemical reactions between stable neutral species grind to a halt at the low temperatures of interstellar clouds because the molecules do not have sufficient thermal energy to overcome activation barriers. However, many reactions involving radicals do not possess barriers and remain rapid or even become more efficient at low temperatures.

In order to study neutral-neutral reactions, pulsed laser photolysis or discharge methods are used to produce radicals. These radicals meet the other more abundant reactant species, and the change in radical concentration is observed as a function of time, typically by laser-induced fluorescence. To our knowledge, rate coefficient data on bimolecular reactions involving 21 different radicals (including different electronic states) and around 50 neutrals 
have been published to date, for a total of around 160 neutral-neutral reactions. These reactions are listed in Table 1, as well as those involving three-body collisions.

The first measurement of a rate coefficient for a radical-radical reaction below $100 \mathrm{~K}$ was made for $\mathrm{CN}+\mathrm{O}_{2} \cdot{ }^{79}$ This study was motivated by results obtained in a cryogenic cell that displayed a negative temperature dependence consistent with a "capture" by the long-range dipole-quadrupole forces between the reagents and the formation of a transient complex. They found that the reaction rate coefficient increases with decrease in temperature, following a $\mathrm{T}^{-1 / 2}$ dependence. Such negative temperature dependences of the rate coefficient have since been observed for a range of radical-radical reactions, for example reactions of $\mathrm{CH}\left(\mathrm{X}^{2} \Pi\right)$ with $\mathrm{O}_{2}$ and $\mathrm{NO},{ }^{111} \mathrm{NH}\left(\mathrm{X}^{3} \Sigma^{-}\right)$with $\mathrm{NO}^{128}$ and $\mathrm{N}\left({ }^{4} \mathrm{~S}\right)$ with $\mathrm{C}_{2}\left({ }^{1} \Sigma_{g}^{+}\right) .{ }^{167}$

The discovery that the rate coefficients of many neutral-neutral reactions increase as the temperature is lowered was one of the most significant findings of CRESU experiments and has had a large impact in the field of astrochemistry. A surprising aspect of early CRESU studies was the observed diversity in the temperature dependence of the measured rate coefficients. While the rate of many reactions increased with temperature, others possessed a "U" shaped temperature dependence, with a marked minimum typically between 100-200 K. This behaviour has been observed for several cases where the reaction passes through an initial weakly bound complex and then over a (submerged) barrier. ${ }^{86,89,157}$

In order to predict whether a neutral-neutral reaction is expected to remain rapid ( $\mathrm{k}>$ $10^{-10} \mathrm{~cm}^{3}$ molecule ${ }^{-1} \mathrm{~s}^{-1}$ ) at $10 \mathrm{~K}$, Smith et al. ${ }^{210}$ proposed two criteria: the rate coefficient must be greater than $\sim 10^{-11}$ at room temperature and the difference between the ionization energy (IE) of the molecule and the electron affinity (EA) of the neutral must be less than $8.75 \mathrm{eV}$. When IE-EA is less than $8.75 \mathrm{eV}$ the reaction will be barrierless or possess barriers below the reactant energy (submerged barriers).

The reactions between ground state oxygen atoms, $\mathrm{O}\left({ }^{3} \mathrm{P}\right)$, and unsaturated hydrocarbons provided a good test of this empirical theory, having IE-EA values that straddle $8.75 \mathrm{eV}$. It was indeed found that the temperature dependences supported the empirical theory proposed 


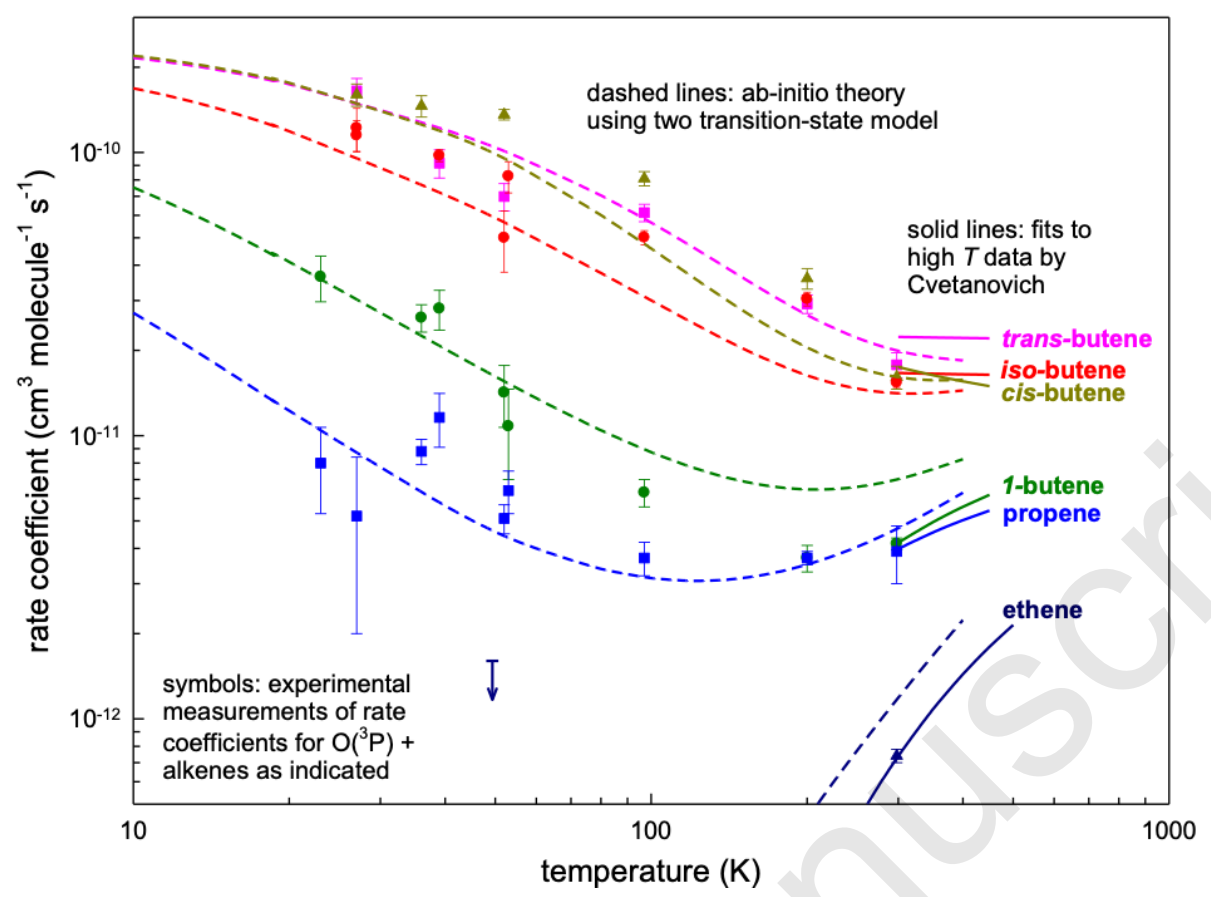

Figure 4: Rate coefficients for the reactions of $\mathrm{O}\left({ }^{3} \mathrm{P}\right)$ atoms with alkenes. The dashed lines show theoretical calculations based on a two-transition state model. The solid lines show the recommended to fit the kinetic data from 300-700 K based on the Arrhenius expression. Adapted with permission from Sabbah et al. ${ }^{157}$ Copyright (2007) AAAS.

by Smith and co-workers. Figure 4 shows the reaction rate coefficients for the $\mathrm{O}\left({ }^{3} \mathrm{P}\right)$ reactions with the unsaturated hydrocarbons ethene, propene and butene isomers. The reaction of oxygen atoms with cis-, trans- and iso-butene isomers, which possess fully submerged barriers and IE-EA values less than $8.75 \mathrm{eV}$, showed negative temperature dependence. The oxygen reaction with ethane possesses a true barrier and an IE-EA much greater than $8.75 \mathrm{eV}$, here the reaction rate coefficient is lower than measurable in the CRESU. The IE-EA for 1butene and propene reactions with $\mathrm{O}\left({ }^{3} \mathrm{P}\right)$ are only slightly below the threshold and displayed the characteristic U-shaped temperature dependence consistent with their barely submerged inner barriers. A number of neutral-neutral reactions of relevance to COM reactivity have been studied using the CRESU technique and we outline some interesting cases below. 

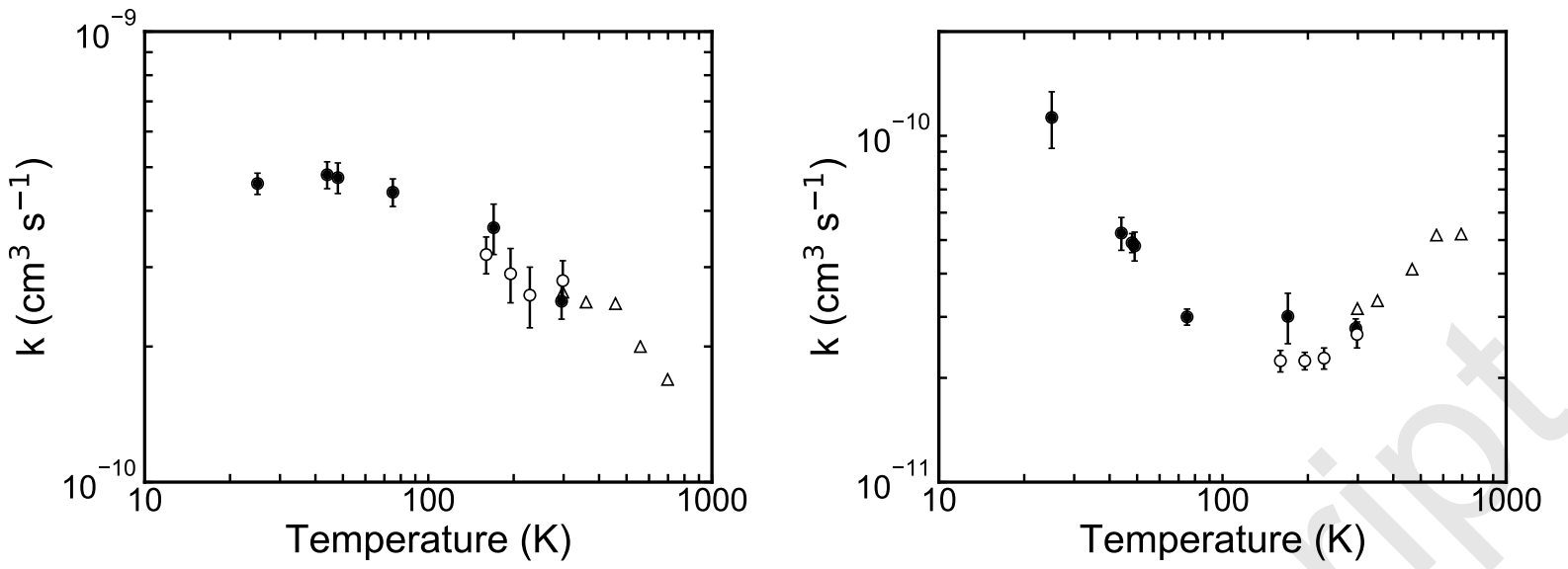

Figure 5: Rate coefficients for the reaction of $\mathrm{CN}$ radicals with $\mathrm{C}_{2} \mathrm{H}_{2}$ (left) and with $\mathrm{C}_{2} \mathrm{H}_{6}$ (right). The circles show data taken from Sims et al. ${ }^{15}$, where the filled circles were measured using a CRESU apparatus and the open circles using a cryogenic cell. The triangles show high temperature data of Herbert et al. ${ }^{211}$.

\section{Reactions between CN and hydrocarbons}

Some of the earliest neutral-neutral reactions studied using the CRESU technique involved the reactions of the cyanogen $(\mathrm{CN})$ radical with saturated $\left(\mathrm{C}_{2} \mathrm{H}_{6}\right)$ and unsaturated $\left(\mathrm{C}_{2} \mathrm{H}_{2}\right.$, $\mathrm{C}_{2} \mathrm{H}_{4}$ ) hydrocarbons. ${ }^{86}$ The temperature dependent rate coefficients were measured between room temperature and $160 \mathrm{~K}$ in a cryogenic cell and down to $25 \mathrm{~K}$ in the CRESU apparatus at Rennes. Similar to the prototypical radical-radical reaction between $\mathrm{CN}$ and molecular oxygen, the rate coefficients for reactions between several unsaturated hydrocarbons and CN displayed negative temperature dependences. The reaction between $\mathrm{C}_{2} \mathrm{H}_{6}$ and $\mathrm{CN}$ displayed a remarkable temperature dependence, decreasing as the temperature was lowered to $\sim 100$ $\mathrm{K}$ and then rapidly increasing to a maximum at $25 \mathrm{~K}$. The rate coefficients for $\mathrm{CN}$ reactions with $\mathrm{C}_{2} \mathrm{H}_{2}$ and $\mathrm{C}_{2} \mathrm{H}_{6}$ are shown in Figure 5 to illustrate the negative temperature dependence $\left(\mathrm{C}_{2} \mathrm{H}_{2}+\mathrm{CN}\right)$ and the $\mathrm{U}$-shaped temperature dependence $\left(\mathrm{C}_{2} \mathrm{H}_{6}+\mathrm{CN}\right)$. The authors explained the temperature dependence by the presence of two transition states along the reaction potential: a "loose" transition state, where the reactants are still well separated, and a "tight" one that is lower in energy but with wider spaced energy levels, beyond which products form. A schematic of a representative potential energy surface for such a reaction is 


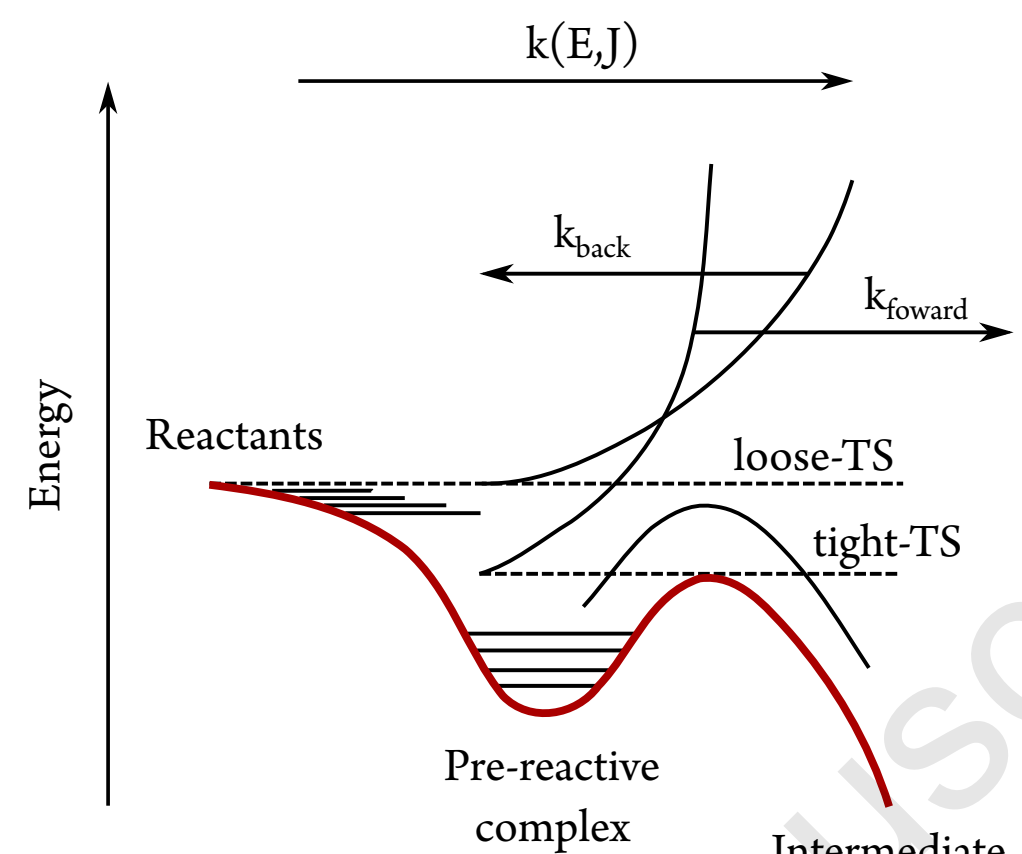

Figure 6: Schematic showing the dynamics of a reaction proceeding through a pre-reactive complex. At low temperatures the reaction rate is dominated by the formation of the prereactive complex via the loose transition state whereas at high-temperatures the the rate is dominated by the passage through the tight transition state. Adapted with permission from Hansmann and Abel ${ }^{107}$ Copyright (2007) Wiley.

shown in Figure 6. At high temperatures, collisions between the two reactants are direct and there is only one chance for the reaction to occur and $\mathrm{k}_{b a c k}$ is dominant. As the temperature is lowered, the proportion of collisions forming pre-reactive complexes is increased and more of the potential surface can be accessed to find a path to products. In other words, at high temperature, passage through the tight transition state governs the reaction rate, while at lower temperatures the loose transition state is rate determining.

Following these early studies, a handful of other reactions between CN and hydrocarbons have been measured. The reaction of $\mathrm{CN}$ with allene $\left(\mathrm{H}_{2}=\mathrm{C}=\mathrm{CH}_{2}\right)$ and methyl acetylene $\left(\mathrm{CH}_{3} \mathrm{CCH}\right)$ were measured by Carty et al. ${ }^{80}$ between $15 \mathrm{~K}$ and $295 \mathrm{~K}$. For both reactions, the temperature-dependence is negligible and the authors recommended the use of a temperature independent value $\mathrm{k}=(4.1 \pm 0.5) \times 10^{-10} \mathrm{~cm}^{3}$ molecule ${ }^{-1} \mathrm{~s}^{-1}$. At all temperatures, the rate coefficients approach the collisional limit and thus the reaction is expected to be significant under ISM temperature conditions. The reaction mechanism was predicted to occur in both 


\section{Reactions of the hydroxyl radical with COMs}

During the last few decades, several reactions between organic molecules and the hydroxyl radical $(\mathrm{OH})$ have been studied, particularly by the group of Dwayne Heard at Leeds. These reactions display a marked increase in the rate coefficient as the temperature is lowered. Such reactions have been shown to proceed via gas-phase hydrogen abstraction reactions, forming weakly bound $\left(<30 \mathrm{~kJ} \mathrm{~mol}^{-1}\right)$ hydrogen-bonded complexes with the organic neutrals. Reactions with $\mathrm{OH}$ at low temperatures have thus far been studied for the alcohols methanol, ${ }^{14,89-91}$ ethanol ${ }^{94,95}$ and propan-2-ol, ${ }^{94}$ dimethyl ether, ${ }^{92,144}$ the ketones butanone (methyl-ether-ketone), ${ }^{92}$ acetone, ${ }^{92,144}$ and formaldehyde ${ }^{97}$ and for the esters methyl formate ${ }^{96}$ and L-alanine ethyl ester. ${ }^{108}$ The reaction between methanol and $\mathrm{OH}$, in particular, has been studied in detail both experimentally ${ }^{14,89-91}$ and theoretically ${ }^{14,214-217}$ by several different groups. The reaction was first studied at low temperature by the Leeds group, who measured the rate coefficient by OH LIF at $63 \mathrm{~K}$ and $80 \mathrm{~K}$. They found the rate coefficient for the reaction between $\mathrm{OH}$ and methanol was almost two orders of magnitude larger at $63 \mathrm{~K}$ than previously measured at $\sim 200 \mathrm{~K} .{ }^{218}$ Later experimental efforts focused on measurements down to lower temperatures (recently, as low as $\sim 12 \mathrm{~K}$ ) and investigations of the 


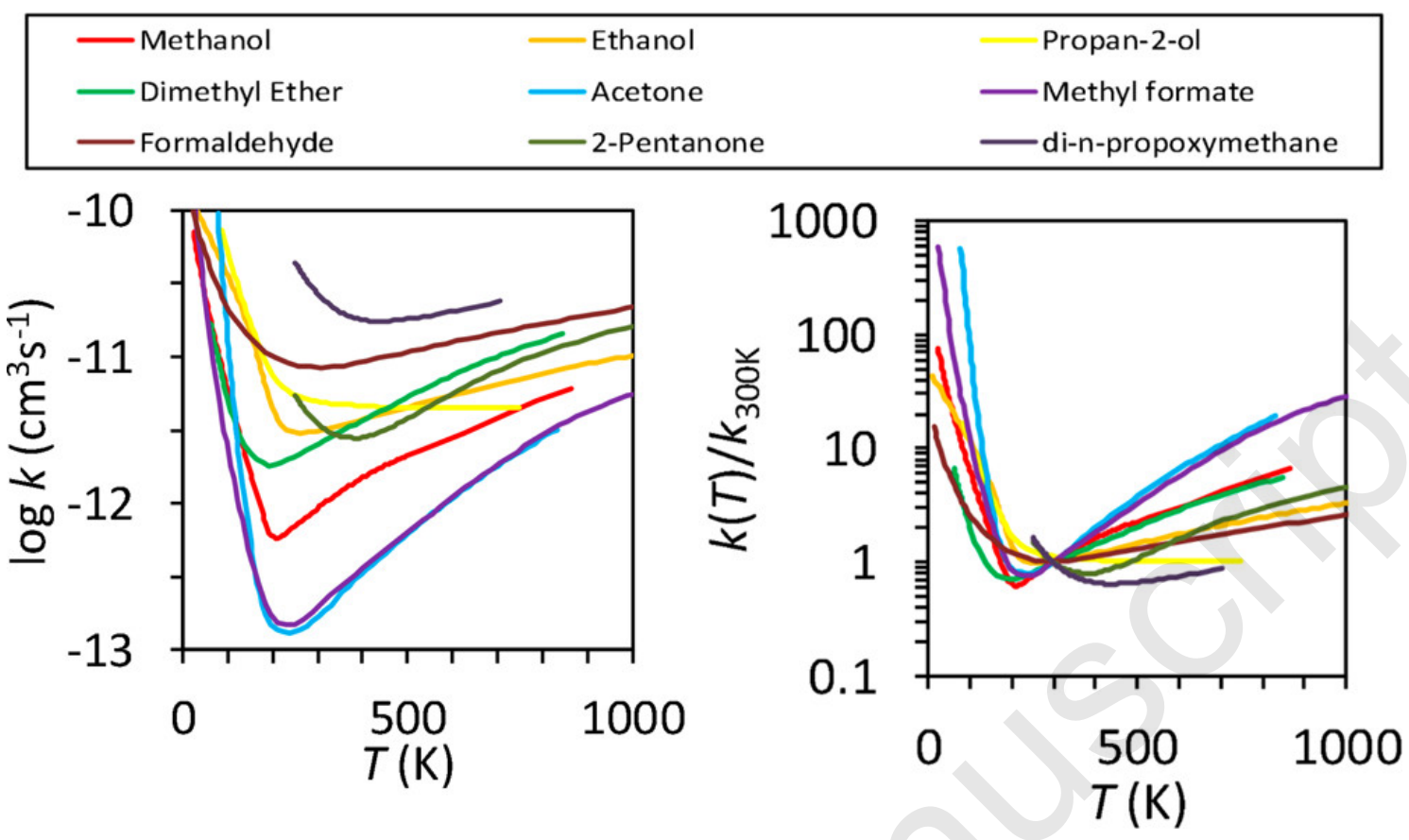

Figure 7: Rate coefficients, $\mathrm{k}$ (left), and the ratio, $\mathrm{k}(\mathrm{T}) / \mathrm{k}(300 \mathrm{~K}$ ) (right), as a function of temperature for reaction of $\mathrm{OH}$ with several organic molecules. The lines are interpolated fits to data in the literature. Reprinted from Heard ${ }^{219}$.

pressure dependence of the reaction rate coefficient.

Figure 7 shows the temperature dependences of the rate coefficients for reactions of $\mathrm{OH}$ with several of these organic molecules, interpolated to the experimental data. In accordance with the empirical treatment of Smith et. al. a rapid U-shaped temperature dependence is observed resulting in low-temperature rate coefficients up to a thousand times faster than those at room temperature. At low temperatures the lifetime of the van der Waals complex increases and the probability of tunnelling under the reaction barrier to form products becomes much higher.

An important aspect of these measurements is the pressure dependence of the rate coefficients. If the rate coefficient is dependent on the total density in the flow the pre-reactive complex may be stabilized by three-body collisions, and thus the enhanced rate coefficient at low temperature will not be applicable to most astrochemical environments due to their low densities. In the low pressure limit (LPL) the reaction can be considered as a direct H-abstraction process without the formation of a stabilized pre-reactive complex, whereas 
in the high-pressure limit (HPL) the pre-reactive complex is fully stabilized with an energy state population following a Boltzmann distribution. For the $\mathrm{CH}_{3} \mathrm{OH}+\mathrm{OH}$ reaction, the rate coefficients were measured as a function of pressure at $80 \mathrm{~K}$ and were found to be independent of the total density which was explained by the presence of a weakly bound complex that is not fully stabilized by collisions but undergoes quantum mechanical tunnelling to the products. ${ }^{89}$ Tunnelling mechanisms can be verified by checking for kinetic isotope effect; however, experiments with deuterated reagents are more experimentally challenging and costly. Measurement of the rate coefficients from $11.7 \mathrm{~K}$ to $177.5 \mathrm{~K}$ by Ocaña et al. ${ }^{14}$ displayed a pressure dependence between $120-150 \mathrm{~K}$, below which the rate coefficients were pressure independent. Gao et al. ${ }^{215}$ computed the rate coefficients between $30 \mathrm{~K}$ and $2000 \mathrm{~K}$ using the competitive canonical unified statistical (CCUS) model. Their results indicated that the rate coefficients measured below $100 \mathrm{~K}$ are close to the HPL. Roncero et al. ${ }^{214}$ calculated a new full-dimensional potential energy surface and used quasi-classical trajectory methods to determine the rate coefficients as a function of temperature. The rate coefficients were found to be almost temperature independent between $20 \mathrm{~K}$ and $300 \mathrm{~K}$ and much lower than the experimental measurements. Recently, Nguyen et al. ${ }^{216}$ have used 2-D master equation methods to compute the temperature and pressure dependent rate coefficients. Their results suggest that the low-temperature measurements are approaching the high-pressure limit. However, del Mazo-Sevillano et al. ${ }^{217}$ used a ring-polymer molecular dynamics method and were able to reproduce well the experimental data assuming the zero pressure limit. Thus, even for the reaction between $\mathrm{OH}$ and one of the simplest COMs, methanol, there is still debate about the reaction mechanism under interstellar conditions.

$\mathrm{OH}$ reactions with larger alcohols ethanol and propan-2-ol and with acetone, methylethyl-ketone, dimethyl ether, methyl formate and $\mathrm{H}_{2} \mathrm{CO}$ also displayed distinct upturns in the rate coefficient for $\mathrm{H}$-abstraction towards low temperature. In reactions of $\mathrm{OH}$ with acetone, a marked pressure dependence was observed, suggesting the enhanced rate coefficients at low temperature are likely due to collisional stabilization. However, rate calculations in the 
low pressure limit predicted that the reaction will remain rapid $\left(\mathrm{k} \sim 10^{-11} \mathrm{~cm}^{3}\right.$ molecule ${ }^{-1}$ $\mathrm{s}^{-1}$ ) under interstellar conditions. ${ }^{93}$ The lifetime of the pre-reactive complex is determined by the density of vibrational states. Complexes of larger molecules will have long enough lifetimes that the enhancement of the rate coefficient at low temperatures can be enhanced by collisional stabilization. For small molecules, the lifetime of the pre-reactive complex is short and the rate coefficient at low temperature is controlled by tunnelling.

The largest enhancement in the rate coefficient observed to date is that for the $\mathrm{OH}$ + methyl formate reaction, increasing by a factor of $\sim 600$ at $22 \mathrm{~K}$ compared to room temperature. The pressure dependence of this reaction has not been investigated and thus the mechanism for the dramatic enhancement in $\mathrm{k}(\mathrm{T})$ at low temperatures is unknown.

\section{Product specific reaction kinetics}

Reactions involving complex organic molecules often have more than one set of products. In such multichannel reactions, rate coefficients can be defined for each channel and related to overall reaction rate coefficient by their branching ratios. Take, for example, a two-channel reaction between $\mathrm{CH}_{3} \mathrm{OH}$ and $\mathrm{OH}$, producing products $\mathrm{CH}_{3} \mathrm{O}$ and $\mathrm{H}_{2} \mathrm{O}$ (channel a) and $\mathrm{CH}_{2} \mathrm{OH}$ and $\mathrm{H}_{2} \mathrm{O}$ (channel b):

$$
\begin{aligned}
\mathrm{CH}_{3} \mathrm{OH}+\mathrm{OH} \stackrel{\mathrm{k}_{1 \mathrm{a}}}{\longrightarrow} \mathrm{CH}_{3} \mathrm{O}+\mathrm{H}_{2} \mathrm{O} \\
\stackrel{\mathrm{k}_{1 \mathrm{~b}}}{\longrightarrow} \mathrm{CH}_{2} \mathrm{OH}+\mathrm{H}_{2} \mathrm{O}
\end{aligned}
$$

Here, the overall rate coefficient, $\mathrm{k}_{1}=\mathrm{k}_{1 a}+\mathrm{k}_{1 b}$, is the sum of the product specific rate coefficients, $\mathrm{k}_{1 a}$ and $\mathrm{k}_{1 b}$. The product branching ratios into channels a and $\mathrm{b}$ are then defined as $\alpha_{a}=\mathrm{k}_{1 a} / \mathrm{k}_{1}$ and $\alpha_{b}=\mathrm{k}_{1 b} / \mathrm{k}_{1}$.

It has long been acknowledged that branching ratios between the products in such multichannel reactions are as important as the overall rate coefficient in order to accurately 
reproduce complex astrophysical environments. ${ }^{220}$ Significant progress has been made in the measurement of overall low-temperature rate coefficients during the last few decades; however, the measurement of reaction products and their branching ratios has lagged behind. This is, in part, because there is no universal way of determining reaction branching ratios. In order to efficiently probe multichannel reactions, the experimental technique should be universal (i.e. detect all reaction channel products), highly sensitive and multiplexed (i.e. able to detect multiple species at the same time). The sensitivity requirement arises from the need to kinetically isolate the bimolecular reaction of interest and minimize the contribution of side or back reactions. These side reactions are reduced by conducting the experiment under pseudo-first order conditions, such that one reactant species (typically an unstable radical) is kept at much lower concentration than the other. The concentrations of the products are then limited by that of the less abundant reactant. Multiplexed detection methods are required in order to detect multiple products simultaneously; thus detection techniques that must be tuned to a specific product are impractical e.g. LIF or other narrow-band spectroscopic techniques. Multiplexed detection also reduces systematic errors that arise from drifts in experimental parameters over time.

In the following sections, we discuss techniques that have been used to determine product branching ratios of elementary reactions and their extension to low-temperature reactions. Only a handful of measurements have been made of product specific reaction kinetics below room temperature, relying on either mass spectrometric or spectroscopic detection methods. We outline these methods and present some key results that have been obtained.

\section{Calibrated LIF experiments}

In addition to measuring the decay of a reactant, LIF measurements can be used to measure the presence and growth kinetics of particular products. These data can be used to check for consistency with the decay kinetics of the reactant and confirm the rate coefficient, as well as to provide some evidence supporting a particular reaction mechanism. The use of LIF 


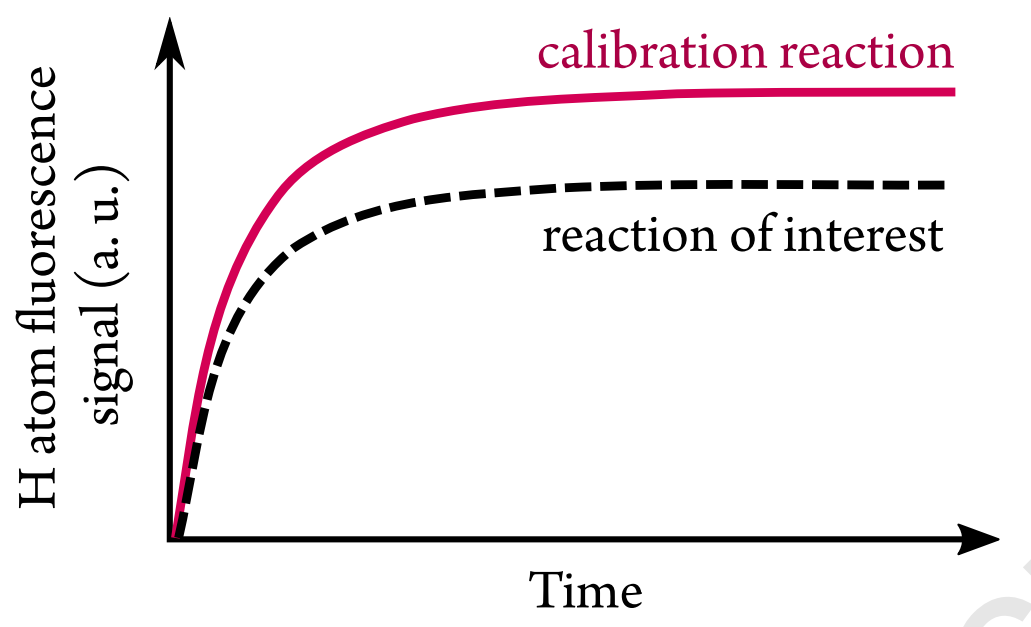

Figure 8: Schematic illustrating a calibration experiment for measurement of H-atom branching ratios. The solid line is the $\mathrm{H}$ atom fluorescence from the calibration reaction which has a $100 \%$ conversion to the $\mathrm{H}$-atom product channel. The dashed line is the $\mathrm{H}$ atom fluorescence from the reaction of interest with an identical initial concentration of the radical reactant. Adapted with permission from Seakins ${ }^{220}$ Copyright (2007) RSC.

to measure reaction product branching ratios, however, remains challenging, as it is difficult to relate fluorescence signals to absolute product yields. LIF methods are highly sensitive and often selective, but require calibration to determine absolute concentrations of products. The use of calibration reactions has enabled some determinations of H-atom product yields; however, no direct information is obtained on the identity of the co-product.

The reactions of acetylene and ethylene with CN were studied by this technique at room temperature. $^{221}$ In this study, the time resolved $\mathrm{H}$ atom signal was compared with that from a chosen calibration reaction, $\mathrm{CN}+\mathrm{H}_{2} \rightarrow \mathrm{HCN}+\mathrm{H}$. Figure 8 shows a schematic of the calibration technique. The time dependence of the radical removal can be measured in addition to the $\mathrm{H}$ atom production to ensure that the observed $\mathrm{H}$ is produced from the target reaction and not from secondary or side reactions. In order to detect $\mathrm{H}$ atom fluorescence at the Lyman- $\alpha$ transition $(121.6 \mathrm{~nm})$, the Lyman- $\alpha$ probe beam was produced by frequency tripling $365.8 \mathrm{~nm}$ radiation in a gas cell containing krypton and argon. The $365.8 \mathrm{~nm}$ beam was first produced by mixing $1064 \mathrm{~nm}$ radiation from a YAG pump laser with dye laser radiation at $554.6 \mathrm{~nm}$. The branching ratio into the $\mathrm{H}$ atom channel was determined by: 


$$
\alpha=\frac{I(\text { reactant }) \times C(\text { reactant })}{I(\text { calibration }) \times C(\text { calibration })}
$$

Where $I$ refers to the intensity of the $\mathrm{H}$ atom signal and $C$ is a correction factor to account for differences in quenching or absorption by the reactant (here $\mathrm{C}_{2} \mathrm{H}_{2}$ or $\mathrm{C}_{2} \mathrm{H}_{4}$ ) as compared to the calibration reactant $\left(\right.$ here $\left.\mathrm{H}_{2}\right)$. Using this method, the authors found room temperature branching ratios to $\mathrm{H}$ atom channels of $(1.08 \pm 0.13)$ and $(1.04 \pm 0.11)$ for the reactions of $\mathrm{CN}$ with $\mathrm{C}_{2} \mathrm{H}_{2}$ and $\mathrm{C}_{2} \mathrm{H}_{4}$, respectively.

The $\mathrm{H}$ atom calibration technique has been applied to a handful of reactions at $\mathrm{T}<300$ K: by the group of Seakins and co-workers at the University of Leeds, to study reactions of ${ }^{1} \mathrm{CH}_{2},{ }^{26,222}$ and by Hickson and co-workers at the Université de Bordeaux for reactions involving $\mathrm{C}\left({ }^{3} \mathrm{P}\right),{ }^{139,142,144} \mathrm{C}\left({ }^{1} \mathrm{D}\right),{ }^{149}$ and $\mathrm{O}\left({ }^{1} \mathrm{D}\right) .{ }^{158,160}$ In the former set of experiments, the authors found that the $\mathrm{H}$ atom branching ratio for the reaction of ${ }^{1} \mathrm{CH}_{2}$ with both acetylene and ethene increases with temperature between 195 and $298 \mathrm{~K}$. The temperature range was later extended down to $100 \mathrm{~K}$ using a pulsed CRESU apparatus and the H-atom branching ratio was shown to continue to decrease at lower temperatures. ${ }^{26}$ The removal of ${ }^{1} \mathrm{CH}_{2}$ was instead dominated by quenching to ${ }^{3} \mathrm{CH}_{2}$ at $100 \mathrm{~K}$. Similar to Choi et al. ${ }^{221}$, the authors used the reaction with $\mathrm{H}_{2}$ as a calibration reaction, as they had previously measured the temperature dependent branching ratios for its reaction with ${ }^{1} \mathrm{CH}_{2}$ in their laboratory. ${ }^{223,224}$ Douglas et al. ${ }^{25}$ have also used LIF from OH to determine the branching ratios for quenching of ${ }^{1} \mathrm{CH}_{2}$ to ${ }^{3} \mathrm{CH}_{2}$ by $\mathrm{H}_{2}$ and $\mathrm{CH}_{4}$ versus reaction to other products. In these experiments, ${ }^{1} \mathrm{CH}_{2}$ is produced in a bath gas of $\mathrm{N}_{2} / \mathrm{He}$ mixed with $\mathrm{O}_{2}$. The ${ }^{1} \mathrm{CH}_{2}$ is quenched by collisions to ${ }^{3} \mathrm{CH}_{2}$, which can then react with $\mathrm{O}_{2}$, producing $\mathrm{OH}$. In the presence of $\mathrm{H}_{2}$ or $\mathrm{CH}_{4}$, some of the ${ }^{1} \mathrm{CH}_{2}$ is removed in chemical reactions, resulting in less ${ }^{3} \mathrm{CH}_{2}$ and therefore less $\mathrm{OH}$ LIF signal.

The H-atom product branching ratios have been determined by Hickson and co-workers for a number of reactions involving carbon $\left(\mathrm{C}\left({ }^{3} \mathrm{P}\right), \mathrm{C}\left({ }^{1} \mathrm{D}\right)\right)$ and oxygen atoms $\left(\mathrm{O}\left({ }^{1} \mathrm{D}\right)\right)$. In most cases, a suitable reference reaction was chosen in order to extract the absolute H-atom 
yields, for example the reaction of $\mathrm{C}\left({ }^{3} \mathrm{P}\right)$ with $\mathrm{C}_{2} \mathrm{H}_{4}$, which has a known H-atom branching ratio of $0.92 \pm 0.04$ at $300 \mathrm{~K} .{ }^{225}$ The $\mathrm{H}$-atom $\mathrm{LIF}$ calibration of $\mathrm{C}\left({ }^{3} \mathrm{P}\right)+\mathrm{CH}_{3} \mathrm{OH}$ reaction is more complicated due to a competing reaction with $\mathrm{C}\left({ }^{1} \mathrm{D}\right)$ atoms, which are also produced during photodissociation of the carbon atom precursor, $\mathrm{CBr}_{4}$. The proportion of $\mathrm{C}\left({ }^{3} \mathrm{P}\right)$ and $\mathrm{C}\left({ }^{1} \mathrm{D}\right)$ produced from $\mathrm{CBr}_{4}$ was first characterized by comparing the $\mathrm{H}$ atom yields from the reactions of the photoproduced $\mathrm{C}$ with $\mathrm{H}_{2}$ and with methylacetylene, $\mathrm{C}_{3} \mathrm{H}_{4} \cdot \mathrm{C}\left({ }^{3} \mathrm{P}\right)$ does not react with $\mathrm{H}_{2}$, whereas $\mathrm{C}\left({ }^{1} \mathrm{D}\right)$ atoms react rapidly with $100 \%$ branching into the $\mathrm{H}$ atom channel; therefore, adding $\mathrm{H}_{2}$ to the flow and monitoring the $\mathrm{H}$ atom signal could be used to determine whether any $\mathrm{C}\left({ }^{1} \mathrm{D}\right)$ was produced. The proportions of $\mathrm{C}\left({ }^{3} \mathrm{P}\right)$ and $\mathrm{C}\left({ }^{1} \mathrm{D}\right)$ were then quantified by comparing the $\mathrm{H}$ atom signal produced in the $\mathrm{C}+\mathrm{C}_{3} \mathrm{H}_{4}$ reaction to that from $\mathrm{C}+\mathrm{H}_{2}$, assuming $\mathrm{H}$ atom branching fractions of 0.85 and 1 for the two reactions, respectively.

Experiments were then performed in the presence and absence of excess $\mathrm{H}_{2}$, allowing the authors to determine the $\mathrm{H}$ atom yield from the $\mathrm{C}\left({ }^{1} \mathrm{D}\right)+\mathrm{CH}_{3} \mathrm{OH}$ reaction to be approximately $100 \%$. The $\mathrm{H}$ atom signals from the $\mathrm{C}+\mathrm{CH}_{3} \mathrm{OH}$ and $\mathrm{C}+\mathrm{C}_{3} \mathrm{H}_{4}$ reactions were thus compared to obtain the $\mathrm{H}$ atom yield from the $\mathrm{C}\left({ }^{3} \mathrm{P}\right)+\mathrm{CH}_{3} \mathrm{OH}$ reaction. These steps can be summarized as follows:

$$
I\left(\mathrm{C}\left({ }^{3} \mathrm{P}\right)+\mathrm{CH}_{3} \mathrm{OH}\right)=0.85 \times \frac{I\left(\mathrm{C}+\mathrm{CH}_{3} \mathrm{OH}\right)-I\left(\mathrm{C}\left({ }^{1} \mathrm{D}\right)+\mathrm{H}_{2}\right)}{I\left(\mathrm{C}+\mathrm{C}_{3} \mathrm{H}_{4}\right)-I\left(\mathrm{C}\left({ }^{1} \mathrm{D}\right)+\mathrm{H}_{2}\right)}
$$

where $I\left(\mathrm{C}\left({ }^{1} \mathrm{D}\right)+\mathrm{H}_{2}\right), I\left(\mathrm{C}+\mathrm{C}_{3} \mathrm{H}_{4}\right)$ and $I\left(\mathrm{C}+\mathrm{CH}_{3} \mathrm{OH}\right)$ are the $\mathrm{H}$ atom LIF signals derived from fitting the signals recorded when the $\mathrm{C}$ atoms were in the presence of $\mathrm{H}_{2}, \mathrm{C}_{3} \mathrm{H}_{4}$ and $\mathrm{CH}_{3} \mathrm{OH}$, respectively. At both $296 \mathrm{~K}$ and $127 \mathrm{~K}$, the $\mathrm{H}$ atom yield of the $\mathrm{C}\left({ }^{3} \mathrm{P}\right)+\mathrm{CH}_{3} \mathrm{OH}$ reaction was seen to represent only $\sim 10 \%$ of the total. This result allowed the authors to place constraints on statistical calculations using the MESMER ${ }^{226}$ (Master Equation Solver for Multi Energy-well Reactions) code to determine that the only major product channel in the $\mathrm{C}\left({ }^{3} \mathrm{P}\right)+\mathrm{CH}_{3} \mathrm{OH}$ reaction is the formation of $\mathrm{HCO}+\mathrm{CH}_{3}$. Some of the $\mathrm{HCO}$ radicals (10-15\% at most) fall apart to give $\mathrm{H}+\mathrm{CO}$, producing the $\mathrm{H}$ atom signal detected by LIF. 


\section{Ionization techniques}

Many species of interest for astrochemistry do not fluoresce (owing to, for example, predissociation) and, as noted above, it is generally not possible to detect multiple species at the same time by this technique as each molecule requires a specific excitation and detection scheme. In contrast, mass spectrometry is a universal detection method that can be used to detect multiple species during the same experiment. Mass spectrometry coupled to tunable vacuum ultraviolet synchrotron photoionization has been used in a number of kinetics experiments to identify reaction products as well as radical intermediates. The photoionization spectra obtained can be used to distinguish between isomeric reaction products with the same $\mathrm{m} / \mathrm{z}$, since each isomer has a distinct ionization threshold and photoionization efficiency (PIE) curve, determined by Franck-Condon overlap between the neutral and the cation. This affords new insights into detailed reaction mechanisms that could not be obtained using mass spectrometry alone.

Osborn and co-workers further developed the photoionization mass spectrometer (PIMS) design of Slagle and Gutman ${ }^{228,229}$ for use with a flow tube reactor. ${ }^{227}$ To avoid the significant fragmentation that occurs using conventional electron-bombardment ionization, the instrument used vacuum ultraviolet (VUV) radiation produced in a synchrotron that could 

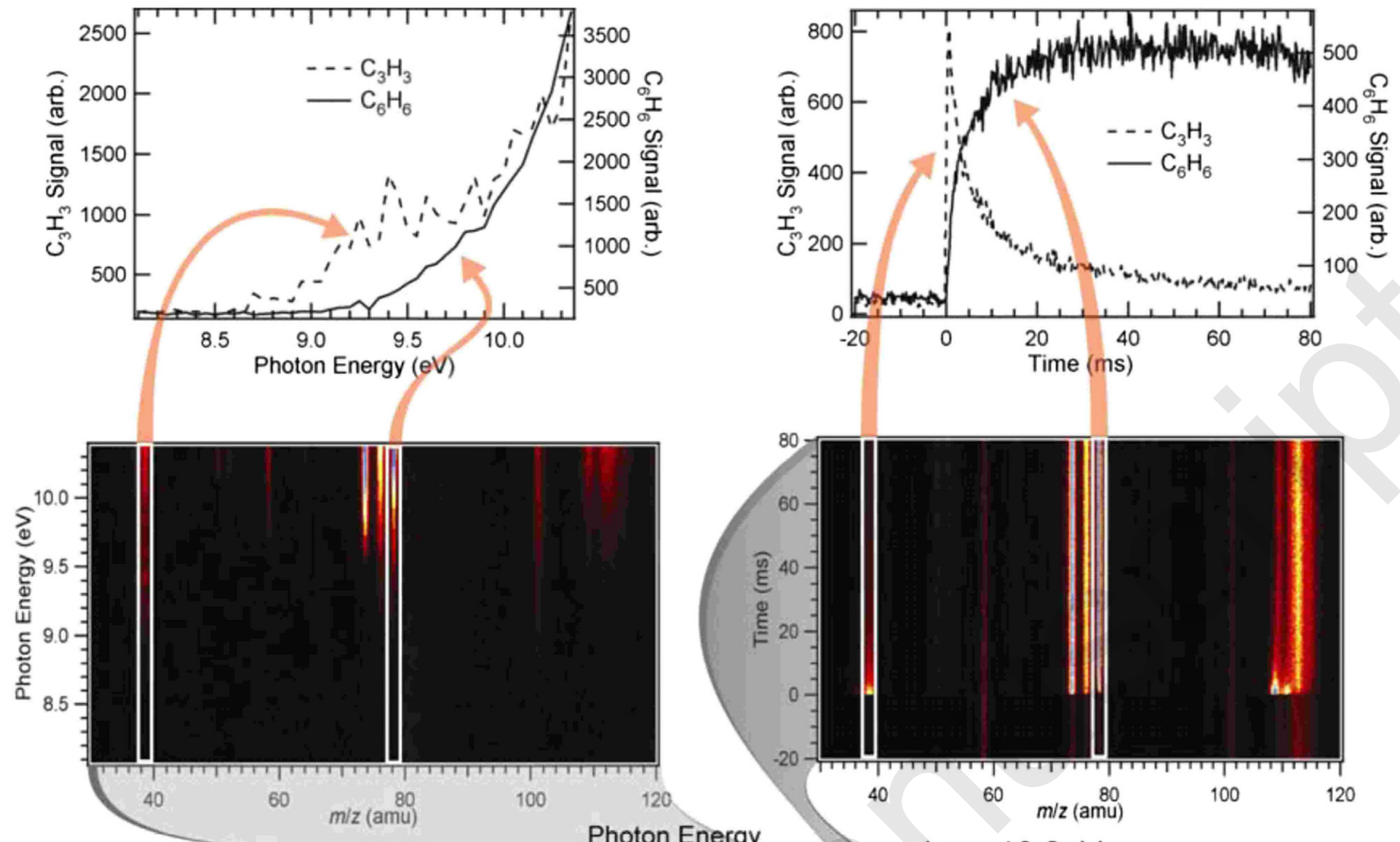

$t=0-60 \mathrm{~ms}$

$h v=10.2 \mathrm{eV}$

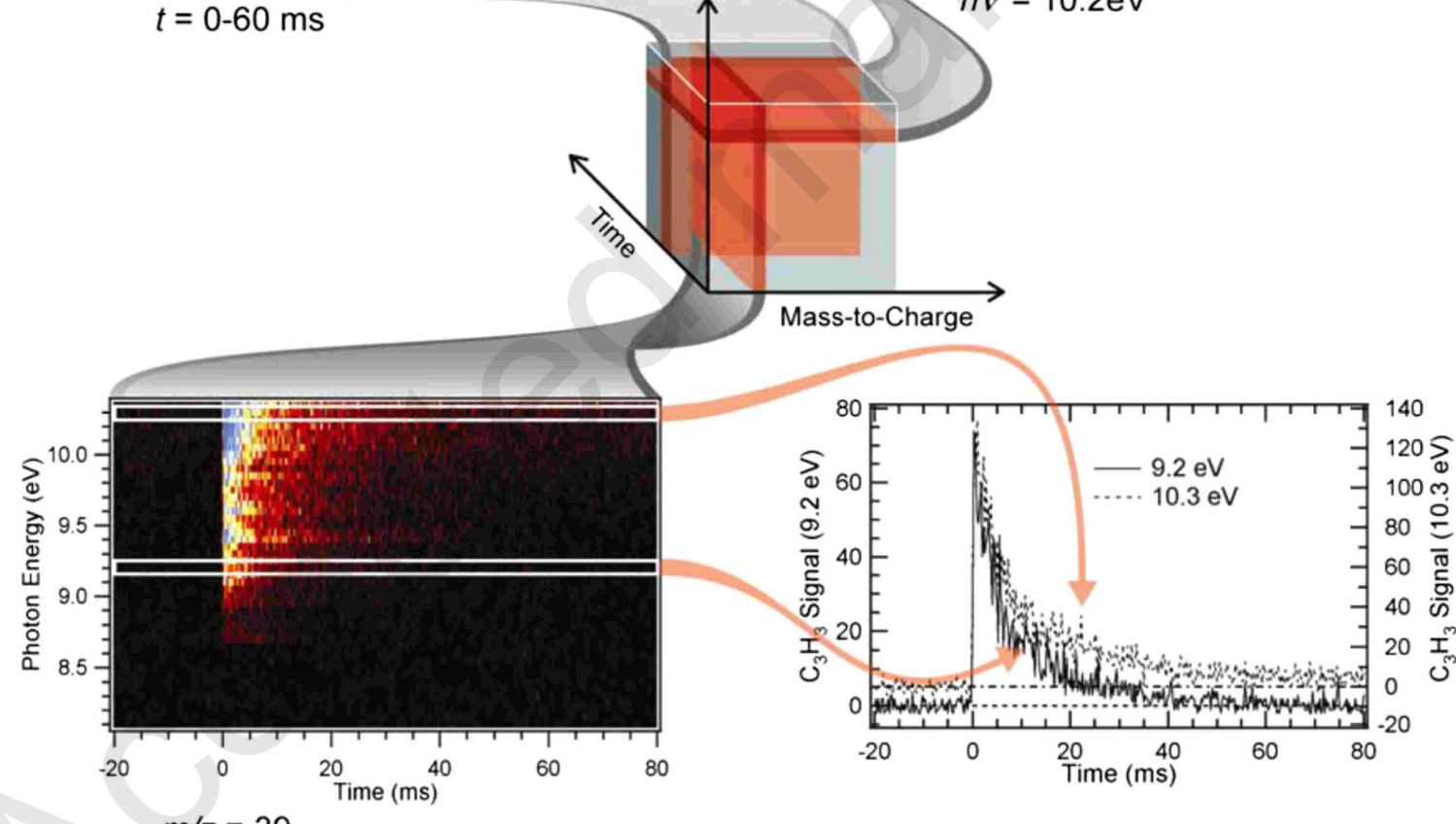

Figure 9: Image representing the 3D data cube that is obtained using photoionization mass spectrometry for measurement of reaction product branching rations. Both the photon energy and the mass-to-charge ratio are measured as a function of time. The 2D slices show examples of data that can be obtained: The mass spectrum over time at a single photon energy, the photoionization spectrum over time at a single mass-to-charge ratio and the mass-to-charge ratio versus photon energy at a given time. Reprinted with permission from Osborn et al. ${ }^{227}$ Copyright (2008) AIP. 
be tuned to energies within a few $\mathrm{eV}$ of the ionization energy of the species of interest. The broad tunability of the synchrotron source provides high selectivity, minimizing fragmentation and allowing one to distinguish between structural isomers due to their different ionization energies and PIE curves. The photoionization spectroscopy was coupled to a multiplexed mass spectrometer producing a data cube signal, as shown in 9, that is a function of time as well as mass $(\mathrm{m} / \mathrm{z})$ and VUV energy (E). In the first version of the instrument, a multiplexed magnetic sector mass spectrometer was employed ${ }^{227}$ but this was subsequently replaced by a rapidly pulsed orthogonal time of flight mass spectrometer. ${ }^{230,231}$

This technique has enabled significant advances in the measurement of product branching ratios for reactions at $300 \mathrm{~K}$ and above, with particular significance to atmospheric and combustion chemistry. ${ }^{232,233}$ It has also been used to study reactions of astrochemical interest, including (at room temperature) the reaction of $\mathrm{CN}$ with benzene to produce benzonitrile, ${ }^{87}$ Here, the authors found that benzonitrile was the only detected product channel, with no evidence for a $\mathrm{C}_{6} \mathrm{H}_{5}+\mathrm{HCN}$ channel; however, it remains unclear if the benzonitrile channel would remain dominant at the $10 \mathrm{~K}$ gas temperature of TMC-1, where it has been recently detected. ${ }^{234}$ The detection of benzonitrile in the ISM provides a link to the simplest aromatic, benzene, which itself cannot be detected by radio astronomy due to its lack of a permanent dipole. A potential formation route to benzene, the reaction of $\mathrm{C}_{2} \mathrm{H}$ with 1,3-butadiene, was also studied using synchrotron photoionization mass spectrometry. ${ }^{235}$ The principal reaction channel involves addition of the $\mathrm{C}_{2} \mathrm{H}$ radical to one of the unsaturated sites of 1,3-butadiene, followed by $\mathrm{H}$ atom loss to give isomers of $\mathrm{C}_{6} \mathrm{H}_{6}$. The photoionization spectra indicated that fulvene is the major isomer product, with a branching fraction of $\sim 60 \%$. These results disagree with the branching fractions found in crossed-beam experiments which found 1,3hexadien-5-yne as the dominant isomer $(70 \pm 10 \%)$ followed by benzene $(30 \pm 10 \%) .{ }^{236}$ They suggested this discrepency may be due the high collisional energy of the crossedbeam experiment (translating to thermal energy of 5400K), emphasizing the importance of studying reactions under both single collision and thermal conditions. 
In a recent development at the Advanced Light Source (ALS) synchrotron in Berkeley, Wilson, Leone and co-workers combined a pulsed Laval nozzle expansion with synchrotron photoionisation and quadrupole mass spectrometric detection to determine the product branching ratios for reactions at $\sim 80 \mathrm{~K} .{ }^{118}$ This development implemented sampling of the collimated expansion through a small pinhole $(450 \mu \mathrm{m})$ in an airfoil in order to reduce the density of the flow for mass spectrometric detection while minimizing the distance between sampling of the flow and photoionization in order to conserve the kinetic time resolution. ${ }^{237}$ They used this technique to study reactions of alkenes: ethene, propene and isomers of butene, with $\mathrm{C}_{2} \mathrm{H}$ radicals. ${ }^{120,124}$

In the case of butene, the isomer-specific product branching ratios for the reaction of $\mathrm{C}_{2} \mathrm{H}$ radicals with the $\mathrm{C}_{4} \mathrm{H}_{8}$ isomers (1-butene, cis-2-butene, trans-2-butene and isobutene) were obtained. ${ }^{124}$ We describe this set of experiments as an illustration of the photoionization mass spectrometry technique for product determination in low temperature reactions. The butene isomers were sequentially introduced into the flow mixed with the $\mathrm{C}_{2} \mathrm{H}$ precursor (acetylene) and nitrogen as a buffer gas. The $\mathrm{C}_{2} \mathrm{H}$ radicals were produced by pulsed-laser photolysis of acetylene at $193 \mathrm{~nm}$. Following its production, $\mathrm{C}_{2} \mathrm{H}$ could react either with the $\mathrm{C}_{4} \mathrm{H}_{8}$ isomer itself, or potentially with one of its photofragments. In order to unravel the origin of the products, the mass spectrum of the butene isomer exposed to the $193 \mathrm{~nm}$ photolysis beam is used as a baseline and to identify the butene photolysis products in absence of $\mathrm{C}_{2} \mathrm{H}$. Following subtraction of the photolysed butene mass spectrum, new features were identified at 50, 52 and 66 amu for 1-butene, at 50 and 66 amu for both 2-butene isomers and at 50, 66 and (weakly at) $80 \mathrm{amu}$ for isobutene. The mass peak at $50 \mathrm{amu}$ was assigned to diacetylene $\left(\mathrm{C}_{4} \mathrm{H}_{2}\right)$, which is a well-known product of the $\mathrm{C}_{2} \mathrm{H}+\mathrm{C}_{2} \mathrm{H}_{2}$ reaction. The masses at 52, 66 and 80 correspond to isomers of $\mathrm{C}_{4} \mathrm{H}_{4}, \mathrm{C}_{5} \mathrm{H}_{6}$ and $\mathrm{C}_{6} \mathrm{H}_{8}$, respectively.

In order to determine the isomeric identity of the product species detected at masses 52 , 66 and 80, photoionization spectra of the products (recorded both as a function of time and $\mathrm{m} / \mathrm{z}$ ) are analyzed at these mass channels. For the 1-butene isomer reaction, the mass 52 
peak was well fit by vinylacetylene with a predicted upper limit of $5 \%$ for the other $\mathrm{C}_{4} \mathrm{H}_{4}$ isomers. The photoionization spectrum at mass 66 displayed a ionization threshold around $9.8 \mathrm{eV}$. This ionization threshold is close to that of 4-penten-1-yne, calculated to fall at $9.9 \mathrm{eV}$, and far from the thresholds of other possible $\mathrm{C}_{5} \mathrm{H}_{6}$ isomers. This gave a product branching ratio of $(65 \pm 10) \% \mathrm{C}_{4} \mathrm{H}_{4}$ in the form of vinylacetylene and $(35 \pm 10) \% \mathrm{C}_{5} \mathrm{H}_{6}$ in the form of 4-penten-1-yne. A similar treatment was applied for the other butene isomers in order to extract the product branching ratios. Both 2-butene reactions produce solely 3-penten-1-yne with no discrimination possible between cis- and trans-3-penten-1-yne. The reaction with isobutene yields $(26 \pm 15) \%$ 3-penten-1-yne, $(35 \pm 15) \%$ 2-methyl-1-buten-3-yne, and (39 15)\% 4-methyl-3-penten1-yne.

The reaction rate coefficients were determined under pseudo first-order conditions by measuring the time dependent ion signal at a set product $\mathrm{m} / \mathrm{z}$ and at a constant ionization energy. The rate coefficients were identical within statistical error for all of the butene isomers with values of $(1.9 \pm 0.5),(1.7 \pm 0.5),(2.1 \pm 0.7)$ and $(1.8 \pm 0.9) \times 10^{10} \mathrm{~cm}^{3} \mathrm{~s}^{-1}$ for the reaction of $\mathrm{C}_{2} \mathrm{H}$ with 1-butene, cis-2-butene, trans-2-butene, and isobutene, respectively.

This technique remains challenging for the quantification of reactions involving complex polyatomic species as they often require fitting of composite and sometimes incompletely resolved photoionization spectra to determine branching ratios, and clear product signatures are often lacking. The other obvious difficulty is obtaining a tunable soft ionization source requires synchrotron time, which is often not readily available. Despite these challenges, several groups are currently using this technique to constrain product branching ratios for reactions of astrochemical relevance. We discuss the perspectives for this technique further in the conclusions section.

\section{Crossed-beam experiments}

Great advances in our understanding of the dynamics of elementary reactions in the gasphase have been made possible using crossed molecular beam (CMB) experiments. CMB 
experiments have the particular advantage that they allow reactions to be studied under single collision conditions, guaranteeing that the products formed are not subject to subsequent reaction. The reactants are confined into distinct beams, with well defined velocities, which cross each other at a defined angle, ensuring that the species of each beam collide only with those of the other beam. Once formed, the reaction products travel to the detector (often a rotatable mass spectrometer i.e. the so-called "universal machine developed by Lee et al. ${ }^{238}$ ) without undergoing secondary collisions, since the reaction chamber is kept under high- or ultra-high vacuum. As a result, the outcome of many identical collisions under well-defined conditions are recorded at the detector. Major advances were made following the implementation of soft ionization sources using low energy electrons or VUV synchrotron radiation in order to eliminate dissociative ionization that occurs in standard hard electron ionization sources. While the CMB in the universal machine setup can be used to study complex reactions with multiple product channels, its resolution is generally insufficient to obtain state-resolved information about the products. Instead, laser spectroscopic methods such as LIF and resonance-enhanced multi-photon ionization (REMPI) can be used to obtain state-resolved differential cross sections. These laser-based techniques have been coupled to a number of sophisticated detection schemes, such Doppler-selected time of flight (TOF), ${ }^{239}$ ion velocity-map imaging technique, ${ }^{240}$ and, in the case of $\mathrm{H}$ atom forming reactions, high resolution Rydberg H-atom TOF. ${ }^{241}$

In many cases, the experiments are performed at fixed or at least high collision energies corresponding to temperatures of often several thousands of Kelvin. As the product branching ratios may vary strongly with temperature, there remains room for debate regarding products at intermediate to low temperatures relevant to the cold ISM. Crossed-beam experiments thus can produce reaction dynamics data that are complementary to the kinetics data obtained under thermal conditions using, for example, the CRESU technique.

The CMB technique has been used to great success for characterizing various elementary reactions involving polyatomics, the details of which can be found in recent reviews articles 
e.g. Pan et al. ${ }^{242}$. Several classes of reactions have been tackled including direct abstraction reactions, indirect insertion reactions and indirect addition elimination reactions. We limit our discussions below to a few measurements made using the universal machine setup.

Much can be gained from joint crossed-beam and low-temperature kinetics studies investigating the same reaction. Recently, the reaction between CN and 1,3-butadiene was investigated in a study which independently measured the low-temperature rate coefficients using a CRESU apparatus and the reaction products under single collision conditions using a crossed-beam experiment. ${ }^{83}$ The low-temperature kinetics demonstrated that the reaction remains fast from room temperature down to $23 \mathrm{~K}$, with rate coefficients close to the gas kinetic limit, indicating that the reaction proceeds potential energy surface that does not have an entrance barrier. The crossed beam studies showed that the reaction proceeds via a long-lived $\mathrm{C}_{5} \mathrm{H}_{6} \mathrm{~N}$ complex, producing $\mathrm{C}_{5} \mathrm{H}_{5} \mathrm{~N}$ and atomic hydrogen. Experiments were also conducted with partially deuterated 1,3-butadienes and these indicated that the $\mathrm{H}$ atom loss originates from a terminal carbon of 1,3-butadiene. Electronic structure calculations were used to support the crossed-beam experiments and suggested that the thermodynamically less favorable 1-cyano-1,3-butadiene isomer is the dominant reaction product; with less than a few percent from the aromatic pyridine molecule feasible but not confirmed.

The authors compared these results to the reaction between $\mathrm{C}_{2} \mathrm{H}$ and 1,3 -butadiene, studied by Jones et al. ${ }^{236}$. In the reaction of $\mathrm{C}_{2} \mathrm{H}$, benzene was found at significant fractions $(30 \% \pm 10 \%)$ in addition to the thermodynamically less stable isomer, hexa-1,3-dien-5-yne. The authors suggested that, despite similar barriers to ring closure and H-atom migration, the formation of benzene may be significant due to a stabilization of the $\mathrm{C}_{2} \mathrm{H}$ addition intermediate $\left(\sim 100 \mathrm{~kJ} \mathrm{~mol}^{-1}\right.$ lower in energy than the CN intermediate) followed by a lower energy transition state. In addition, the addition intermediates pass through barriers to cyclization of $-90 \mathrm{~kJ} \mathrm{~mol}^{-1}$ and $-181 \mathrm{~kJ} \mathrm{~mol}^{-1}$ followed by barriers to hydrogen shift of $+4 \mathrm{~kJ} \mathrm{~mol}^{-1}$ and $-144 \mathrm{~kJ} \mathrm{~mol}^{-1}$ for the $\mathrm{CN}$ and $\mathrm{C}_{2} \mathrm{H}$ reactions, respectively. These results suggested that in the case of isoelectronic $\mathrm{CN}$ and $\mathrm{C}_{2} \mathrm{H}$ reactions, benzene may be 
formed favourably compared to pyridine in the ISM. This study also serves to highlight that thermodynamics does not necessarily control the reaction products. In the case of $\mathrm{CN}+$ 1,3-butadiene, the thermodynically less stable isomer 1-cyano-1,3-butadiene was favoured over pyridine. As mentioned above, products formed in the $\mathrm{C}_{2} \mathrm{H}+1,3$-butadiene reaction were also probed at room temperature in a separate study using photoionization time-offlight mass spectrometry. ${ }^{235}$ The observation of fulvene as the major reaction product is not in good agreement with the crossed-beam study of Jones et. al., highlighting differences between the two methods (i.e. the collisional environment) for study of reaction products and suggesting the need for further investigation of the $\mathrm{C}_{2} \mathrm{H}+1$,3-butadiene reaction.

Most crossed molecular beam experiments work with the beams at right angles, with collisional energies of a few to a few tens of $\mathrm{kcal} \mathrm{mol}^{-1}$, where $1 \mathrm{kcal} \mathrm{mol}^{-1}$ corresponds to $\sim 300 \mathrm{~K}$. Thus most crossed-beam experiments operate at collisional energies much higher than those relevant to the cold ISM. A molecular beam apparatus has been built at the University of Bordeaux that enables the beam intersection angle to be varied between 90 and $12.5^{\circ}$, facilitating very low relative translational energies. ${ }^{13,243,244}$ These measurements at low collisional energies are an important step towards understanding the reaction products that can be formed under ISM conditions.

\section{Microwave spectroscopy}

Rotational spectroscopy can provide a high degree of molecular specificity, allowing unambiguous assignment of reaction products that possess at least a modest permanent electric dipole. Traditional cavity-based microwave spectroscopic techniques are not well suited to the measurement of reaction kinetics, due to the need to tune the resonant cavities to the specific rotational lines of the products. This requires knowledge of the expected reaction products and their rotational spectra prior to commencing the measurement. In addition, their high resolution means that scanning between different rotational lines can be very slow. Broadband chirped-pulse Fourier transform microwave (CP-FTMW) spectroscopy, pioneered 
by Brooks Pate and colleagues at the University of Virginia, ${ }^{245}$ has revolutionized the field of microwave spectroscopy and has found applications across a wide range of fields. The technique enables a broadband spectrum (typically $\geq 10 \mathrm{GHz}$ bandwidth) to be collected in a single shot of the spectrometer, allowing high-resolution spectra to be measured several orders of magnitude faster than what was previously possible.

A high bandwidth, frequency stabilized arbitrary waveform generator (AWG) is used to produce a short pulse ( $\sim 1 \mu$ s or less) with a frequency sweep that is linear in time, this chirped pulse is upconverted to the microwave frequency range of interest and, if necessary, amplified for irradiation of the sample. The molecular sample absorbs at all rotational transitions within the frequency range of the chirp and is polarized by the radiation. The emitted free induction decay (FID) radiation is collected, down-converted if necessary, and broadbandshot-by-broadband-shot averaged in the time-domain by a high bandwidth oscilloscope or digitizer card, after which the collected signal is Fourier-transformed to give the rotational spectrum at $\mathrm{MHz}$ resolution. The use of the chirped pulse as opposed to the traditional approach of narrowband scanning of the microwave frequency in a resonant cavity has led to several orders of magnitude improvement in the rate of data acquisition, as the power delivered to the sample is decoupled from the bandwidth, and dead time associated with stepping the cavity resonance frequency is eliminated.

In a recent development, born from a collaboration between the groups of Arthur Suits (Wayne State, now University of Missouri), Robert Field (MIT) and Ian Sims (University of Rennes), the CPMW method has been combined with a pulsed CRESU system. ${ }^{22,246}$ This chirped pulse in uniform flow (CPUF) experiment provides broadband spectra with $\mathrm{MHz}$ resolution and allows monitoring, on the $\mu$ s timescale, of the appearance of transient reaction products. This CPUF apparatus has two main components: a chirped pulse broadband microwave spectrometer and a uniform flow system utilizing a pulsed Laval nozzle. Following laser initiation of the reaction, a frequency chirped microwave pulse is broadcast into the pulsed uniform flow at chosen time intervals. The FID of the polarized sample is collected 


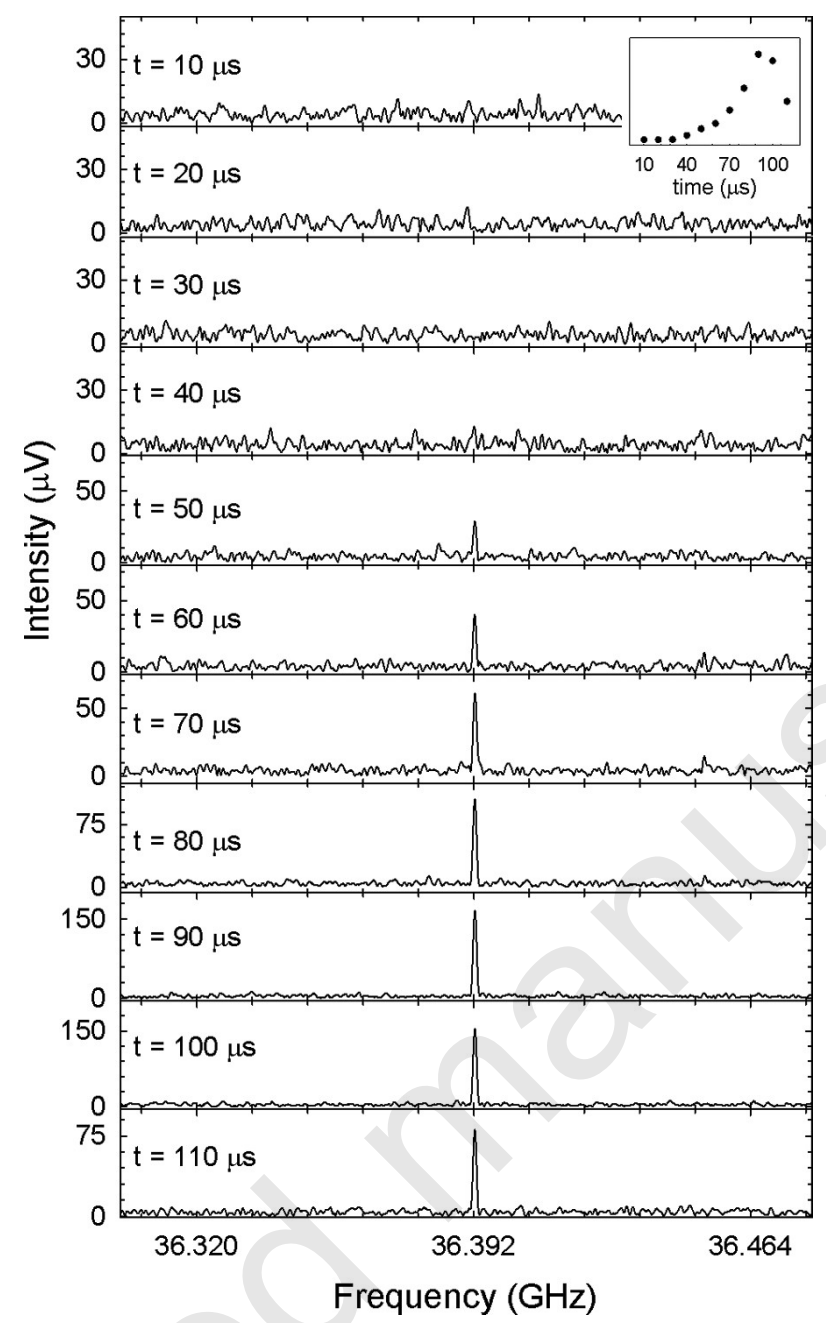

Figure 10: Spectra displaying the time evolution of the $\mathrm{J}=4$ - 3 rotational transition of $\mathrm{HC}_{3} \mathrm{~N}$ during the reaction of $\mathrm{CN}$ with $\mathrm{C}_{2} \mathrm{H}_{2}$ at $22 \mathrm{~K}$. Reprinted with permission from Abeysekera et al. ${ }^{246}$ Copyright (2014) AIP.

at each interval through the receiver horn; the signal is then amplified and sent to a digital oscilloscope where the signal is averaged and processed in the time-domain. The FIDs are Fourier transformed to give a series of frequency domain spectra as a function of time.

This technique has been applied thus far to measure the products formed in the reactions of $\mathrm{CN}$ with acetylene $\left(\mathrm{C}_{2} \mathrm{H}_{2}\right)$ and propyne $\left(\mathrm{C}_{3} \mathrm{H}_{4}\right)$ at $\sim 22 \mathrm{~K} .{ }^{81,246}$ Figure 10 shows the time dependent production of the $\mathrm{J}=4-3$ rotational transition for the $\mathrm{HC}_{3} \mathrm{~N}$ product measured during the reaction of $\mathrm{CN}$ with $\mathrm{C}_{2} \mathrm{H}_{2}$. The $\mathrm{H}_{3} \mathrm{CN}$ product was seen to appear roughly 40 $\mu \mathrm{s}$ after the photolysis laser was fired. The product branching ratios were determined for 
the multichannel $\mathrm{CN}+\mathrm{C}_{3} \mathrm{H}_{4}$ reaction and are discussed below. The following pathways are energetically accessible in the reaction between $\mathrm{CN}$ and propyne:

$$
\begin{aligned}
& \mathrm{CN}+\mathrm{CH}_{3} \mathrm{CCH} \longrightarrow \mathrm{HCN}+\mathrm{CH}_{2} \mathrm{CCH} \\
& \longrightarrow \mathrm{CH}_{3}+\mathrm{HCCCN} \\
& \longrightarrow \mathrm{H}+\mathrm{CH}_{3} \mathrm{CCN} \\
& \longrightarrow \mathrm{H}+\mathrm{CH}_{2} \mathrm{CCHCN}
\end{aligned}
$$

Channel 14 occurs via direct abstraction whereas channels 15, 16 and 17 occur by indirect addition/elimination pathways. The potential energy surface was modeled at the CBS-QB3 level of theory, indicating cis- and trans- barrierless C1 addition complexes as well as a barrierless $\mathrm{C} 2$ addition complex, $18.5 \mathrm{~kJ} \mathrm{~mol}^{-1}$ higher in energy than the trans-C1 complex. A low isomerization barrier separating the $\mathrm{C} 1$ and $\mathrm{C} 2$ complexes facilitates equilibration between these complexes prior to dissociation. The reaction was probed in a uniform flow consisting of $0.5 \%$ of the $\mathrm{CN}$ precursor $\mathrm{BrCN}$ and $1.5 \%$ propyne in a helium buffer gas. The reaction was initiated by photolysis of the $\mathrm{BrCN}$ at $193 \mathrm{~nm}$. The AWG was used to produce a linear frequency chirp and a phase-locked dielectric resonator oscillator (PDRO) at 8.125 GHz was used to upconvert the pulse via a broadband mixer. The resulting pulse was amplified, passed through a bandpass filter and frequency multiplied $8 \times$ by a multiplication chain to obtain the $60-90 \mathrm{GHz}$ frequency output. Spectra were obtained at $10 \mu$ s intervals following the laser pulse, resulting in 12 independent spectra per gas pulse, each averaged for $\sim 62500$ acquisitions.

The product column densities were calculated from the integrated line intensities and branching ratios of $(12 \pm 5) \%,(66 \pm 4) \%,(22 \pm 6) \%$, and $(0 \pm 8) \%$ were determined for the $\mathrm{HCN}, \mathrm{HCCCN}, \mathrm{CH}_{3} \mathrm{CCCN}$, and $\mathrm{CH}_{2} \mathrm{CCHCN}$ channels, respectively. The relatively small branching to the direct abstraction (HCN product) was attributed to the low colli- 
sion energy and the strong electrophilic interaction of $\mathrm{CN}$ with the propyne $\pi$ electrons. The experimental results were well supported by a series of Rice-Ramsperger-Kassel-Marcus (RRKM) calculations, with 48 or $65 \%$ into $\mathrm{HCCCN}$ and 33 or $19 \%$ into $\mathrm{CH}_{3} \mathrm{CCCN}$ when initiated at the $\mathrm{C} 1$ and $\mathrm{C} 2$ minima, respectively.

A remaining challenge in combining CP-FTMW spectrocopy with CRESU flows is the balance between the high-density flows $\left(10^{16}-10^{17}\right.$ molecules $\mathrm{cm}^{-3}$ buffer gas) required to ensure that the species in the flow are thermalized at a well-defined temperature, and the lower densities required to ensure that the microwave coherence times are long enough to produce detectable signals. We discuss this challenge and the current work being undertaken in this area in the future prospects section.

\section{Infrared absorption spectroscopy}

The use of infrared absorption spectroscopy for reaction product detection has a number of advantages. Firstly, infrared absorption is nearly universal; that is, with the exception of homonuclear diatomics, all molecules absorb in the infrared. In contrast to LIF, absorption spectroscopy can be used in quenching environments and can be used to detect non-fluorescent species. The absorption signal is a direct and quantitative measure of the absolute concentration without the need for calibration. However, absorption spectroscopy notoriously suffers from inherent low sensitivity, making it difficult to detect low concentration products in kinetically isolated reactions. Various methods have been have been employed to enhance the sensitivity by increasing the effective path length (e.g. multipass cells, ${ }^{247,248}$ cavity ring-down spectroscopy ${ }^{249-251}$ ) or by reducing background noise (e.g. frequency modulation $\left.{ }^{252,253}\right)$.

These highly sensitive techniques, such as continuous wave cavity ringdown spectroscopy, allow for the detection of trace concentrations at relatively short timescales and with high spectral resolution but do not possess a sufficiently broad bandwidth to capture multiple products. Traditional broadband techniques, for example time-resolved step-scan FTIR, 
provide the time resolution and broad bandwidth required to detect multiple products, but normally use incoherent light sources and thus require long acquisition times to achieve high sensitivity.

Cavity-enhanced direct frequency comb spectroscopy (CE-DFCS) possesses a broad bandwidth that allows detection of multiple species simultaneously, while the signal is enhanced by the increased absorption length afforded by the cavity. The time resolution is limited by the ringdown time of the optical cavity (which can be a few $\mu \mathrm{s}$ ) while the spectral resolution is limited only by the linewidth of the comb teeth, i.e. $<1 \mathrm{MHz}$. This high spectral resolution can access narrow rotational features of heavy molecules at low temperatures. Below, we discuss application of this technique to the measurement of product-specific reaction kinetics.

\section{Infrared frequency comb spectroscopy}

Time-resolved frequency comb spectroscopy (TRFCS) is a promising sensitive and multiplexed technique for the observation of reactive chemical intermediates on the microsecond timescale. ${ }^{254}$ Frequency combs are coherent light sources that emit a broad spectrum consisting of discrete and evenly spaced narrow lines, each possessing an absolute frequency measurable within the accuracy of an atomic clock. In particular, the development of frequency combs in the mid-infrared offers unique sensitivity for the detection of trace species based on fingerprint bands specific to this spectral region. ${ }^{255,256}$

Recently, the group of Jun Ye at JILA used the unique sensitive, broadband, and highresolution capabilities of time-resolved CE-DFCS to probe the $\mathrm{OH}+\mathrm{CO}$ reaction kinetics and dynamics. ${ }^{257}$ This reaction is widely believed to involve a transient HOCO intermediate; however, it has eluded direct detection under the thermal conditions required to extract rate coefficients. The $\mathrm{OH}+\mathrm{CO}$ reaction passes through a pre-reactive weakly bound OHCO complex to form the energized, vibrationally excited $\mathrm{HOCO}^{*}$ species. In the low-pressure limit at room temperature, $\mathrm{HOCO}^{*}$ primarily dissociates to reform $\mathrm{OH}+\mathrm{CO}$, with a small probability of overcoming the low barrier to form $\mathrm{H}+\mathrm{CO}_{2}$ products. In the presence of a 
Figure 11: A schematic showing the setup of the time-resolved frequency comb spectroscopy (TRFCS) technique. A mid-IR frequency comb is coupled into an high-finesse optical cavity, consisting of two high reflectivity crystalline (HRc) mirrors. A laser pulse (266 nm) initiates the reaction. The transmitted light from the cavity is spatially dispersed by a virtually imaged phased array (VIPA) etalon and a diffraction grating and is then imaged on an InSb camera. Absorbance intensity is then recorded as a function of wavelength and delay time. The panels shown are simulated cavity absorbance images for OD (red), trans-DOCO (green), and $\mathrm{D}_{2} \mathrm{O}$ (magenta). Reprinted with permission from Bjork et al. ${ }^{257}$ Copyright (2016) AAAS.

buffer gas, collisions can stabilize the thermalized HOCO product, diminishing the formation of $\mathrm{H}+\mathrm{CO}_{2}$. In the high-pressure limit, $\mathrm{HOCO}$ formation is the dominant channel and $\mathrm{H}+$ $\mathrm{CO}_{2}$ product channel becomes negligible.

Bjork et al. ${ }^{257}$ observed the formation of the deuterated analogue of HOCO (DOCO), while simultaneously monitoring the OD reactant using an infrared frequency comb. Figure 11 illustrates the experimental setup used to measure the DOCO and OD species. The mid-IR frequency comb was generated using an optical parametric oscillator (OPO) whose spectrum was composed of narrow and evenly spaced comb teeth. The transmitted light covered a bandwidth of $\sim 65 \mathrm{~cm}^{-1}$, corresponding to around 7100 comb teeth. This light was dispersed in two dimensions by a virtually imaged phased array (VIPA) etalon and 
a diffraction grating and was imaged using a InSb camera. The absorption spectra were constructed as a function of time, and were used to obtain the absolute concentrations using known line intensities. Using this technique, they observed unambiguous low-pressure dependence of the rate coefficients on the bath gas pressure, and thus were able to confirm the HOCO formation mechanism and determine its yield.

In a complementary study, they measured the kinetics of the $\mathrm{D}+\mathrm{CO}_{2}$ channel at room temperature. ${ }^{258}$ The time-dependence of $\mathrm{OD}$ and $\mathrm{CO}_{2}$ concentrations were used to determine the product channel-specific rates as well as their dependence on pressure and bath gas. These measurements, in combination with the DOCO formation rate, provided the branching channel yields for the DOCO and $\mathrm{D}+\mathrm{CO}_{2}$ products of $\mathrm{OD}+\mathrm{CO}$ reaction in the low-pressure limit. They derived product yields in $\mathrm{N}_{2}$ bath gas at 75 Torr of $27 \pm 11 \%$ for the DOCO channel and $73 \pm 16 \%$ for $\mathrm{D}+\mathrm{CO}_{2}$; while in a $\mathrm{CO}$ bath gas, the product channel yields were roughly equivalent with of $47 \pm 10 \%$ and $53 \pm 7 \%$ for DOCO and D $+\mathrm{CO}_{2}$, respectively.

\section{Conclusions and future prospects for low temperature}

\section{gas-phase kinetics}

In this review, we have discussed laboratory efforts to measure elementary reactions that may play a role in the formation of complex organic molecules in the ISM, with particular emphasis on experiments to measure directly product branching ratios. Significant advances are being made due to collaborative efforts between observational, computational, and laboratory astrochemists and it is clear that these will be necessary in order to explain the presence of the increasing number of molecules that are being observed. There are three significant gaps in the available gas-phase laboratory data relevant to COM formation. Firstly, there remain few data for gas-phase reactions measured at the temperatures of cold cores. This is a particular challenge for reactions involving volatile organic species which can condense and dimerize at low temperature and therefore their rate coefficients cannot be measured 
accurately under pseudo-first order conditions. The second gap is due to difficulties associated with making kinetic measurements for reactions where both species are unstable such as those involving only ions and radicals. This difficulty extends to the solid phase, where laboratory measurements involving radical reactions are particularly sparse. The third major gap in laboratory data involves the measurement of reaction products and their branching ratios at low temperatures, and is particularly pertinent to reactions involving COMs, which are often multichannel. This is an active area of research within the community and large advances are expected to be made in the coming years with new techniques available capable of product detection. Below we discuss some perspectives for the measurement of productspecific reaction kinetics, highlighting new techniques that are currently being developed.

\section{Ionization-based techniques for measuring product-specific reaction kinetics}

Mass spectrometric methods are particularly promising for the measurement of productspecific reaction kinetics, particularly when combined with photoionization spectrocopy allowing one to distinguish between isomers of products. A pulsed version of the CRESU technique has been developed in Rennes in collaboration with the DESIRS beamline group at SOLEIL. This technique, named CRESUSOL, aims to identify the product of reactions below $100 \mathrm{~K}$ and estimate their branching ratios. The CRESU chamber is coupled to a photoelectron-photoioncoincidence (PEPICO) mass spectrometer to probe reactants and products of reaction after threshold photoionisation by the VUV beamline of the SOLEIL synchrotron. This technique is currently being used to detect reaction products and derive branching ratios at very low temperatures, down to $20 \mathrm{~K}$. 


\section{Spectroscopic techniques for measuring product-specific reaction}

\section{kinetics}

The combination of the CRESU technique with rotational spectroscopy will significantly improve the measurement of product specific reaction kinetics due to its high degree of molecular specificity. In addition to the CPUF technique of the Suits group discussed above, CPUF apparatuses are currently being built in Bordeaux and in Rennes. A key difficulty in studying reaction kinetics using CPUF is the pressure balance required to maintain thermalization through buffer gas collisions while avoiding too severe collisional dephasing and thus reduction in FID signal intensity and duration, which could reduce the sensitivity of the technique to below what is needed to observe low concentration products. One way to mitigate this problem is by sampling the supersonic flow via a second expansion and performing the CPMW detection at lower pressures.

A particular advantage of using rotational spectroscopy to study cold reactions is that the spectral information about reaction products that is obtained during the experiments can be directly compared with spectra obtained from radio telescope observatories operating at the microwave and millimeter-wave frequencies. As a state-specific technique, information on, for example, vibrationally excited products is available.

The use of infrared spectroscopic techniques can likewise provide spectra directly comparable to astronomical observations, for example, spectra taken using space-based infrared observatories. The use of infrared frequency-combs to measure reaction products can provide data that will be of use to the next generation infrared observatories like the James Webb Space Telescope (JWST). The CE-DFCS technique has inherent spectral congestion for large molecules at room temperature. This problem could be overcome by implementing CE-DFCS with techniques that produce a continuous source of cooled molecules such as CRESU flows or buffer gas cooling. ${ }^{259}$ The use of buffer gas cooling has recently been used to great success to rotationally resolve the $8.5 \mu \mathrm{m}$ band of buckminsterfullerene $\left(\mathrm{C}_{60}\right),{ }^{260}$ providing a glimpse of the power of the CE-DFCS technique for the study of cold molecules. 
The application of frequency combs to study chemical reaction kinetics will likewise continue to grow with technical developments in higher power combs as well as their extension to longer wavelengths.

\section{Acknowledgement}

The authors thank Lucile Rutowski, Olivier Durif, Sébastien Le Picard, Brian Hays, Sophie Carles and Divita Gupta for helpful discussions. The authors thank especially André Canosa for helpful discussion regarding Table 1. The authors also thank two anonymous reviewers for helpful comments that greatly improved the quality of the manuscript. The authors acknowledge funding from the European Research Council (ERC) under the European Union's Horizon 2020 research and innovation programme under grant agreement 695724-CRESUCHIRP and under the Marie Skłodowska-Curie grant agreement 845165-MIRAGE.

\section{References}

(1) McGuire, B. A. 2018 Census of Interstellar, Circumstellar, Extragalactic, Protoplanetary Disk, and Exoplanetary Molecules. ApJS 2018, 239, 17.

(2) Bacmann, A.; Taquet, V.; Faure, A.; Kahane, C.; Ceccarelli, C. Detection of Complex Organic Molecules in a Prestellar Core: A New Challenge for Astrochemical Models. Astron. Astrophys. 2012, 541, L12.

(3) van Dishoeck, E. F.; Blake, G. A. Chemical Evolution of Star-forming Regions. Annu. Rev. Astron. Astrophys. 1998, 36, 317-368.

(4) Benson, P. J.; Myers, P. C. A Survey for Dense Cores in Dark Clouds. ApJS 1989, 71, 89.

(5) Herbst, E.; Klemperer, W. The Formation and Depletion of Molecules in Dense Interstellar Clouds. ApJ 1973, 185, 505.

(6) Garrod, R. T.; Widicus Weaver, S. L. Simulations of Hot-Core Chemistry. Chem. Rev. 2013, 113, 8939-8960.

(7) Herbst, E.; Lee, H.-H.; Howe, D. A.; Millar, T. J. The Effect of Rapid Neutral-Neutral Reactions on Chemical Models of Dense Interstellar Clouds. MNRAS 1994, 268, 335344. 
(8) Gerlich, D.; Horning, S. Experimental Investigations of Radiative Association Processes As Related to Interstellar Chemistry. Chem. Rev. 1992, 92, 1509-1539.

(9) Qi, C.; Oberg, K. I.; Wilner, D. J.; D'Alessio, P.; Bergin, E.; Andrews, S. M.; Blake, G. A.; Hogerheijde, M. R.; van Dishoeck, E. F. Imaging of the CO Snow Line in a Solar Nebula Analog. Science 2013, 341, 630-632.

(10) van’t Hoff, M. L. R.; Walsh, C.; Kama, M.; Facchini, S.; van Dishoeck, E. F. Robustness of $\mathrm{N}_{2} \mathrm{H}^{+}$As Tracer of the CO Snowline. Astron. Astrophys. 2017, 599, A101.

(11) Sims, I. R.; Smith, I. W. M. Rate Constants for the Radical-Radical Reaction between $\mathrm{CN}$ and $\mathrm{O}_{2}$ at Temperatures down to $99 \mathrm{~K}$. Chem. Phys. Lett. 1988, 151, 481-484.

(12) Frost, M. J.; Sharkey, P.; Smith, I. W. M. Reaction between Hydroxyl (Deuteroxyl) Radicals and Carbon Monoxide at Temperatures down to $80 \mathrm{~K}$ : Experiment and Theory. J. Phys. Chem. 1993, 97, 12254-12259.

(13) Berteloite, C.; Lara, M.; Bergeat, A.; Le Picard, S. D.; Dayou, F.; Hickson, K. M.; Canosa, A.; Naulin, C.; Launay, J. M.; Sims, I. R.; Costes, M. Kinetics and Dynamics of the $\mathrm{S}\left({ }^{1} \mathrm{D}_{2}\right)+\mathrm{H}_{2} \rightarrow \mathrm{SH}+\mathrm{H}$ Reaction at Very Low Temperatures and Collision Energies. Phys. Rev. Lett. 2010, 105, 203201.

(14) Ocaña, A. J.; Blázquez, S.; Potapov, A.; Ballesteros, B.; Canosa, A.; Antiñolo, M.; Vereecken, L.; Albaladejo, J.; Jiménez, E. Gas-phase Reactivity of $\mathrm{CH}_{3} \mathrm{OH}$ toward $\mathrm{OH}$ at Interstellar Temperatures (11.7-177.5 K): Experimental and Theoretical Study. PCCP 2019, 21, 6942-6957.

(15) Sims, I. R.; Queffelec, J.-L.; Defrance, A.; Rebrion-Rowe, C.; Travers, D.; Bocherel, P.; Rowe, B. R.; Smith, I. W. M. Ultralow Temperature Kinetics of Neutral-Neutral Reactions. the Technique and Results for the Reactions $\mathrm{CN}+\mathrm{O}_{2}$ down to $13 \mathrm{~K}$ and $\mathrm{CN}+\mathrm{NH}_{3}$ down to 25 K. J. Chem. Phys. 1994, 100, 4229-4241.

(16) James, P. L.; Sims, I. R.; Smith, I. W. Total and State-to-state Rate Coefficients for Rotational Energy Transfer in Collisions between $\mathrm{NO}\left(\mathrm{X}^{2} \Pi\right)$ and He at Temperatures down to 15 K. Chem. Phys. Lett. 1997, 272, 412-418.

(17) Daugey, N.; Caubet, P.; Retail, B.; Costes, M.; Bergeat, A.; Dorthe, G. Kinetic Measurements on Methylidyne Radical Reactions with Several Hydrocarbons at Low Temperatures. PCCP 2005, 7, 2921-2927.

(18) Atkinson, D. B.; Smith, M. A. Design and Characterization of Pulsed Uniform Supersonic Expansions for Chemical Applications. Rev. Sci. Instrum. 1995, 66, 4434-4446.

(19) Lee, S.; Hoobler, R. J.; Leone, S. R. A Pulsed Laval Nozzle Apparatus with Laser Ionization Mass Spectroscopy for Direct Measurements of Rate Coefficients at Low Temperatures with Condensable Gases. Rev. Sci. Instrum. 2000, 71, 1816-1823. 
(20) Spangenberg, T.; Köhler, S.; Hansmann, B.; Wachsmuth, U.; Abel, B.; Smith, M. A. Low-temperature Reactions of $\mathrm{OH}$ Radicals with Propene and Isoprene in Pulsed Laval Nozzle Expansions. J. Phys. Chem. A 2004, 108, 7527-7534.

(21) Taylor, S. E.; Goddard, A.; Blitz, M. A.; Cleary, P. A.; Heard, D. E. Pulsed Laval Nozzle Study of the Kinetics of $\mathrm{OH}$ with Unsaturated Hydrocarbons at Very Low Temperatures. PCCP 2008, 10, 422-437.

(22) Oldham, J. M.; Abeysekera, C.; Joalland, B.; Zack, L. N.; Prozument, K.; Sims, I. R.; Park, G. B.; Field, R. W.; Suits, A. G. A Chirped-Pulse Fourier-transform Microwave/pulsed Uniform Flow Spectrometer. i. the Low-temperature Flow System. J. Chem. Phys. 2014, 141, 154202.

(23) Cheikh Sid Ely, S.; Morales, S. B.; Guillemin, J. C.; Klippenstein, S. J.; Sims, I. R. Low Temperature Rate Coefficients for the Reaction $\mathrm{CN}+\mathrm{HC}_{3} \mathrm{~N}$. J. Phys. Chem. A 2013, 117, 12155-12164.

(24) Jiménez, E.; Ballesteros, B.; Canosa, A.; Townsend, T. M.; Maigler, F. J.; Napal, V.; Rowe, B. R.; Albaladejo, J. Development of a Pulsed Uniform Supersonic Gas Expansion System Based on an Aerodynamic Chopper for Gas Phase Reaction Kinetic Studies at Ultra-low Temperatures. Rev. Sci. Instrum. 2015, 86, 045108.

(25) Douglas, K.; Blitz, M. A.; Feng, W.; Heard, D. E.; Plane, J. M. C.; Slater, E.; Willacy, K.; Seakins, P. W. Low Temperature Studies of the Removal Reactions of ${ }^{1} \mathrm{CH}_{2}$ with Particular Relevance to the Atmosphere of Titan. Icarus 2018, 303, 1021.

(26) Douglas, K. M.; Blitz, M. A.; Feng, W.; Heard, D. E.; Plane, J. M. C.; Rashid, H.; Seakins, P. W. Low Temperature Studies of the Rate Coefficients and Branching Ratios of Reactive Loss vs Quenching for the Reactions of ${ }^{1} \mathrm{CH}_{2}$ with $\mathrm{C}_{2} \mathrm{H}_{6}, \mathrm{C}_{2} \mathrm{H}_{4}, \mathrm{C}_{2} \mathrm{H}_{2}$. Icarus 2019, 321, 752-766.

(27) Herbst, E.; Klemperer, W. The Formation and Depletion of Molecules in Dense Interstellar Clouds. ApJ 1973, 185, 505-534.

(28) Bohme, D. K.; Rakshit, A. B.; Schiff, H. I. Reactions of ${ }^{12} \mathrm{C}^{+}$with Hydrocarbons at 296 K: Carbon-Carbon Bond Formation. Chem. Phys. Lett. 1982, 93, 592-597.

(29) Smith, D.; Adams, N. G. A Brief Review of Interstellar Ion Chemistry. J. Chem. Soc., Faraday Trans. 2 1989, 85, 1613-1630.

(30) Martinez, O.; Betts, N. B.; Villano, S. M.; Eyet, N.; Snow, T. P.; Bierbaum, V. M. Gas Phase Study of $\mathrm{C}^{+}$reactions of Interstellar Relevance. ApJ 2008, 686, 1486-1492.

(31) Su, T.; Chesnavich, W. J. Parametrization of the Ion-Polar Molecule Collision Rate Constant by Trajectory Calculations. J. Chem. Phys. 1982, 76, 5183-5185.

(32) McMahon, T. B.; Beauchamp, J. L. A Versatile Trapped Ion Cell for Ion Cyclotron Resonance Spectroscopy. Rev. Sci. Instrum. 1972, 43, 509-512. 
(33) Barlow, S. E.; Dunn, G. H.; Schauer, M. Radiative Association of $\mathrm{CH}_{3}^{+}$and $\mathrm{H}_{2}$ at 13 K. Phys. Rev. Lett. 1984, 52, 902-905.

(34) Barlow, S. E.; Luine, J. A.; Dunn, G. H. Measurement of Ion/Molecule Reactions between 10 and 20 K. Int. J. Mass Spectrom. Ion Process. 1986, 74, 97-128.

(35) Schauer, M. M.; Jefferts, S. R.; Barlow, S. E.; Dunn, G. H. Reactions of $\mathrm{H}_{2}$ with $\mathrm{He}^{+}$ at Temperatures below 40 K. J. Chem. Phys. 1989, 91, 4593-4596.

(36) Gerlich, D. Ion-neutral Collisions in a 22-pole Trap at Very Low Energies. Phys. Scr. 1995, T59, 256-263.

(37) Borodi, G.; Luca, A.; Gerlich, D. Reactions of $\mathrm{CO}_{2}^{+}$with $\mathrm{H}, \mathrm{H}_{2}$ and Deuterated Analogues. Int. J. Mass Spectrom. 2009, 280, 218-225.

(38) Fehsenfeld, F. C.; Schmeltekopf, A. L.; Goldan, P. D.; Schiff, H. I.; Ferguson, E. E. Thermal Energy Ion-neutral Reaction Rates. i. Some Reactions of Helium Ions. J. Chem. Phys. 1966, 44, 4087-4094.

(39) Dunkin, D. B.; Fehsenfeld, F. C.; Schmeltekopf, A. L.; Ferguson, E. E. Ion-Molecule Reaction Studies from $300^{\circ}$ to $600^{\circ} \mathrm{K}$ in a Temperature-controlled Flowing Afterglow System. J. Chem. Phys. 1968, 49, 1365-1371.

(40) Adams, N. G.; Smith, D. The Selected Ion Flow Tube (SIFT): A Technique for Studying Ion-Neutral Reactions. Int. J. Mass Spectrom. Ion Phys. 1976, 21, 349-359.

(41) Snow, T. P.; Bierbaum, V. M. Ion Chemistry in the Interstellar Medium. Annu. Rev. Anal. Chem. 2008, 1, 229-259.

(42) Larsson, M. Atomic and Molecular Physics with Ion Storage Rings. Reports on Progress in Physics 1995, 58, 1267-1319.

(43) Geppert, W. D.; Larsson, M. Dissociative Recombination in the Interstellar Medium and Planetary Ionospheres. Molecular Physics 2008, 106, 2199-2226.

(44) Rowe, B. R.; Dupeyrat, G.; Marquette, J. B.; Gaucherel, P. Study of the Reactions $\mathrm{N}_{2}^{+}+2 \mathrm{~N}_{2} \rightarrow \mathrm{N}_{4}^{+}+\mathrm{N}_{2}$ and $\mathrm{O}_{2}^{+}+2 \mathrm{O}_{2} \rightarrow \mathrm{O}_{4}^{+}+\mathrm{O}_{2}$ from 20 to $160 \mathrm{~K}$ by the CRESU Technique. J. Chem. Phys 1984, 80, 4915-4921.

(45) Rowe, B. R.; Marquette, J.-B.; Rebrion, C. Mass-Selected Ion-Molecule Reactions at Very Low Temperatures: The CRESUS Apparatus. J. Chem. Soc., Faraday Trans. 2 1989, 85, 1631-1641.

(46) Rowe, B. R.; Dupeyrat, G.; Marquette, J. B.; Smith, D.; Adams, N. G.; Ferguson, E. E. The Reaction $\mathrm{O}_{2}^{+}+\mathrm{CH}_{4} \rightarrow \mathrm{CH}_{3} \mathrm{O}_{2}^{+}+\mathrm{H}$ Studied from 20 to $560 \mathrm{~K}$ in a Supersonic Jet and in a SIFT. J. Chem. Phys. 1984, 80, 241-245.

(47) Marquette, J.; Rebrion, C.; Rowe, B. Proton Transfer Reactions of $\mathrm{H}_{3}^{+}$with Molecular Neutrals at 30 K. Astron. Astrophys. 1989, 213, L29-L32. 
(48) Rowe, B.; Marquette, J.; Dupeyrat, G.; Ferguson, E. Reactions of $\mathrm{He}^{+}$and $\mathrm{N}^{+}$Ions with Several Molecules at 8 K. Chem. Phys. Lett. 1985, 113, 403-406.

(49) Rebrion, C.; Marquette, J.; Rowe, B.; Adams, N.; Smith, D. Low-temperature Reactions of Some Atomic Ions with Molecules of Large Quadrupole Moment: $\mathrm{C}_{6} \mathrm{~F}_{6}$ and c- $\mathrm{C}_{6} \mathrm{H}_{12}$. Chem. Phys. Lett. 1987, 136, 495-500.

(50) Rebrion, C.; Marquette, J.; Rowe, B.; Clary, D. Low-temperature Reactions of $\mathrm{He}^{+}$ and $\mathrm{C}^{+}$with $\mathrm{HCl}, \mathrm{SO}_{2}$ and $\mathrm{H}_{2} \mathrm{~S}$. Chem. Phys. Lett. 1988, 143, 130-134.

(51) Marquette, J. B.; Rowe, B. R.; Dupeyrat, G.; Poissant, G.; Rebrion, C. Ion-polarmolecule Reactions: A CRESU Study of $\mathrm{He}^{+}, \mathrm{C}^{+}, \mathrm{N}^{+}+\mathrm{H}_{2} \mathrm{O}, \mathrm{NH}_{3}$ at 27, 68 and 163 K. Chem. Phys. Lett. 1985, 122, 431-435.

(52) Rebrion, C.; Rowe, B. R.; Marquette, J. B. Reactions of $\mathrm{Ar}^{+}$with $\mathrm{H}_{2}, \mathrm{~N}_{2}, \mathrm{O}_{2}$, and CO at 20, 30, and 70 K. J. Chem. Phys. 1989, 91, 6142-6147.

(53) Dupeyrat, G.; Marquette, J.; Rowe, B.; Rebrion, C. Reactions of $\operatorname{Ar}^{2+}\left({ }^{3} \mathrm{P}\right)$ Ions with Some Neutrals at 30 K. Int. J. Mass Spectrom. Ion Process. 1991, 103, 149-156.

(54) Gaucherel, P.; Marquette, J. B.; Rebrion, C.; Poissant, G.; Dupeyrat, G.; Rowe, B. R. Temperature Dependence of Slow Charge-Exchange Reactions: $\mathrm{N}_{2}^{+}+\mathrm{O}_{2}$ from 8 to 163 K. Chem. Phys. Lett. 1986, 132, 63-66.

(55) Speck, T.; Mostefaoui, T. I.; Travers, D.; Rowe, B. R. Pulsed Injection of Ions into the CRESU Experiment. Int. J. Mass Spec. 2001, 208, 73-80.

(56) Le Garrec, J. L.; Lepage, V.; Rowe, B.; Ferguson, E. The Temperature Dependence of the Rate Constant for $\mathrm{O}^{+}+\mathrm{NO} \rightarrow \mathrm{NO}^{+}+\mathrm{O}$ from 23 to $30000 \mathrm{~K}$. Chem. Phys. Lett. 1997, 270, 66-70.

(57) Rowe, B. R.; Canosa, A.; Le Page, V. FALP and CRESU Studies of Ionic Reactions. Int. J. Mass Spectromet. Ion Process. 1995, 149-150, 573-596.

(58) Hamon, S.; Mitchell, J.; Rowe, B. Low-temperature Measurements of the Atomic Association Reaction $\mathrm{Ar}^{+}+2 \mathrm{Ar} \rightarrow \mathrm{Ar}^{2+}+$ Ar. Chem. Phys. Lett. 1998, 288, 523-526.

(59) Hamon, S.; Speck, T.; Mitchell, J. B. A.; Rowe, B. R.; Troe, J. Experimental and Theoretical Study of the Ion-Molecule Association Reaction $\mathrm{NH}_{4}^{+}+\mathrm{NH}_{3}(+\mathrm{M}) \rightarrow$ $\mathrm{N}_{2} \mathrm{H}_{7}^{+}(+\mathrm{M})$. J. Chem. Phys. 2002, 117, 2557-2567.

(60) Hamon, S.; Speck, T.; Mitchell, J. B. A.; Rowe, B.; Troe, J. Experimental and Modeling Study of the Ion-Molecule Association Reaction $\mathrm{H}_{3} \mathrm{O}^{+}+\mathrm{H}_{2} \mathrm{O}(+\mathrm{M}) \rightarrow \mathrm{H}_{5} \mathrm{O}_{2}^{+}$ (+M). J. Chem. Phys. 2005, 123, 054303.

(61) Douglas, A. E.; Herzberg, G. Note on $\mathrm{CH}^{+}$in Interstellar Space and in the Laboratory. ApJ 1941, 94, 381.

(62) McCarthy, M. C.; Gottlieb, C. A.; Gupta, H.; Thaddeus, P. Laboratory and Astronomical Identification of the Negative Molecular Ion $\mathrm{C}_{6} \mathrm{H}^{-}$. ApJ 2006, 652, L141-1144. 
(63) Le Garrec, J.-L.; Rowe, B. R.; Queffelec, J. L.; Mitchell, J. B. A.; Clary, D. C. Temperature Dependence of the Rate Constant for the $\mathrm{Cl}^{-}+\mathrm{CH}_{3} \mathrm{Br}$ Reaction down to 23 K. J. Chem. Phys. 1997, 10\%, 1021.

(64) Cernicharo, J.; Guélin, M.; Agúndez, M.; Kawaguchi, K.; Mccarthy, M.; Thaddeus, P. Astronomical Detection of $\mathrm{C}_{4} \mathrm{H}^{-}$, the Second Interstellar Anion. Astron. Astrophys. 2007, 467, L37-L40.

(65) Brünken, S.; Gupta, H.; Gottlieb, C. A.; McCarthy, M. C.; Thaddeus, P. Detection of the Carbon Chain Negative Ion $\mathrm{C}_{8} \mathrm{H}^{-}$in TMC-1. ApJ 2007, 664, L43-L46.

(66) Thaddeus, P.; Gottlieb, C. A.; Gupta, H.; Brünken, S.; McCarthy, M. C.; Agúndez, M.; Guélin, M.; Cernicharo, J. Laboratory and Astronomical Detection of the Negative Molecular Ion $\mathrm{C}_{3} \mathrm{~N}^{-}$. ApJ 2008, 677, 1132-1139.

(67) Cernicharo, J.; Guélin, M.; Agúndez, M.; McCarthy, M. C.; Thaddeus, P. Detection of $\mathrm{C}_{5} \mathrm{~N}^{-}$and Vibrationally Excited $\mathrm{C}_{6} \mathrm{H}$ in $\mathrm{IRC}+10216$. ApJ 2008, 688, L83-L86.

(68) Agúndez, M.; Cernicharo, J.; Guélin, M.; Kahane, C.; Roueff, E.; Kłos, J.; Aoiz, F. J.; Lique, F.; Marcelino, N.; Goicoechea, J. R.; González García, M.; Gottlieb, C. A.; McCarthy, M. C.; Thaddeus, P. Astronomical Identification of $\mathrm{CN}^{-}$, the Smallest Observed Molecular Anion. Astron. Astrophys. 2010, 517, L2.

(69) Biennier, L.; Carles, S.; Cordier, D.; Guillemin, J.-C.; Le Picard, S. D.; Faure, A. Low Temperature Reaction Kinetics of $\mathrm{CN}^{-}+\mathrm{HC}_{3} \mathrm{~N}$ and Implications for the Growth of Anions in Titan's Atmosphere. Icarus 2014, 22\%, 123-131.

(70) Bourgalais, J.; Jamal-Eddine, N.; Joalland, B.; Capron, M.; Balaganesh, M.; Guillemin, J.-C.; Le Picard, S. D.; Faure, A.; Carles, S.; Biennier, L. Elusive Anion Growth in Titan's Atmosphere: Low Temperature Kinetics of the $\mathrm{C}_{3} \mathrm{~N}^{-}+\mathrm{HC}_{3} \mathrm{~N}$ Reaction. Icarus 2016, 271, 194-201.

(71) Joalland, B.; Jamal-Eddine, N.; Kłos, J.; Lique, F.; Trolez, Y.; Guillemin, J.-C.; Carles, S.; Biennier, L. Low-temperature Reactivity of $\mathrm{C}_{2 n+1} \mathrm{~N}^{-}$Anions with Polar Molecules. J. Phys. Chem. Lett. 2016, 7, 2957-2961.

(72) Smith, I. W. M.; Rowe, B. R. Reaction Kinetics at Very Low Temperatures: Laboratory Studies and Interstellar Chemistry. Acc. Chem. Res. 2000, 33, 261-268.

(73) Chastaing, D.; James, P. L.; Sims, I. R.; Smith, I. W. M. Neutral-Neutral Reactions at the Temperatures of Interstellar Clouds Rate Coefficients for Reactions of $\mathrm{C}_{2} \mathrm{H}$ Radicals with $\mathrm{O}_{2}, \mathrm{C}_{2} \mathrm{H}_{2}, \mathrm{C}_{2} \mathrm{H}_{4}$ and $\mathrm{C}_{3} \mathrm{H}_{6}$ down to $15 \mathrm{~K}$. Faraday Discuss. 1998, 109, $165-181$.

(74) Barlow, S. E.; van Doren, J. M.; Depuy, C. H.; Bierbaum, V. M.; Dotan, I.; Ferguson, E. E.; Adams, N. G.; Smith, D.; Rowe, B. R.; Marquette, J. B.; Dupeyrat, G.; Durup-Ferguson, M. Studies of the Reaction of $\mathrm{O}_{2}^{+}$with Deuterated Methanes. J. Chem. Phys. 1986, 85, 3851-3859. 
(75) Joalland, B.; Jamal-Eddine, N.; Papanastasiou, D.; Lekkas, A.; Carles, S.; Biennier, L. A Mass-selective Ion Transfer Line Coupled with a Uniform Supersonic Flow for Studying Ion-molecule Reactions at Low Temperatures. J. Chem. Phys. 2019, 150, 164201.

(76) Marquette, J. B.; Rebrion, C.; Rowe, B. R. Reactions of $\mathrm{N}^{+}\left({ }^{3} \mathrm{P}\right)$ Ions with Normal, Para, and Deuterated Hydrogens at Low Temperatures. J. Chem. Phys. 1988, 89, 2041-2047.

(77) Rebrion, C.; Marquette, J. B.; Rowe, B. R.; Chakravarty, C.; Clary, D. C.; Adams, N. G.; Smith, D. Reactions of $\mathrm{N}^{+}$and $\mathrm{H}_{3}^{+}$with the Structural Isomers of Dichloroethene. J. Phys. Chem. 1988, 92, 6572-6574.

(78) Le Garrec, J.-L.; Carles, S.; Speck, T.; Mitchell, J. B. A.; Rowe, B. R.; Ferguson, E. E. The Ion-molecule Reaction of $\mathrm{O}^{+}$with $\mathrm{N}_{2}$ Measured Down to $23 \mathrm{~K}$. Chem. Phys. Lett. 2003, 372, 485-488.

(79) Sims, I. R.; Queffelec, J. L.; Defrance, A.; Rebrion-Rowe, C.; Travers, D.; Rowe, B. R.; Smith, I. W. M. Ultra-low Temperature Kinetics of Neutral-Neutral Reactions: The Reaction $\mathrm{CN}+\mathrm{O}_{2}$ down to 26 K. J. Chem. Phys. 1992, 97, 8798-8800.

(80) Carty, D.; Le Page, V.; Sims, I. R.; Smith, I. W. M. Low Temperature Rate Coefficients for the Reactions of $\mathrm{CN}$ and $\mathrm{C}_{2} \mathrm{H}$ Radicals with Allene $\left(\mathrm{CH}_{2}=\mathrm{C}=\mathrm{CH}_{2}\right)$ and Methyl Acetylene $\left(\mathrm{CH}_{3} \mathrm{CCH}\right)$. Chem. Phys. Lett. 2001, 344, 310-316.

(81) Abeysekera, C.; Joalland, B.; Ariyasingha, N.; Zack, L. N.; Sims, I. R.; Field, R. W.; Suits, A. G. Product Branching in the Low Temperature Reaction of CN with Propyne by Chirped-Pulse Microwave Spectroscopy in a Uniform Supersonic Flow. J. Phys. Chem. Lett 2015, 6, 1599-1604.

(82) Morales, S. B.; Le Picard, S. D.; Canosa, A.; Sims, I. R. Experimental Measurements of Low Temperature Rate Coefficients for Neutral-Neutral Reactions of Interest for Atmospheric Chemistry of Titan, Pluto and Triton: Reactions of the CN Radical. Faraday Discuss. 2010, 147, 155.

(83) Morales, S. B.; Bennett, C. J.; Le Picard, S. D.; Canosa, A.; Sims, I. R.; Sun, B. J.; Chen, P. H.; Chang, A. H. H.; Kislov, V. V.; Mebel, A. M.; Gu, X.; Zhang, F.; Maksyutenko, P.; Kaiser, R. I. A Crossed Molecular Beam, Low-temperature Kinetics, and Theoretical Investigation of the Reaction of the Cyano Radical (CN) with 1,3-butadiene $\left(\mathrm{C}_{4} \mathrm{H}_{6}\right)$ : A Route to Complex Nitrogen-bearing Molecules in Lowtemperature Extraterrestrial Environments. ApJ 2011, 742, 26.

(84) Sleiman, C.; El Dib, G.; Rosi, M.; Skouteris, D.; Balucani, N.; Canosa, A. Low Temperature Kinetics and Theoretical Studies of the Reaction $\mathrm{CN}+\mathrm{CH}_{3} \mathrm{NH}_{2}$ : A Potential Source of Cyanamide and Methyl Cyanamide in the Interstellar Medium. PCCP 2018, 20, 5478-5489.

(85) Sleiman, C.; El Dib, G.; Talbi, D.; Canosa, A. Gas Phase Reactivity of the CN Radical with Methyl Amines at Low Temperatures (23-297 K): A Combined Experimental and Theoretical Investigation. ACS Earth Sp. Chem. 2018, 2, 1047-1057. 
(86) Sims, I. R.; Queffelec, J.-L.; Travers, D.; Rowe, B. R.; Herbert, L. B.; Karthäuser, J.; Smith, I. W. Rate Constants for the Reactions of CN with Hydrocarbons at Low and Ultra-low Temperatures. Chem. Phys. Lett. 1993, 211, 461-468.

(87) Trevitt, A. J.; Goulay, F.; Taatjes, C. A.; Osborn, D. L.; Leone, S. R. Reactions of the CN Radical with Benzene and Toluene: Product Detection and Low-temperature Kinetics. J. Phys. Chem. A 2010, 114, 1749-1755.

(88) Bennett, C. J.; Morales, S. B.; Le Picard, S. D.; Canosa, A.; Sims, I. R.; Shih, Y. H.; Chang, A. H. H.; Gu, X.; Zhang, F.; Kaiser, R. I. A Chemical Dynamics, Kinetics, and Theoretical Study on the Reaction of the Cyano Radical (CN; $\mathrm{X}^{2} \Sigma^{+}$) with Phenylacetylene $\left(\mathrm{C}_{6} \mathrm{H}_{5} \mathrm{CCH} ; \mathrm{X}^{1} \mathrm{~A}_{1}\right)$. PCCP 2010, 12, 8737-8749.

(89) Shannon, R. J.; Blitz, M. A.; Goddard, A.; Heard, D. E. Accelerated Chemistry in the Reaction between the Hydroxyl Radical and Methanol at Interstellar Temperatures Facilitated by Tunnelling. Nat. Chem. 2013, 5, 745-749.

(90) Gómez-Martín, J. C.; Caravan, R. L.; Blitz, M. A.; Heard, D. E.; Plane, J. M. C. Low Temperature Kinetics of the $\mathrm{CH}_{3} \mathrm{OH}+\mathrm{OH}$ Reaction. J. Phys. Chem. A 2014, 118, 2693-2701.

(91) Antiñolo, M.; Agundez, M.; Jiménez, E.; Ballesteros, B.; Canosa, A.; El Dib, G.; Albaladejo, J.; Cernicharo, J. Reactivity of $\mathrm{OH}$ and $\mathrm{CH}_{3} \mathrm{OH}$ between 22 and $64 \mathrm{~K}$ : Modelling the Gas Phase Production of $\mathrm{CH}_{3} \mathrm{O}$ in Barnard 1b. ApJ 2016, 823.

(92) Shannon, R. J.; Taylor, S.; Goddard, A.; Blitz, M. A.; Heard, D. E. Observation of a Large Negative Temperature Dependence for Rate Coefficients of Reactions of $\mathrm{OH}$ with Oxygenated Volatile Organic Compounds Studied at 86-112 K. PCCP 2010, 12, $13511-13514$.

(93) Shannon, R. J.; Caravan, R. L.; Blitz, M. A.; Heard, D. E. A Combined Experimental and Theoretical Study of Reactions between the Hydroxyl Radical and Oxygenated Hydrocarbons Relevant to Astrochemical Environments. PCCP 2014, 16, 3466-3478.

(94) Caravan, R. L.; Shannon, R. J.; Lewis, T.; Blitz, M. A.; Heard, D. E. Measurements of Rate Coefficients for Reactions of $\mathrm{OH}$ with Ethanol and Propan-2-ol at Very Low Temperatures. J. Phys. Chem. A 2015, 119, 7130-7137.

(95) Ocaña, A. J.; Blázquez, S.; Ballesteros, B.; Canosa, A.; Antiñolo, M.; Albaladejo, J.; Jiménez, E. Gas Phase Kinetics of the $\mathrm{OH}+\mathrm{CH}_{3} \mathrm{CH}_{2} \mathrm{OH}$ Reaction at Temperatures of the Interstellar Medium $(\mathrm{T}=21-107 \mathrm{~K})$. PCCP 2018, 20, 5865-5873.

(96) Jiménez, E.; Antiñolo, M.; Ballesteros, B.; Canosa, A.; Albaladejo, J. First Evidence of the Dramatic Enhancement of the Reactivity of Methyl Formate $\left(\mathrm{HC}(\mathrm{O}) \mathrm{OCH}_{3}\right)$ with $\mathrm{OH}$ at Temperatures of the Interstellar Medium: A Gas-Phase Kinetic Study between $22 \mathrm{~K}$ and $64 \mathrm{~K}$. PCCP 2016, 18, 2183-2191. 
(97) Ocaña, A. J.; Jiménez, E.; Ballesteros, B.; Canosa, A.; Antiñolo, M.; Albaladejo, J.; Agúndez, M.; Cernicharo, J.; Zanchet, A.; Del Mazo, P.; Roncero, O.; Aguado, A. Is the Gas-phase $\mathrm{OH}+\mathrm{H}_{2} \mathrm{CO}$ Reaction a Source of $\mathrm{HCO}$ in Interstellar Cold Dark Clouds? A Kinetic, Dynamic, and Modeling Study. ApJ 2017, 850.

(98) Sims, I. R.; Smith, I. W. M.; Clary, D. C.; Bocherel, P.; Rowe, B. R. Ultra-low Temperature Kinetics of Neutral-Neutral Reactions: New Experimental and Theoretical Results for $\mathrm{OH}+\mathrm{HBr}$ between 295 and 23 K. J. Chem. Phys. 1994, 101, 1748-1751.

(99) Jaramillo, V. I.; Smith, M. A. Temperature-dependent Kinetic Isotope Effects in the Gas-Phase Reaction: OH + HBr. J. Phys. Chem. A 2001, 105, 5854-5859.

(100) Jaramillo, V. I.; Gougeon, S.; Le Picard, S. D.; Canosa, A.; Smith, M. A.; Rowe, B. R. A Consensus View of the Temperature Dependence of the Gas Phase Reaction: OH $+\mathrm{HBr} \rightarrow \mathrm{H}_{2} \mathrm{O}+$ Br. Int. J. Chem. Kinet. 2002, 34, 339-344.

(101) Sims, I. R.; Smith, I. W. M.; Bocherel, P.; Defrance, A.; Travers, D.; Rowe, B. R. Ultra-low Temperature Kinetics of Neutral-Neutral Reactions: Rate Constants for the Reactions of OH Radicals with Butenes between 295 and 23 K. J. Chem. Soc., Faraday Trans. 1994, 90, 1473-1478.

(102) Daranlot, J.; Bergeat, A.; Caralp, F.; Caubet, P.; Costes, M.; Forst, W.; Loison, J.C.; Hickson, K. M. Gas-phase Kinetics of Hydroxyl Radical Reactions with Alkenes: Experiment and Theory. Chem. Phys. Chem. 2010, 11, 4002-4010.

(103) Vakhtin, A. B.; Lee, S.; Heard, D. E.; Smith, I. W. M.; Leone, S. R. Low-temperature Kinetics of Reactions of the $\mathrm{OH}$ Radical with Propene and 1-butene Studied by a Pulsed Laval Nozzle Apparatus Combined with Laser-induced Fluorescence. J. Phys. Chem. A 2001, 105, 7889-7895.

(104) Vakhtin, A. B.; Murphy, J. E.; Leone, S. R. Low-temperature Kinetics of Reactions of $\mathrm{OH}$ Radical with Ethene, Propene, and 1-butene. J. Phys. Chem. A 2003, 107, 10055-10062.

(105) Carty, D.; Goddard, A.; Köhler, S. P. K.; Sims, I. R.; Smith, I. W. M. Kinetics of the Radical-radical Reaction, $\mathrm{O}\left({ }^{3} \mathrm{P}_{j}\right)+\mathrm{OH}\left(\mathrm{X}^{2} \Pi_{\Omega}\right) \rightarrow \mathrm{O}_{2}+\mathrm{H}$, at Temperatures down to 39 K. J. Phys. Chem. A 2006, 110, 3101-3109.

(106) Vöhringer-Martinez, E.; Hansmann, B.; Hernandez, H.; Francisco, J. S.; Troe, J.; Abel, B. Water Catalysis of a Radical-molecule Gas-phase Reaction. Science 2007, 315, 497-501.

(107) Hansmann, B.; Abel, B. Kinetics in Cold Laval Nozzle Expansions: From Atmospheric Chemistry to Oxidation of Biomolecules in the Gas Phase. Chem. Phys. Chem. 2007, 8, 343-356.

(108) Liessmann, M.; Hansmann, B.; Blachly, P. G.; Francisco, J. S.; Abel, B. Primary Steps in the Reaction of $\mathrm{OH}$ Radicals with Amino Acids at Low Temperatures in 
Laval Nozzle Expansions: Perspectives from Experiment and Theory. J. Phys. Chem. A 2009, 113, 7570-7575.

(109) Vöhringer-Martinez, E.; Tellbach, E.; Liessmann, M.; Abel, B. Role of Water Complexes in the Reaction of Propionaldehyde with OH Radicals. J. Phys. Chem. A 2010, 114, 9720-9724.

(110) Vakhtin, A. B.; McCabe, D. C.; Ravishankara, A. R.; Leone, S. R. Low-temperature Kinetics of the Reaction of the $\mathrm{OH}$ Radical with Hydrogen Peroxide. J. Phys. Chem. A 2003, 10\%, 10642-10647.

(111) Bocherel, P.; Herbert, L. B.; Rowe, B. R.; Sims, I. R.; Smith, I. W. M.; Travers, D. Ultralow-temperature Kinetics of $\mathrm{CH}\left(\mathrm{X}^{2} \Pi\right)$ Reactions: Rate Coefficients for Reactions with $\mathrm{O}_{2}$ and $\mathrm{NO}(\mathrm{T}=13-708 \mathrm{~K})$, and with $\mathrm{NH}_{3}(\mathrm{~T}=23-295 \mathrm{~K})$. J. Phys. Chem. 1996, 100, 3063-3069.

(112) Brownsword, R. A.; Canosa, A.; Rowe, B. R.; Sims, I. R.; Smith, I. W. M.; Stewart, D. W. A.; Symonds, A. C.; Travers, D. Kinetics Over a Wide Range of Temperature (13$744 \mathrm{~K})$ : Rate Constants for the Reactions of $\mathrm{CH}(\nu=0)$ with $\mathrm{H}_{2}$ and $\mathrm{D}_{2}$ and for the Removal of $\mathrm{CH}(\nu=1)$ by $\mathrm{H}_{2}$ and $\mathrm{D}_{2}$. J. Chem. Phys. 1997, 106, 7662-7677.

(113) Canosa, A.; Sims, I. R.; Travers, D.; Smith, I. W. M.; Rowe, B. R. Reactions of the Methylidine Radical with $\mathrm{CH}_{4}, \mathrm{C}_{2} \mathrm{H}_{2}, \mathrm{C}_{2} \mathrm{H}_{4}, \mathrm{C}_{2} \mathrm{H}_{6}$, and But-1-ene Studied between 23 and $295 \mathrm{~K}$ with a CRESU Apparatus. Astron. Astrophys. 1997, 323, 644-651.

(114) Hickson, K. M.; Caubet, P.; Loison, J. C. Unusual Low-temperature Reactivity of Water: The $\mathrm{CH}+\mathrm{H}_{2} \mathrm{O}$ Reaction as a Source of Interstellar Formaldehyde. J. Phys. Chem. Lett. 2013, 4, 2843-2846.

(115) Goulay, F.; Rebrion-Rowe, C.; Biennier, L.; Le Picard, S. D.; Canosa, A.; Rowe, B. R. Reaction of Anthracene with CH Radicals: An Experimental Study of the Kinetics between 58 and 470 K. J. Phys. Chem. A 2006, 110, 3132-3137.

(116) Lee, S.; Leone, S. R. Rate Coefficients for the Reaction of $\mathrm{C}_{2} \mathrm{H}$ with $\mathrm{O}_{2}$ at $90 \mathrm{~K}$ and 120 K Using a Pulsed Laval Nozzle Apparatus. Chem. Phys. Lett. 2000, 329, 443-449.

(117) Vakhtin, A. B.; Heard, D. E.; Smith, I. W. M.; Leone, S. R. Kinetics of Reactions of $\mathrm{C}_{2} \mathrm{H}$ Radical with Acetylene, $\mathrm{O}_{2}$, Methylacetylene, and Allene in a Pulsed Laval Nozzle Apparatus at T=103 K. Chem. Phys. Lett. 2001, 344, 317-324.

(118) Soorkia, S.; Liu, C.-L.; Savee, J. D.; Ferrell, S. J.; Leone, S. R.; Wilson, K. R. Airfoil Sampling of a Pulsed Laval Beam with Tunable Vacuum Ultraviolet Synchrotron Ionization Quadrupole Mass Spectrometry: Application to Low-Temperature Kinetics and Product Detection. Rev. Sci. Instrum. 2011, 82, 124102.

(119) Lee, S.; Samuels, D. A.; Hoobler, R. J.; Leone, S. R. Direct Measurements of Rate Coefficients for the Reaction of Ethynyl Radical $\left(\mathrm{C}_{2} \mathrm{H}\right)$ with $\mathrm{C}_{2} \mathrm{H}_{2}$ at 90 and $120 \mathrm{~K}$ Using a Pulsed Laval Nozzle Apparatus. J. Geophys. Res. Planets 2000, 105, 1508515090. 
(120) Bouwman, J.; Goulay, F.; Leone, S. R.; Wilson, K. R. Bimolecular Rate Constant and Product Branching Ratio Measurements for the Reaction of $\mathrm{C}_{2} \mathrm{H}$ with Ethene and Propene at 79 K. J. Phys. Chem. A 2012, 116, 3907-3917.

(121) Soorkia, S.; Trevitt, A. J.; Selby, T. M.; Osborn, D. L.; Taatjes, C. A.; Wilson, K. R.; Leone, S. R. Reaction of the $\mathrm{C}_{2} \mathrm{H}$ Radical with 1-butyne $\left(\mathrm{C}_{4} \mathrm{H}_{6}\right)$ : Low-Temperature Kinetics and Isomer-Specific Product Detection. J. Phys. Chem. A 2010, 114, 33403354 .

(122) Vakhtin, A. B.; Heard, D. E.; Smith, I. W. M.; Leone, S. R. Kinetics of $\mathrm{C}_{2}$ H Radical Reactions with Ethene, Propene and 1-Butene Measured in a Pulsed Laval Nozzle Apparatus at $\mathrm{T}=103$ and 296 K. Chem. Phys. Lett. 2001, 348, 21-26.

(123) Nizamov, B.; Leone, S. R. Kinetics of $\mathrm{C}_{2} \mathrm{H}$ Reactions with Hydrocarbons and Nitriles in the 104-296 K Temperature Range. J. Phys. Chem. A 2004, 108, 1746-1752.

(124) Bouwman, J.; Fournier, M.; Sims, I. R.; Leone, S. R.; Wilson, K. R. Reaction Rate and Isomer-specific Product Branching Ratios of $\mathrm{C}_{2} \mathrm{H}+\mathrm{C}_{4} \mathrm{H}_{8}$ : 1-Butene, Cis -2-butene, Trans -2-butene, and Isobutene at 79 K. J. Phys. Chem. A 2013, 117, 5093-5105.

(125) Murphy, J. E.; Vakhtin, A. B.; Leone, S. R. Laboratory Kinetics of $\mathrm{C}_{2} \mathrm{H}$ Radical Reactions with Ethane, Propane, and n-Butane at $\mathrm{T}=96-296 \mathrm{~K}$ : Implications for Titan. Icarus 2003, 163, 175-181.

(126) Nizamov, B.; Leone, S. R. Rate Coefficients and Kinetic Isotope Effect for the $\mathrm{C}_{2} \mathrm{H}$ Reactions with $\mathrm{NH}_{3}$ and $\mathrm{ND}_{3}$ in the 104-294 K Temperature Range. J. Phys. Chem. A 2004, 108, 3766-3771.

(127) Goulay, F.; Leone, S. R. Low-Temperature Rate Coefficients for the Reaction of Ethynyl Radical $\left(\mathrm{C}_{2} \mathrm{H}\right)$ with Benzene. J. Phys. Chem. A 2006, 110, 1875-1880.

(128) Mullen, C.; Smith, M. A. Low Temperature NH( $\left.\mathrm{X}^{3} \Sigma^{-}\right)$Radical Reactions with NO, Saturated, and Unsaturated Hydrocarbons Studied in a Pulsed Supersonic Laval Nozzle Flow Reactor between 53 and 188 K. J. Phys. Chem. A 2005, 109, 1391-1399.

(129) Páramo, A.; Canosa, A.; Le Picard, S. D.; Sims, I. R. An Experimental Study of the Intersystem Crossing and Reactions of $\mathrm{C}_{2}\left(\mathrm{X}^{1} \Sigma_{g}^{+}\right)$and $\mathrm{C}_{2}\left(\mathrm{a}^{3} \Pi_{u}\right)$ with $\mathrm{O}_{2}$ and $\mathrm{NO}$ at Very Low Temperature (24-300 K). J. Phys. Chem. A 2006, 110, 3121-3127.

(130) Canosa, A.; Páramo, A.; Le Picard, S. D.; Sims, I. R. An Experimental Study of the Reaction Kinetics of $\mathrm{C}_{2}\left(\mathrm{X}^{1} \Sigma_{g}^{+}\right)$with Hydrocarbons $\left(\mathrm{CH}_{4}, \mathrm{C}_{2} \mathrm{H}_{2}, \mathrm{C}_{2} \mathrm{H}_{4}, \mathrm{C}_{2} \mathrm{H}_{6}\right.$ and $\mathrm{C}_{3} \mathrm{H}_{8}$ ) Over the Temperature Range 24-300 K: Implications for the Atmospheres of Titan and the Giant Planets. Icarus 2007, 187, 558-568.

(131) Daugey, N.; Caubet, P.; Bergeat, A.; Costes, M.; Hickson, K. M. Reaction Kinetics to Low Temperatures. Dicarbon + Acetylene, Methylacetylene, Allene and Propene from $77 \leq \mathrm{T} \leq 296 \mathrm{~K}$. PCCP 2008, 10, 729-737. 
(133) Berteloite, C.; Le Picard, S. D.; Birza, P.; Gazeau, M.-C.; Canosa, A.; Bénilan, Y.; Sims, I. R. Low Temperature (39-298 K) Kinetics Study of the Reactions of the $\mathrm{C}_{4} \mathrm{H}$ Radical with Various Hydrocarbons Observed in Titan's Atmosphere. Icarus 2008, $194,746-757$.

(134) Berteloite, C.; Le Picard, S. D.; Balucani, N.; Canosa, A.; Sims, I. R. Low Temperature Rate Coefficients for Reactions of the Butadiynyl Radical, $\mathrm{C}_{4} \mathrm{H}$, with Various Hydrocarbons. Part II: Reactions with Alkenes (ethylene, Propene, 1-butene), Dienes (allene, 1,3-butadiene) and Alkynes (acetylene, Propyne and 1-butyne). PCCP 2010, 12, 3677-3689.

(135) Berteloite, C.; Le Picard, S. D.; Balucani, N.; Canosa, A.; Sims, I. R. Low Temperature Rate Coefficients for Reactions of the Butadiynyl Radical, $\mathrm{C}_{4} \mathrm{H}$, with Various Hydrocarbons. Part I: Reactions with Alkanes $\left(\mathrm{CH}_{4}, \mathrm{C}_{2} \mathrm{H}_{6}, \mathrm{C}_{3} \mathrm{H}_{8}, \mathrm{C}_{4} \mathrm{H}_{10}\right)$. PCCP 2010, 12, 3666-3676.

(136) Chastaing, D.; Le Picard, S. D.; Sims, I. R. Direct Kinetic Measurements on Reactions of Atomic Carbon, $\mathrm{C}\left({ }^{3} \mathrm{P}\right)$, with $\mathrm{O}_{2}$ and $\mathrm{NO}$ at Temperatures down to $15 \mathrm{~K}$. J. Chem. Phys. 2000, 112, 8466-8469.

(137) Geppert, W. D.; Reignier, D.; Stoecklin, T.; Naulin, C.; Costes, M.; Chastaing, D.; Le Picard, S. D.; Sims, I. R.; Smith, I. W. M. Comparison of the Cross-sections and Thermal Rate Constants for the Reactions of $\mathrm{C}\left({ }^{3} \mathrm{Pj}\right)$ Atoms with $\mathrm{O}_{2}$ and NO. PCCP 2000, 2, 2873-2881.

(138) Chastaing, D.; James, P. L.; Sims, I. R.; Smith, I. W. M. Neutral-Neutral Reactions at the Temperatures of Interstellar Clouds: Rate Coefficients for Reactions of Atomic Carbon, $\mathrm{C}\left({ }^{3} \mathrm{P}\right)$, with $\mathrm{O}_{2}, \mathrm{C}_{2} \mathrm{H}_{2}, \mathrm{C}_{2} \mathrm{H}_{4}$ and $\mathrm{C}_{3} \mathrm{H}_{6}$ down to $15 \mathrm{~K}$. PCCP 1999, 1, 22472256 .

(139) Hickson, K. M.; Loison, J.-C.; Wakelam, V. Temperature Dependent Product Yields for the Spin Forbidden Singlet Channel of the $\mathrm{C}\left({ }^{3} \mathrm{P}\right)+\mathrm{C}_{2} \mathrm{H}_{2}$ Reaction. Chem. Phys. Lett. 2016, 659, 70-75.

(140) Chastaing, D.; Le Picard, S. D.; Sims, I. R.; Smith, I. W.; Geppert, W. D.; Naulin, C.; Costes, M. Rate Coefficients and Cross-sections for the Reactions of $\mathrm{C}\left({ }^{3} \mathrm{P}_{j}\right)$ Atoms with Methylacetylene and Allene. Chem. Phys. Lett. 2000, 331, 170-176.

(141) Hickson, K. M.; Loison, J.-C.; Bourgalais, J.; Capron, M.; Le Picard, S. D.; Goulay, F.; Wakelam, V. The $\mathrm{C}\left({ }^{3} \mathrm{P}\right)+\mathrm{NH}_{3}$ Reaction in Interstellar Chemistry. ii. Low Temperature Rate Constants and Modeling of $\mathrm{NH}, \mathrm{NH}_{2}$, and $\mathrm{NH}_{3}$ Abundances in Dense Interstellar Clouds. ApJ 2015, 812, 107. 
(142) Bourgalais, J.; Capron, M.; Kailasanathan, R. K. A.; Osborn, D. L.; Hickson, K. M.; Loison, J. C.; Wakelam, V.; Goulay, F.; Le Picard, S. D. The $\mathrm{C}\left({ }^{3} \mathrm{P}\right)+\mathrm{NH}_{3}$ Reaction in Interstellar Chemistry. i. Investigation of the Product Formation Channels. ApJ 2015, 812, 106.

(143) Hickson, K. M.; Loison, J.-C.; Nuñez-Reyes, D.; Méreau, R. Quantum Tunneling Enhancement of the $\mathrm{C}+\mathrm{H}_{2} \mathrm{O}$ and $\mathrm{C}+\mathrm{D}_{2} \mathrm{O}$ Reactions at Low Temperature. J. Phys. Chem. Lett. 2016, 7, 3641-3646.

(144) Shannon, R. J.; Cossou, C.; Loison, J.-C.; Caubet, P.; Balucani, N.; Seakins, P. W.; Wakelam, V.; Hickson, K. M. The Fast $\mathrm{C}\left({ }^{3} \mathrm{P}\right)+\mathrm{CH}_{3} \mathrm{OH}$ Reaction As an Efficient Loss Process for Gas-phase Interstellar Methanol. R. Soc. Chem. Adv. 2014, 4, 2634226353.

(145) Nuñez Reyes, D.; Hickson, K. M. The Reactivity of C $\left({ }^{1} \mathrm{D}\right)$ with Oxygen Bearing Molecules $\mathrm{NO}$ and $\mathrm{O}_{2}$ at Low Temperature. Chem. Phys. Lett. 2017, 687, 330-335.

(146) Hickson, K. M.; Loison, J.-C.; Guo, H.; Suleimanov, Y. V. Ring-polymer Molecular Dynamics for the Prediction of Low-temperature Rates: An Investigation of the $\mathrm{C}\left({ }^{1} \mathrm{D}\right)$ $+\mathrm{H}_{2}$ Reaction. J. Phys. Chem. Lett. 2015, 6, 4194-4199.

(147) Hickson, K. M.; Suleimanov, Y. V. An Experimental and Theoretical Investigation of the $\mathrm{C}\left({ }^{1} \mathrm{D}\right)+\mathrm{D}_{2}$ Reaction. PCCP 2017, 19, 480-486.

(148) Nuñez Reyes, D.; Hickson, K. M. Kinetics of the Gas-Phase $\mathrm{O}\left({ }^{1} \mathrm{D}\right)+\mathrm{CO}_{2}$ and $\mathrm{C}\left({ }^{1} \mathrm{D}\right)$ $+\mathrm{CO}_{2}$ Reactions Over the 50-296 K Range. J. Phys. Chem. A 2018, 122, 4002-4008.

(149) Nuñez Reyes, D.; Hickson, K. M. Kinetic and Product Study of the Reactions of C $\left({ }^{1} \mathrm{D}\right)$ with $\mathrm{CH}_{4}$ and $\mathrm{C}_{2} \mathrm{H}_{6}$ at Low Temperature. J. Phys. Chem. A 2017, 121, 3851-3857.

(150) Le Picard, S. D.; Canosa, A.; Travers, D.; Chastaing, D.; Rowe, B. R.; Stoecklin, T. Experimental and Theoretical Kinetics for the Reaction of $\mathrm{Al}$ with $\mathrm{O}_{2}$ at Temperatures between 23 and 295 K. J. Chem. Phys. 1997, 101, 1748-1751.

(151) Canosa, A.; Le Picard, S. D.; Gougeon, S.; Rebrion-Rowe, C.; Travers, D.; Rowe, B. R. Rate Coefficients for the Reactions of $\mathrm{Si}\left({ }^{3} \mathrm{P}_{j}\right)$ with $\mathrm{C}_{2} \mathrm{H}_{2}$ and $\mathrm{C}_{2} \mathrm{H}_{4}$ : Experimental Results down to 15 K. J. Chem. Phys. 2001, 115, 6495-6503.

(152) Le Picard, S. D.; Canosa, A.; Reignier, D.; Stoecklin, T. A Comparative Study of the Reactivity of the Silicon Atom $\mathrm{Si}\left({ }^{3} \mathrm{P}_{j}\right)$ Towards $\mathrm{O}_{2}$ and NO Molecules at Very Low Temperature. PCCP 2002, 4, 3659-3664.

(153) Le Picard, S. D.; Canosa, A.; G. Pineau des Forêts, C.; Rebrion-Rowe, C.; Rowe, B. R. The $\mathrm{Si}\left({ }^{3} \mathrm{P}_{j}\right)+\mathrm{O}_{2}$ Reaction: A Fast Source of SiO at Very Low Temperature; CRESU Measurements and Interstellar Consequences. Astron. Astrophys. 2001, 372, 10641070. 
(154) Geppert, W. D.; Goulay, F.; Naulin, C.; Costes, M.; Canosa, A.; Le Picard, S. D.; Rowe, B. R. Rate Coefficients and Integral Cross-sections for the Reaction of $\mathrm{B}\left({ }^{2} \mathrm{Pj}\right)$ Atoms with Acetylene. PCCP 2004, 6, 566-571.

(155) Canosa, A.; Le Picard, S. D.; Geppert, W. D. Experimental Kinetics Study of the Reaction of Boron Atoms, $\mathrm{B}\left({ }^{2} \mathrm{P}_{j}\right)$, with Ethylene at Very Low Temperatures (23-295 K). J. Phys. Chem. A 2004, 108, 6183-6185.

(156) Le Picard, S. D.; Canosa, A.; Geppert, W.; Stoecklin, T. Experimental and Theoretical Temperature Dependence of the Rate Coefficient of the $\mathrm{B}\left({ }^{2} \mathrm{P}_{1 / 2,3 / 2}\right)+\mathrm{O}_{2}\left(\mathrm{X}^{3} \Sigma_{g}^{-}\right)$ Reaction in the 24-295 K Temperature Range. Chem. Phys. Lett. 2004, 385, 502-506.

(157) Sabbah, H.; Biennier, L.; Sims, I. R.; Georgievskii, Y.; Klippenstein, S. J.; Smith, I. W. M. Understanding Reactivity at Very Low Temperatures: The Reactions of Oxygen Atoms with Alkenes. Science 2007, 317, 102-105.

(158) Meng, Q.; Hickson, K. M.; Shao, K.; Loison, J.-C.; Zhang, D. H. Theoretical and Experimental Investigations of Rate Coefficients of $\mathrm{O}\left({ }^{1} \mathrm{D}\right)+\mathrm{CH}_{4}$ at Low Temperature. PCCP 2016, 18, 29286-29292.

(159) Hickson, K. M.; Suleimanov, Y. V. Low-temperature Experimental and Theoretical Rate Constants for the $\mathrm{O}\left({ }^{1} \mathrm{D}\right)+\mathrm{H}_{2}$ Reaction. J. Phys. Chem. A 2017, 121, 1916-1923.

(160) Nuñez Reyes, D.; Hickson, K. M. Rate Constants and H-atom Product Yields for the Reactions of $\mathrm{O}\left({ }^{1} \mathrm{D}\right)$ Atoms with Ethane and Acetylene from 50 to $296 \mathrm{~K}$. J. Phys. Chem. A 2018, 122, 4696-4703.

(161) Nuñez Reyes, D.; Hickson, K. M.; Larrégaray, P.; Bonnet, L.; González-Lezana, T.; Suleimanov, Y. V. A Combined Theoretical and Experimental Investigation of the Kinetics and Dynamics of the $\mathrm{O}\left({ }^{1} \mathrm{D}\right)+\mathrm{D}_{2}$ Reaction at Low Temperature. PCCP 2018, 20, 4404-4414.

(162) Bergeat, A.; Hickson, K. M.; Daugey, N.; Caubet, P.; Costes, M. A Low Temperature Investigation of the $\mathrm{N}\left({ }^{4} \mathrm{~S}^{\circ}\right)+\mathrm{NO}$ Reaction. PCCP 2009, 11, 8149-8155.

(163) Stubbing, J. W.; Vanuzzo, G.; Moudens, A.; Loison, J. C.; Hickson, K. M. Gas-Phase Kinetics of the $\mathrm{N}+\mathrm{C}_{2} \mathrm{~N}$ Reaction at Low Temperature. J. Phys. Chem. A 2015, 119, 3194-3199.

(164) Daranlot, J.; Jorfi, M.; Xie, C.; Bergeat, A.; Costes, M.; Caubet, P.; Xie, D.; Guo, H.; Honvault, P.; Hickson, K. M. Revealing Atom-Radical Reactivity at Low Temperature through the N + OH Reaction. Science 2011, 334, 1538-1541.

(165) Daranlot, J.; Hincelin, U.; Bergeat, A.; Costes, M.; Loison, J.-C.; Wakelam, V.; Hickson, K. M. Elemental Nitrogen Partitioning in Dense Interstellar Clouds. PNAS 2012, 109, 10233-10238. 
(166) Daranlot, J.; Hu, X.; Xie, C.; Loison, J.-C.; Caubet, P.; Costes, M.; Wakelam, V.; Xie, D.; Guo, H.; Hickson, K. M. Low Temperature Rate Constants for the $\mathrm{N}\left({ }^{4} \mathrm{~S}\right)$ $+\mathrm{CH}\left(\mathrm{X}^{2} \Pi_{r}\right)$ Reaction. Implications for $\mathrm{N}_{2}$ Formation Cycles in Dense Interstellar Clouds. PCCP 2013, 15, 13888-13896.

(167) Loison, J. C.; Hu, X.; Han, S.; Hickson, K. M.; Guo, H.; Xie, D. An Experimental and Theoretical Investigation of the $\mathrm{N}\left({ }^{4} \mathrm{~S}\right)+\mathrm{C}_{2}\left({ }^{1} \Sigma \mathrm{g}+\right)$ Reaction at Low Temperature. PCCP 2014, 16, 14212-14219.

(168) Nuñez Reyes, D.; Hickson, K. M. A Low Temperature Investigation of the Gas-Phase $\mathrm{N}\left({ }^{2} \mathrm{D}\right)+\mathrm{NO}$ Reaction. Towards a Viable Source of $\mathrm{N}\left({ }^{2} \mathrm{D}\right)$ Atoms for Kinetic Studies in Astrochemistry. PCCP 2018, 20, 17442-17447.

(169) Nuñez Reyes, D.; Loison, J.-C.; Hickson, K. M.; Dobrijevic, M. A Low Temperature Investigation of the $\mathrm{N}\left({ }^{2} \mathrm{D}\right)+\mathrm{CH}_{4}, \mathrm{C}_{2} \mathrm{H}_{6}$ and $\mathrm{C}_{3} \mathrm{H}_{8}$ Reactions. PCCP 2019, 21, 65746581.

(170) Berteloite, C.; Le Picard, S. D.; Sims, I. R.; Rosi, M.; Leonori, F.; Petrucci, R.; Balucani, N.; Wang, X.; Casavecchia, P. Low Temperature Kinetics, Crossed Beam Dynamics and Theoretical Studies of the Reaction $\mathrm{S}\left({ }^{1} \mathrm{D}\right)+\mathrm{CH}_{4}$ and Low Temperature Kinetics of $\mathrm{S}\left({ }^{1} \mathrm{D}\right)+\mathrm{C}_{2} \mathrm{H}_{2}$. PCCP 2011, 13, 8485-8501.

(171) Leonori, F.; Petrucci, R.; Balucani, N.; Casavecchia, P.; Rosi, M.; Berteloite, C.; Le Picard, S. D.; Canosa, A.; Sims, I. R. Observation of Organosulfur Products (thiovinoxy, Thioketene and Thioformyl) in Crossed-beam Experiments and Low Temperature Rate Coefficients for the Reaction $\mathrm{S}\left({ }^{1} \mathrm{D}\right)+\mathrm{C}_{2} \mathrm{H}_{4}$. PCCP 2009, 11, 4701-4706.

(172) Leonori, F.; Petrucci, R.; Balucani, N.; Casavecchia, P.; Rosi, M.; Skouteris, D.; Berteloite, C.; Le Picard, S. D.; Canosa, A.; Sims, I. R. Crossed-beam Dynamics, Low-temperature Kinetics, and Theoretical Studies of the Reaction $\mathrm{S}\left({ }^{1} \mathrm{D}\right)+\mathrm{C}_{2} \mathrm{H}_{4} . J$. Phys. Chem. A 2009, 113, 15328-15345.

(173) Hickson, K. M.; Bergeat, A.; Costes, M. A Low Temperature Study of the Reactions of Atomic Chlorine with Simple Alkanes. J. Phys. Chem. A 2010, 114, 3038-3044.

(174) Tizniti, M.; Le Picard, S. D.; Lique, F.; Berteloite, C.; Canosa, A.; Alexander, M. H.; Sims, I. R. The Rate of the $\mathrm{F}+\mathrm{H}_{2}$ Reaction at Very Low Temperatures. Nature Chemistry 2014, 6, 141-145.

(175) Sharkey, P.; Sims, I. R.; Smith, I. W. M.; Bocherel, P.; Rowe, B. R. Pressure and Temperature Dependence of the Rate Constants for the Association Reaction of OH Radicals with NO between 301 and 23 K. J. Chem. Soc. Faraday Trans. 1994, 90, 3609-3616.

(176) Atkinson, D. B.; Smith, M. A. Radical-Molecule Kinetics in Pulsed Uniform Supersonic Flows: Termolecular Association of $\mathrm{OH}+\mathrm{NO}$ between 90 and $220 \mathrm{~K}$. J. Phys. Chem. 1994, 98, 5797-5800. 
(177) Liessmann, M.; Miller, Y.; Gerber, R. B.; Abel, B. Reaction of OH and NO at Low Temperatures in the Presence of Water: the Role of Clusters. Z. Phys. Chem. 2011, 225, 1129-1144.

(178) Daranlot, J.; Hickson, K. M.; Loison, J.-C.; Méreau, R.; Caralp, F.; Forst, W.; Bergeat, A. Gas-phase Kinetics of the Hydroxyl Radical Reaction with Allene: Absolute Rate Measurements at Low Temperature, Product Determinations, and Calculations. J. Phys. Chem. A 2012, 116, 10871-10881.

(179) Le Picard, S. D.; Tizniti, M.; Canosa, A.; Sims, I. R.; Smith, I. W. M. The Thermodynamics of the Elusive $\mathrm{HO}_{3}$ Radical. Science 2010, 328, 1258-1262.

(180) Tizniti, M.; Le Picard, S. D.; Canosa, A.; Sims, I. R.; Smith, I. W. M. Low Temperature Kinetics: The Association of $\mathrm{OH}$ Radicals with $\mathrm{O}_{2}$. PCCP 2010, 12, 12702-12710.

(181) Smith, I. W. M.; Le Picard, S. D.; Tizniti, M.; Canosa, A.; Sims, I. R. The Quest for the Hydroxyl-peroxy Radical. Z. Phys. Chem. 2010, 224, 949-965.

(182) Goulay, F.; Rebrion-Rowe, C.; Le Garrec, J. L.; Le Picard, S. D.; Canosa, A.; Rowe, B. R. The Reaction of Anthracene with OH Radicals: An Experimental Study of the Kinetics between 58 and 470 K. J. Chem. Phys. 2005, 122, 104308.

(183) Hamon, S.; Le Picard, S. D.; Canosa, A.; Rowe, B. R.; Smith, I. W. M. Low Temperature Measurements of the Rate of Association to Benzene Dimers in Helium. J. Chem. Phys. 2000, 112, 4506-4516.

(184) Brownsword, R. A.; Sims, I. R.; Smith, I. W. M.; Stewart, D. W. A.; Canosa, A.; Rowe, B. R. The Radiative Association of $\mathrm{CH}$ with $\mathrm{H}_{2}$ : A Mechanism for Formation of $\mathrm{CH}_{3}$ in Interstellar Clouds. ApJ 1997, 485, 195-202.

(185) Le Picard, S. D.; Canosa, A.; Rowe, B. R.; Brownsword, R. A.; Smith, I. W. M. Determination of the Limiting Low Pressure Rate Constants of the Reactions of $\mathrm{CH}$ with $\mathrm{N}_{2}$ and CO: A CRESU Measurement at 53 K. J. Chem. Soc. Faraday Trans. 1998, 94, 2889-2893.

(186) Le Picard, S. D.; Canosa, A. Measurement of the Rate Constant for the Association Reaction $\mathrm{CH}+\mathrm{N}_{2}$ at $53 \mathrm{~K}$ and its Relevance to Triton's Atmosphere. Geophys. Res. Lett. 1998, 25, 485-488.

(187) Sleiman, C.; González, S.; Klippenstein, S. J.; Talbi, D.; El Dib, G.; Canosa, A. Pressure Dependent Low Temperature Kinetics for $\mathrm{CN}+\mathrm{CH}_{3} \mathrm{CN}$ : Competition between Chemical Reaction and van der Waals Complex Formation. PCCP 2016, 18, $15118-15132$.

(188) Biennier, L.; Sabbah, H.; Chandrasekaran, V.; Klippenstein, S. J.; Sims, I. R.; Rowe, B. R. Insights into the Role of Polycyclic Aromatic Hydrocarbon Condensation in Haze Formation in Jupiter's Atmosphere. Astron. Astrophys. 2011, 532, A40. 
(189) Sabbah, H.; Biennier, L.; Klippenstein, S. J.; Sims, I. R.; Rowe, B. R. Exploring the Role of PAHs in the Formation of Soot: Pyrene Dimerization. J. Phys. Chem. Lett. 2010, 1, 2962-2967.

(190) Bourgalais, J.; Roussel, V.; Capron, M.; Benidar, A.; Jasper, A. W.; Klippenstein, S. J.; Biennier, L.; Le Picard, S. D. Low Temperature Kinetics of the First Steps of Water Cluster Formation. Phys. Rev. Lett. 2016, 116, 113401.

(191) Sánchez-González, R.; Eveland, W. D.; West, N. A.; Mai, C. L. N.; Bowersox, R. D. W.; North, S. W. Low-temperature Collisional Quenching of $\mathrm{NO} \mathrm{A}^{2} \Sigma^{+}\left(\mathrm{v}^{\prime}=0\right)$ by $\mathrm{NO}\left(\mathrm{X}^{2} \Pi\right)$ and $\mathrm{O}_{2}$ between 34 and 109 K. J. Chem. Phys. 2014, 141, 074313.

(192) James, P. L.; Sims, I. R.; Smith, I. W. Rate Coefficients for the Vibrational Selfrelaxation of $\mathrm{NO}\left(\mathrm{X}^{2} \Pi, \nu=3\right)$ at Temperatures down to 7 K. Chem. Phys. Lett. 1997, 276, 423-429.

(193) James, P. L.; Sims, I. R.; Smith, I. W. M.; Alexander, M. H.; Yang, M. A Combined Experimental and Theoretical Study of Rotational Energy Transfer in Collisions between $\mathrm{NO}\left(\mathrm{X}^{2} \Pi_{1 / 2}, \mathrm{v}=3, \mathrm{j}\right)$ and $\mathrm{He}, \mathrm{Ar}$ and $\mathrm{N}_{2}$ at Temperatures down to $7 \mathrm{~K}$. J. Chem. Phys. 1998, 109, 3882-3897.

(194) Wright, S. M.; Sims, I. R.; Smith, L. W. Vibrational Relaxation of Highly Excited Toluene in Collisions with He, Ar, and $\mathrm{N}_{2}$ at Temperatures down to $38 \mathrm{~K}$. J. Phys. Chem. A 2000, 104, 10347-10355.

(195) Carty, D.; Goddard, A.; Sims, I. R.; Smith, I. W. M. Rotational Energy Transfer in Collisions between $\mathrm{CO}\left(\mathrm{X}^{1} \Sigma^{+}, \mathrm{v}=2, \mathrm{~J}=0,1,4\right.$, and 6$)$ and He at Temperatures from 294 to 15 K. J. Chem. Phys. 2004, 121, 4671-4683.

(196) Mertens, L. A.; Labiad, H.; Denis-Alpizar, O.; Fournier, M.; Carty, D.; Le Picard, S. D.; Stoecklin, T.; Sims, I. R. Rotational Energy Transfer in Collisions between $\mathrm{CO}$ and Ar at Temperatures from 293 to 30 K. Chem. Phys. Lett. 2017, 683, 521-528.

(197) Herbert, L. B.; Sims, I. R.; Smith, I. W. M.; Stewart, D. W. A.; Symonds, A. C.; Canosa, A.; Rowe, B. R. Rate Constants for the Relaxation of $\mathrm{CH}\left(\mathrm{X}^{2} \Pi, \nu=1\right)$ by $\mathrm{CO}$ and $\mathrm{N}_{2}$ at Temperatures from 23 to 584 K. J. Phys. Chem. 1996, 100, 14928-14935.

(198) Le Picard, S. D.; Bussery-Honvault, B.; Rebrion-Rowe, C.; Honvault, P.; Canosa, A.; Launay, J. M.; Rowe, B. R. Fine Structure Relaxation of Aluminum by Atomic Argon between 30 and 300 K: An Experimental and Theoretical Study. J. Chem. Phys. 1998, 108, 10319-10326.

(199) Le Picard, S. D.; Honvault, P.; Bussery-Honvault, B.; Canosa, A.; Laubé, S.; Launay, J.-M.; Rowe, B.; Chastaing, D.; Sims, I. R. Experimental and Theoretical Study of Intramultiplet Transitions in Collisions of $\mathrm{C}\left({ }^{3} \mathrm{P}\right)$ and $\operatorname{Si}\left({ }^{3} \mathrm{P}\right)$ with He. J. Chem. Phys. 2002, 117, 10109-10120.

(200) Grondin, R.; Loison, J.-C.; Hickson, K. M. Low Temperature Rate Constants for the Reactions of $\mathrm{O}\left({ }^{1} \mathrm{D}\right)$ with $\mathrm{N}_{2}, \mathrm{O}_{2}$, and Ar. J. Phys. Chem. A 2016, 120, 4838-4844. 
(202) Hickson, K. M.; Loison, J.-C.; Lique, F.; Kłos, J. An Experimental and Theoretical Investigation of the $\mathrm{C}\left({ }^{1} \mathrm{D}\right)+\mathrm{N}_{2} \rightarrow \mathrm{C}\left({ }^{3} \mathrm{P}\right)+\mathrm{N}_{2}$ Quenching Reaction at Low Temperature. J. Phys. Chem. A 2016, 120, 2504-2513.

(203) Lara, M.; Berteloite, C.; Paniagua, M.; Dayou, F.; Le Picard, S. D.; Launay, J.-M. Experimental and Theoretical Study of the Collisional Quenching of $\mathrm{S}\left({ }^{1} \mathrm{D}\right)$ by Ar. PCCP 2017, 19, 28555-28571.

(204) Le Garrec, J. L.; Sidko, O.; Queffelec, J. L.; Hamon, S.; Mitchell, J. B. A.; Rowe, B. R. Experimental Studies of Cold Electron Attachment to $\mathrm{SF}_{6}, \mathrm{CF}_{3} \mathrm{Br}$, and $\mathrm{CCl}_{2} \mathrm{~F}_{2}$. J. Chem. Phys. 1997, 107, 54-63.

(205) Moustefaoui, T.; Rebrion-Rowe, C.; Le Garrec, J.-L.; Rowe, B. R.; Brian A. Mitchell, J. Low Temperature Electron Attachment to Polycyclic Aromatic Hydrocarbons. Faraday Discuss. 1998, 109, 71-82.

(206) Speck, T.; Mostefaoui, T.; Rebrion-Rowe, C.; Mitchell, J. B. A.; Rowe, B. R. Lowtemperature Electron Attachment to $\mathrm{CH}_{3}$ I. J. Phys. B At. Mol. Opt. Phys. 2000, 33 , $3575-3582$.

(207) Goulay, F.; Rebrion-Rowe, C.; Carles, S.; Le Garrec, J. L.; Rowe, B. R. Electron Attachment on HI and DI in a Uniform Supersonic Flow: Thermalization of the Electrons. J. Chem. Phys. 2004, 121, 1303-1308.

(208) Speck, T.; Le Garrec, J. L.; Le Picard, S.; Canosa, A.; Mitchell, J. B. A.; Rowe, B. R. Electron Attachment in $\mathrm{HBr}$ and HCl. J. Chem. Phys. 2001, 114, 8303-8309.

(209) Carles, S.; Saidani, G.; Le Garrec, J.-L.; Guen, N.; Mitchell, J. B.; Viggiano, A. A.; Shuman, N. S. Demonstration of the Branching Ratio Inversion for the Electron Attachment to Phosphoryl Chloride $\mathrm{POCl}_{3}$ in the Gas Phase between 300 and $200 \mathrm{~K}$. Chem. Phys. Lett. 2016, 650, 144-147.

(210) Smith, I. W. M.; Sage, A. M.; Donahue, N. M.; Herbst, E.; Quan, D. The Temperaturedependence of Rapid Low Temperature Reactions: Experiment, Understanding and Prediction. Faraday Discuss. 2006, 133, 137.

(211) Herbert, L.; Smith, I. W. M.; Spencer-Smith, R. D. Rate Constants for the Elementary Reactions between $\mathrm{CN}$ Radicals and $\mathrm{CH}_{4}, \mathrm{C}_{2} \mathrm{H}_{6}, \mathrm{C}_{2} \mathrm{H}_{4}, \mathrm{C}_{3} \mathrm{H}_{6}$, and $\mathrm{C}_{2} \mathrm{H}_{2}$ in the Range: $295 \leq \mathrm{T} / \mathrm{K} \leq 700$. Int. J. Chem. Kinet. 1992, 24, 791-802.

(212) Huang, L. C. L.; Balucani, N.; Lee, Y. T.; Kaiser, R. I.; Osamura, Y. Crossed Beam Reaction of the Cyano Radical, $\mathrm{CN}\left(\mathrm{X}^{2} \Sigma^{+}\right)$, with Methylacetylene, $\mathrm{CH}_{3} \mathrm{CCH}\left(\mathrm{X}^{1} A_{1}\right)$ : Observation of Cyanopropyne, $\mathrm{CH}_{3} \mathrm{CCCN}\left(\mathrm{X}^{1} \mathrm{~A}_{1}\right)$, and Cyanoallene, $\mathrm{H}_{2} \mathrm{CCCHCN}$ $\left(\mathrm{X}^{1} A\right.$ ) $)$. J. Chem. Phys. 1999, 111, 2857-2860. 
(213) Balucani, N.; Asvany, O.; Huang, L. C. L.; Lee, Y. T.; Kaiser, R. I.; Osamura, Y.; Bettinger, H. F. Formation of Nitriles in the Interstellar Medium via Reactions of Cyano Radicals, $\mathrm{CN}\left(\mathrm{X}^{2} \Sigma^{+}\right)$, with Unsaturated Hydrocarbons. ApJ 2000, 545, 892906.

(214) Roncero, O.; Zanchet, A.; Aguado, A. Low Temperature Reaction Dynamics for $\mathrm{CH}_{3} \mathrm{OH}+\mathrm{OH}$ Collisions on a New Full Dimensional Potential Energy Surface. PCCP 2018, 20, 25951-25958.

(215) Gao, L. G.; Zheng, J.; Fernández-Ramos, A.; Truhlar, D. G.; Xu, X. Kinetics of the Methanol Reaction with $\mathrm{OH}$ at Interstellar, Atmospheric, and Combustion Temperatures. J. Am. Chem. Soc. 2018, 140, 2906-2918.

(216) Nguyen, T. L.; Ruscic, B.; Stanton, J. F. A Master Equation Simulation for the $\bullet \mathrm{OH}$ $+\mathrm{CH}_{3} \mathrm{OH}$ Reaction. J. Chem. Phys. 2019, 150, 084105.

(217) del Mazo-Sevillano, P.; Aguado, A.; Jiménez, E.; Suleimanov, Y. V.; Roncero, O. Quantum Roaming in the Complex-forming Mechanism of the Reactions of $\mathrm{OH}$ with Formaldehyde and Methanol at Low Temperature and Zero Pressure: A Ring Polymer Molecular Dynamics Approach. J. Phys. Chem. Lett. 2019, 10, 1900-1907.

(218) Dillon, T. J.; Hölscher, D.; Sivakumaran, V.; Horowitz, A.; Crowley, J. N. Kinetics of the Reactions of HO with Methanol (210-351 K) and with Ethanol (216-368 K). PCCP 2005, 7, 349-355.

(219) Heard, D. E. Rapid Acceleration of Hydrogen Atom Abstraction Reactions of OH at Very Low Temperatures through Weakly Bound Complexes and Tunneling. Acc. Chem. Res. 2018, 51, 2620-2627.

(220) Seakins, P. W. Product Branching Ratios in Simple Gas Phase Reactions. Annu. Reports Sect. C 2007, 103, 173.

(221) Choi, N.; Blitz, M. A.; Mckee, K.; Pilling, M. J.; Seakins, P. W. H Atom Branching Ratios from the Reactions of CN Radicals with $\mathrm{C}_{2} \mathrm{H}_{2}$ and $\mathrm{C}_{2} \mathrm{H}_{4}$. Chem. Phys. Lett. 2004, 384, 68-72.

(222) Gannon, K. L.; Blitz, M. A.; Liang, C.-H.; Pilling, M. J.; Seakins, P. W.; Glowacki, D. R.; Harvey, J. N. An Experimental and Theoretical Investigation of the Competition between Chemical Reaction and Relaxation for the Reactions of ${ }^{1} \mathrm{CH}_{2}$ with Acetylene and Ethene: Implications for the Chemistry of the Giant Planets. Faraday Discuss. 2010, 147, 173-188.

(223) Blitz, M. A.; Choi, N.; Kovàcs, T.; Seakins, P. W.; Pilling, M. J. The Effect of Temperature on Collision Induced Intersystem Crossing in the Reaction of ${ }^{1} \mathrm{CH}_{2}$ with $\mathrm{H}_{2}$. Proceedings of the Combustion Institute 2005, 30, 927-933.

(224) Gannon, K. L.; Blitz, M. A.; Pilling, M. J.; Seakins, P. W.; Klippenstein, S. J.; Harding, L. B. Kinetics and Product Branching Ratios of the Reaction of ${ }^{1} \mathrm{CH}_{2}$ with $\mathrm{H}_{2}$ and $\mathrm{D}_{2}$. J. Phys. Chem. A 2008, 112, 9575-9583. 
(235) Lockyear, J. F.; Fournier, M.; Sims, I. R.; Guillemin, J.-c.; Taatjes, C. A.; Osborn, D. L.; Leone, S. R. Formation of Fulvene in the Reaction of $\mathrm{C}_{2} \mathrm{H}$ with 1,3butadiene. Int. J. Mass Spectrom. 2015, 378, 232-245.

(236) Jones, B. M.; Zhang, F.; Kaiser, R. I.; Jamal, A.; Mebel, A. M.; Cordiner, M. A.; Charnley, S. B. Formation of Benzene in the Interstellar Medium. PNAS 2011, 108, $452-457$.

(225) Bergeat, A.; Loison, J.-C. Reaction of Carbon Atoms, $\mathrm{C}\left(2 \mathrm{p}^{2},{ }^{3} \mathrm{P}\right)$ with $\mathrm{C}_{2} \mathrm{H}_{2}, \mathrm{C}_{2} \mathrm{H}_{4}$ and $\mathrm{C}_{6} \mathrm{H}_{6}$ : Overall Rate Constant and Relative Atomic Hydrogen Production. PCCP 2001, 3, 2038-2042.

(226) Glowacki, D. R.; Liang, C. H.; Morley, C.; Pilling, M. J.; Robertson, S. H. MESMER: An Open-source Master Equation Solver for Multi-Energy Well Reactions. J. Phys. Chem. A 2012, 116, 9545-9560.

(227) Osborn, D. L.; Zou, P.; Johnsen, H.; Hayden, C. C.; Taatjes, C. A.; Knyazev, V. D.; North, S. W.; Peterka, D. S.; Ahmed, M.; Leone, S. R. The Multiplexed Chemical Kinetic Photoionization Mass Spectrometer: A New Approach to Isomer-resolved Chemical Kinetics. Rev. Sci. Instrum. 2008, 79, 104103.

(228) Slagle, I. R.; Yamada, F.; Gutman, D. Kinetics of Free Radicals Produced by Infrared Multiphoton-induced Decompositions. 1. Reactions of Allyl Radicals with Nitrogen Dioxide and Bromine. J. Am. Chem. Soc. 1981, 103, 149-153.

(229) Slagle, I. R.; Gutman, D. Kinetics of Polyatomic Free Radicals Produced by Laser Photolysis. 5. Study of the Equilibrium Methyl + Oxygen $\rightleftharpoons \mathrm{CH}_{3} \mathrm{O}_{2}$ between 421 and 538 degree Celsius. J. Am. Chem. Soc. 1985, 107, 5342-5347.

(230) Soorkia, S.; Taatjes, C. A.; Osborn, D. L.; Selby, T. M.; Trevitt, A. J.; Wilson, K. R.; Leone, S. R. Direct Detection of Pyridine Formation by the Reaction of CH (CD) with Pyrrole: A Ring Expansion Reaction. PCCP 2010, 12, 8750-8758.

(231) Goulay, F.; Soorkia, S.; Meloni, G.; Osborn, D. L.; Taatjes, C. A.; Leone, S. R. Detection of Pentatetraene by Reaction of the Ethynyl Radical $\left(\mathrm{C}_{2} \mathrm{H}\right)$ with Allene $\left(\mathrm{CH}_{2}=\mathrm{C}=\mathrm{CH}_{2}\right)$ at Room Temperature. PCCP 2011, 13, 20820-20827.

(232) Welz, O.; Savee, J. D.; Osborn, D. L.; Vasu, S. S.; Percival, C. J.; Shallcross, D. E.; Taatjes, C. A. Direct Kinetic Measurements of Criegee Intermediate $\left(\mathrm{CH}_{2} \mathrm{OO}\right)$ Formed by Reaction of $\mathrm{CH}_{2} \mathrm{I}$ with $\mathrm{O}_{2}$. Science 2012, 335, 204-207.

(233) Savee, J. D.; Papajak, E.; Rotavera, B.; Huang, H.; Eskola, A. J.; Welz, O.; Sheps, L.; Taatjes, C.; Zádor, J.; Osborn, D. L. Direct Observation and Kinetics of a Hydroperoxyalkyl Radical (QOOH). Science 2015, 347, 643-645.

(234) McGuire, B. A.; Burkhardt, A. M.; Kalenskii, S.; Shingledecker, C. N.; Remijan, A. J.; Herbst, E.; Mccarthy, M. C. Detection of the Aromatic Molecule Benzonitrile (c$\mathrm{C}_{6} \mathrm{H}_{5} \mathrm{CN}$ ) in the Interstellar Medium. Science 2018, 359, 202-205. 
(237) Taatjes, C. A. How Does the Molecular Velocity Distribution Affect Kinetics Measurements by Time-resolved Mass Spectrometry? Int. J. Chem. Kinet. 2007, 39, 565-570.

(238) Lee, Y. T.; McDonald, J. D.; Lebreton, P. R.; Herschbach, D. R. Molecular Beam Reactive Scattering Apparatus with Electron Bombardment Detector. Rev. Sci. Instrum. 1969, 40, 1402-1408.

(239) Lai, L.-H.; Wang, J.-H.; Che, D.-C.; Liu, K. Direct Mapping of Vibrational-specific Angular Distributions of the Polyatomic Reaction Product: $\mathrm{CN}+\mathrm{D}_{2} \rightarrow \mathrm{DCN}+\mathrm{D}$. $J$. Chem. Phys. 1996, 105, 3332-3335.

(240) Lin, J. J.; Zhou, J.; Shiu, W.; Liu, K. Application of Time-sliced Ion Velocity Imaging to Crossed Molecular Beam Experiments. Review of Scientific Instruments 2003, 74 , 2495-2500.

(241) Schnieder, L.; Meier, W.; Welge, K. H.; Ashfold, M. N. R.; Western, C. M. Photodissociation Dynamics of $\mathrm{H}_{2} \mathrm{~S}$ at $121.6 \mathrm{~nm}$ and a Determination of the Potential Energy Function of $\mathrm{SH}\left(\mathrm{A}^{2} \Sigma^{+}\right)$. J. Chem. Phys. 1990, 92, 7027-7037.

(242) Pan, H.; Liu, K.; Caracciolo, A.; Casavecchia, P. Crossed Beam Polyatomic Reaction Dynamics: Recent Advances and New Insights. Chem. Soc. Rev. 2017, 46, 7517-7547.

(243) Naulin, C.; Costes, M. Crossed-beam Study of the $\mathrm{Al}\left({ }^{2} \mathrm{P}_{1 / 2,3 / 2}+\mathrm{O}_{2}\left(\mathrm{X}^{3} \Sigma^{-} \mathrm{g}\right) \rightarrow \mathrm{AlO}\right.$ $\left(\mathrm{X}^{2} \Sigma^{+}\right)+\mathrm{O}\left({ }^{3} \mathrm{P}_{\mathrm{J}}\right)$ Reaction at Low and Very Low Kinetic Energies. Chem. Phys. Lett. 1999, 310, 231-239.

(244) Naulin, C.; Daugey, N.; Hickson, K. M.; Costes, M. Dynamics of the Reactions of $\mathrm{C}\left({ }^{3} \mathrm{P}_{\mathrm{J}}\right)$ Atoms with Ethylene, Allene, and Methylacetylene at Low Energy Revealed by Doppler-Fizeau Spectroscopy. J. Phys. Chem. A 2009, 113, 14447-14457.

(245) Brown, G. G.; Dian, B. C.; Douglass, K. O.; Geyer, S. M.; Shipman, S. T.; Pate, B. H. A Broadband Fourier Transform Microwave Spectrometer Based on Chirped Pulse Excitation. Rev. Sci. Instrum. 2008, 79, 053103.

(246) Abeysekera, C.; Zack, L. N.; Park, G. B.; Joalland, B.; Oldham, J. M.; Prozument, K.; Ariyasingha, N. M.; Sims, I. R.; Field, R. W.; Suits, A. G. A Chirped-pulse Fouriertransform Microwave/pulsed Uniform Flow Spectrometer. Ii. Performance and Applications for Reaction Dynamics. J. Chem. Phys 2014, 141, 214203.

(247) Pilgrim, J. S.; McIlroy, A.; Taatjes, C. A. Kinetics of Cl Atom Reactions with Methane, Ethane, and Propane from 292 to 800 K. J. Phys. Chem. A 1997, 101, 1873-1880.

(248) Taatjes, C. A.; Hershberger, J. F. Recent Progress in Infrared Absorption Techniques for Elementary Gas-phase Reaction Kinetics. Annu. Rev. Phys. Chem. 2001, 52, 4170 .

(249) Yu, T.; Lin, M. C. Kinetics of the $\mathrm{C}_{6} \mathrm{H}_{5}+\mathrm{O}_{2}$ Reaction at Low Temperatures. J. Am. Chem. Soc. 1994, 116, 9571-9576. 
(250) Friedrichs, G. Sensitive Absorption Methods for Quantitative Gas Phase Kinetic Measurements. Part 2: Cavity Ringdown Spectroscopy. Z. Phys. Chem. 2008, 222, 31-61.

(251) Sprague, M. K.; Mertens, L. A.; Widgren, H. N.; Okumura, M.; Sander, S. P.; Mccoy, A. B. Cavity Ringdown Spectroscopy of the Hydroxy-methyl-peroxy Radical. J. Phys. Chem. A 2013, 117, 10006-10017.

(252) North, S. W.; Fei, R.; Sears, T. J.; Hall, G. E. CN Radical Reaction Rate Measurements by Time-resolved FM Spectroscopy. Int. J. Chem. Kinet. 1997, 29, 127-129.

(253) Friedrichs, G. Sensitive Absorption Methods for Quantitative Gas Phase Kinetic Measurements. Part 1: Frequency Modulation Spectroscopy. Z. Phys. Chem. 2008, 222, $1-30$.

(254) Fleisher, A. J.; Bjork, B. J.; Bui, T. Q.; Cossel, K. C.; Okumura, M.; Ye, J. Midinfrared Time-resolved Frequency Comb Spectroscopy of Transient Free Radicals. J. Phys. Chem. Lett. 2014, 5, 2241-2246.

(255) Schliesser, A.; Brehm, M.; Keilmann, F.; van der Weide, D. W. Frequency-comb Infrared Spectrometer for Rapid, Remote Chemical Sensing. Opt. Express 2005, 13, 9029-9038.

(256) Adler, F.; Masłowski, P.; Foltynowicz, A.; Cossel, K. C.; Briles, T. C.; Hartl, I.; Ye, J. Mid-infrared Fourier Transform Spectroscopy with a Broadband Frequency Comb. Opt. Express 2010, 18, 21861-21872.

(257) Bjork, B. J.; Bui, T. Q.; Heckl, O. H.; Changala, P. B.; Spaun, B.; Heu, P.; Follman, D.; Deutsch, C.; Cole, G. D.; Aspelmeyer, M.; Okumura, M.; Ye, J. Direct Frequency Comb Measurement of OD $+\mathrm{CO} \rightarrow$ DOCO Kinetics. Science 2016, 354, 444-448.

(258) Bui, T. Q.; Bjork, B. J.; Changala, P. B.; Heckl, O. H.; Spaun, B.; Ye, J. OD + $\mathrm{CO} \rightarrow \mathrm{D}+\mathrm{CO}_{2}$ Branching Kinetics Probed with Time-resolved Frequency Comb Spectroscopy. Chem. Phys. Lett. 2017, 683, 91-95.

(259) Spaun, B.; Changala, P. B.; Patterson, D.; Bjork, B. J.; Heckl, O. H.; Doyle, J. M.; Ye, J. Continuous Probing of Cold Complex Molecules with Infrared Frequency Comb Spectroscopy. Nature 2016, 533, 517-520.

(260) Changala, P. B.; Weichman, M. L.; Lee, K. F.; Fermann, M. E.; Ye, J. Rovibrational Quantum State Resolution of the $\mathrm{C}_{60}$ Fullerene. Science 2019, 363, 49-54. 


\section{For TOC Only}

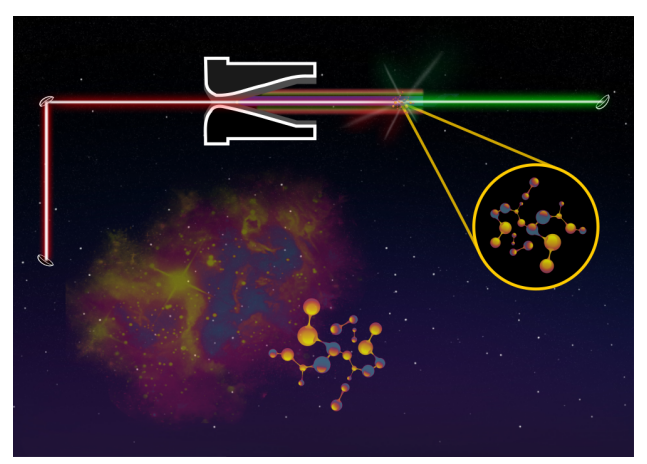

